\title{
Genetics and cardiovascular risk in a primary care population : studies from the HIPPOCRATES project
}

Citation for published version (APA):

Plat, A. W. (2009). Genetics and cardiovascular risk in a primary care population : studies from the HIPPOCRATES project. [Doctoral Thesis, Maastricht University]. Datawyse / Universitaire Pers Maastricht. https://doi.org/10.26481/dis.20090529ap

Document status and date:

Published: 01/01/2009

DOI:

10.26481/dis.20090529ap

Document Version:

Publisher's PDF, also known as Version of record

\section{Please check the document version of this publication:}

- A submitted manuscript is the version of the article upon submission and before peer-review. There can be important differences between the submitted version and the official published version of record.

People interested in the research are advised to contact the author for the final version of the publication, or visit the DOI to the publisher's website.

- The final author version and the galley proof are versions of the publication after peer review.

- The final published version features the final layout of the paper including the volume, issue and page numbers.

Link to publication

\footnotetext{
General rights rights.

- You may freely distribute the URL identifying the publication in the public portal. please follow below link for the End User Agreement:

www.umlib.nl/taverne-license

Take down policy

If you believe that this document breaches copyright please contact us at:

repository@maastrichtuniversity.nl

providing details and we will investigate your claim.
}

Copyright and moral rights for the publications made accessible in the public portal are retained by the authors and/or other copyright owners and it is a condition of accessing publications that users recognise and abide by the legal requirements associated with these

- Users may download and print one copy of any publication from the public portal for the purpose of private study or research.

- You may not further distribute the material or use it for any profit-making activity or commercial gain

If the publication is distributed under the terms of Article $25 \mathrm{fa}$ of the Dutch Copyright Act, indicated by the "Taverne" license above, 


\section{Genetics and cardiovascular risk}

in a primary care population Studies from the HIPPOCRATES project 
C A.W. Plat, Maastricht 2009

ISBN: 978-90-5278-821-0

Layout: Tiny Wouters

Cover: Datawyse in samenwerking met Leen Liefsoens

Production: Datawyse | Universitaire Pers Maastricht

Scientific studies in this thesis were supported by unrestricted research grants from SOHO (Stichting Ondersteuning Hypertensie Onderzoek) Amsterdam, the Netherlands, and the Maastricht University Medical Center (Profileringsfonds grant no. PF194), Maastricht, the Netherlands.

Printing of this thesis was financially supported by Astellas Pharma B.V., AstraZeneca B.V., Pfizer B.V., Schering-Plough B.V. 


\title{
Genetics and cardiovascular risk
}

\author{
in a primary care population
}

\section{Studies from the HIPPOCRATES project}

\author{
PROEFSCHRIFT
}

ter verkrijging van de graad van doctor aan de Universiteit Maastricht, op gezag van de Rector Magnificus, Prof. mr. G.P.M.F. Mols volgens besluit van het College van Decanen in het openbaar te verdedigen op vrijdag 29 mei 2009 om 14.00 uur

door

Adrianus Wilhelmus Plat

geboren op 1 maart 1975 te Steenwijk

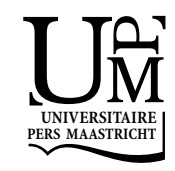




\section{Promotores}

Prof. dr. C.P. van Schayck

Prof. dr. P.W. de Leeuw

\section{Copromotores}

dr. H.E.J.H. Stoffers

dr. A.A. Kroon

\section{Beoordelingscommissie}

Prof. dr. M.H. Prins, voorzitter

Prof. dr. M.C. Cornel, (VUMC Amsterdam)

Prof. dr. J.P.M. Geraerdts

Prof. dr. J.A. Knottnerus

Prof. dr. H.A.J. Struijker Boudier

Financial support by the Netherlands Heart Foundation for the publication of this thesis is gratefully acknowledged. 
de morgen breekt aan

de stormen van vannacht zijn

in sneeuw begraven

(Shiro)

Voor Ma

Ter herinnering aan $\mathrm{Pa}$

Aan Leen 



\section{Contents}

List of abbreviations $\quad 9$

$\begin{array}{lll}\text { Chapter } 1 & \text { Introduction } & 11\end{array}$

Chapter 2 Regional differences in cardiovascular risk factor profile 21 cannot fully explain differences in cardiovascular morbidity in the Netherlands: a comparison of two urban areas The Netherlands Journal of Medicine 2005;63:309-315

Chapter 3 The contribution of six polymorphisms to cardiovascular risk in a Dutch high risk primary care population:

The HIPPOCRATES project

Journal of Human Hypertension 2009; in press

Chapter 4 The influence of six cardiovascular polymorphisms on a

first event of ischemic heart disease is modified by gender and age

Submitted

Chapter 5 Gender-specific effect of the $\alpha$-adducin (G460W) and

AGTR1 (A1166C) polymorphism on carotid intima media

thickness

Submitted

Chapter 6 The association between arterial stiffness and the angiotensin II type 1 receptor (A1166C) polymorphism is influenced by the use of cardiovascular medication Journal of Hypertension 2009;27:69-75

Chapter 7 Family history of common diseases as genetic tool in primary care: what is the evidence? A systematic review Submitted

Chapter 8 General discussion

Summary

Samenvatting

List of publications

Dankwoord

Curriculum vitae 



\section{List of abbreviations}

ACE

AGT

ADD1

AGTR1

Angl

Angll

ANOVA

AUC

BMI

CBS

CIMT

CVD

DBP

DM

DNA

GNB3

GP

$\mathrm{FHQ}$

HDL

HGP

$\mathrm{HR}$

ICPC

I/D

IHD

LDL

mRNA

$\mathrm{RNH}$

NOS3

OR

PCR

PP

PHARMO RLS

PWV

RAS

ROC

SBE

SBP

SD

SEM

SNP angiotensin-converting enzyme

angiotensinogen

alpha adducin

angiotensin II type 1 receptor

angiotensin I

angiotensin II

analysis of variance

area under the curve

body mass index

statistics Netherlands

carotid intima media thickness

cardiovascular disease

diastolic blood pressure

diabetes mellitus

desoxy-ribonucleic acid

G-protein $\beta 3$ subunit

general practitioner

family history questionnaire

high-density lipoprotein

human genome project

heart rate

international classification of primary care

insertion/deletion

ischemic heart disease

low-density lipoprotein

messenger ribonucleic acid

registration network general practices

endothelial nitric oxide synthase

odds ratio

polymerase chain reaction

pulse pressure

PHARmacoMOrbidity record linkage system

pulse wave velocity

renin-angiotensin system

receiver operating characteristic

multiplex single base extension

systolic blood pressure

standard deviation

standard error of the mean

single nucleotide polymorphism 


\section{Chapter 1}

INTRODUCTION

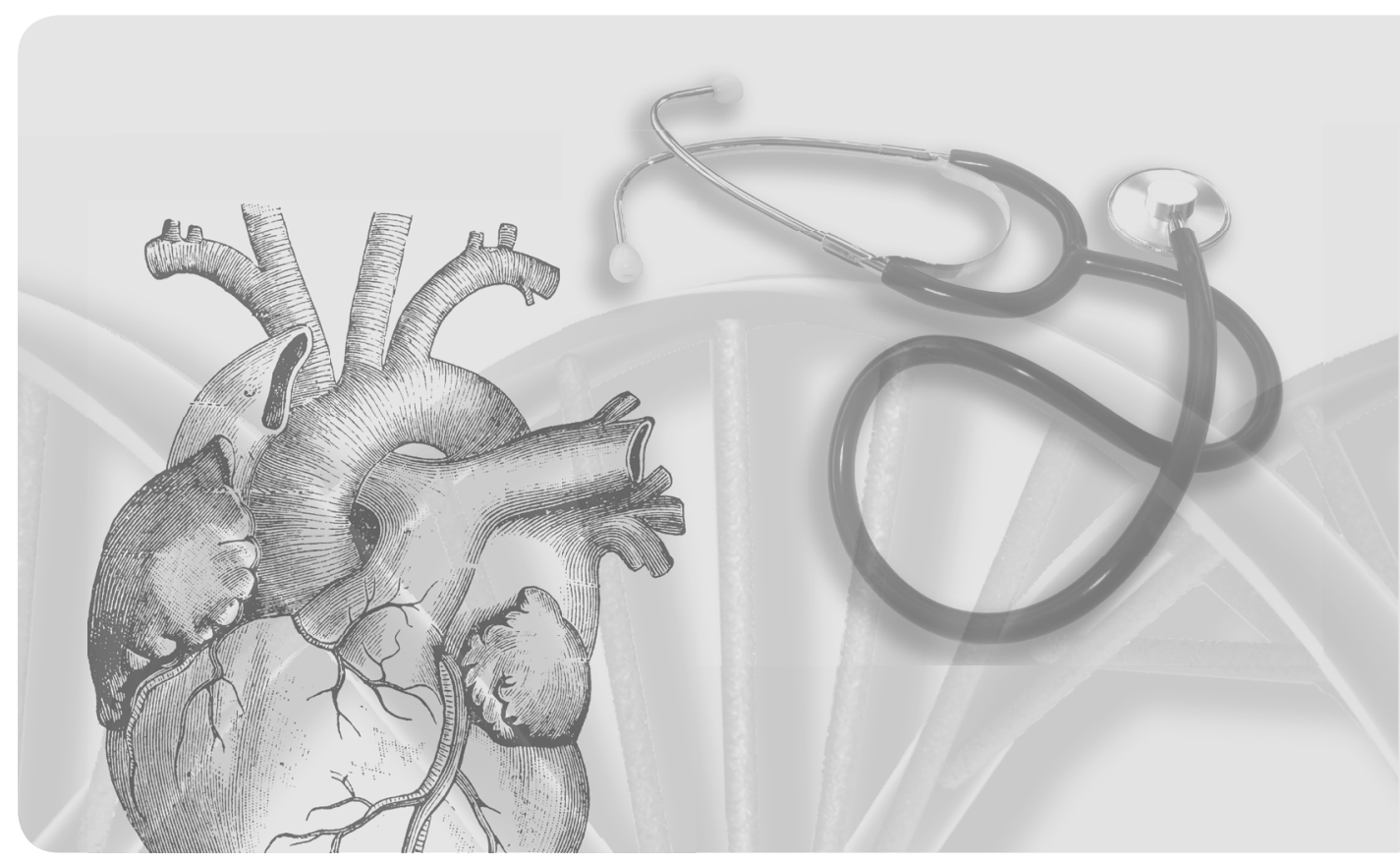


12 Chapter 1 


\section{Introduction}

\section{Cardiovascular genetics}

Atherosclerotic cardiovascular disease (CVD) - involving the heart, brain and peripheral arteries of the legs - is a major health problem worldwide. ${ }^{1,2}$ The aetiology of CVD is multifactorial, with both genetic and environmental factors playing important roles. Several monogenetic disorders contribute to CVD, such as familial hypercholesterolemia and hypertrophic cardiomyopathy. ${ }^{3,4}$ Although most of these monogenetic mutations are rare, they are associated with an elevated cardiovascular risk. Moreover, the most common forms of CVD are believed to be multifactorial, resulting from the interaction of several genes, each with a relatively small effect, working alone or in combination with other modifiers, genes and/or environmental factors. Little is currently known about which genes or mutations therein are involved in atherosclerosis. However, there is accumulating evidence that a positive family history for CVD in a first-grade family member is associated with an increased cardiovascular risk in other (affected) family members. ${ }^{5-7}$ Therefore, there is active research (predominantly epidemiologic studies) aimed at elucidating the combination of genes or genetic factors that play active roles in the aetiology of CVD.

Genetic epidemiology involves the aetiology, distribution and control of disease in groups of relatives and also in populations. ${ }^{8,9}$ Major topics considered in the genetic epidemiology of CVD include cholesterol and lipid levels, blood coagulation, leukocyte adhesion, endothelial cells of blood vessels, the renin-angiotensin system, homocysteine and left ventricular hypertrophy.

\section{Intermediate endpoints}

The role of the renin-angiotensin system (RAS) in the development of CVD has being studied for several years at the Department of Internal Medicine, Maastricht University Medical Center. Figure 1.1 presents a schematic of the RAS, which is an important system involved in blood pressure regulation, cardiovascular cellular growth and remodelling, and thus also in the aetiology of atherosclerotic vascular disease. Many association studies have connected specific genes of the RAS with myocardial infarction, hypertrophic cardiomyopathy, hypertension, left ventricular hypertrophy and stroke. ${ }^{10-12}$ Other association studies have found correlations between certain polymorphisms of RAS genes and so-called intermediate vascular endpoints, such as carotid intima media thickness (CIMT) and arterial stiffness ${ }^{13-15}$ as assessed by pulse wave velocity (PWV) measurements. CIMT measurements provide a non-invasive assessment of the (preclinical) atherosclerotic burden caused by cardiovascular risk factors such as hypertension, diabetes mellitus and hypercholesterolemia. ${ }^{16}$ Non-invasive PWV measurements have revealed increased systolic and pulse pressures and, consequently, increased arterial stiffness. ${ }^{17}$ Both 
increased CIMT and PWV have been indicated as independent predictors of future CVD. $^{16,17}$

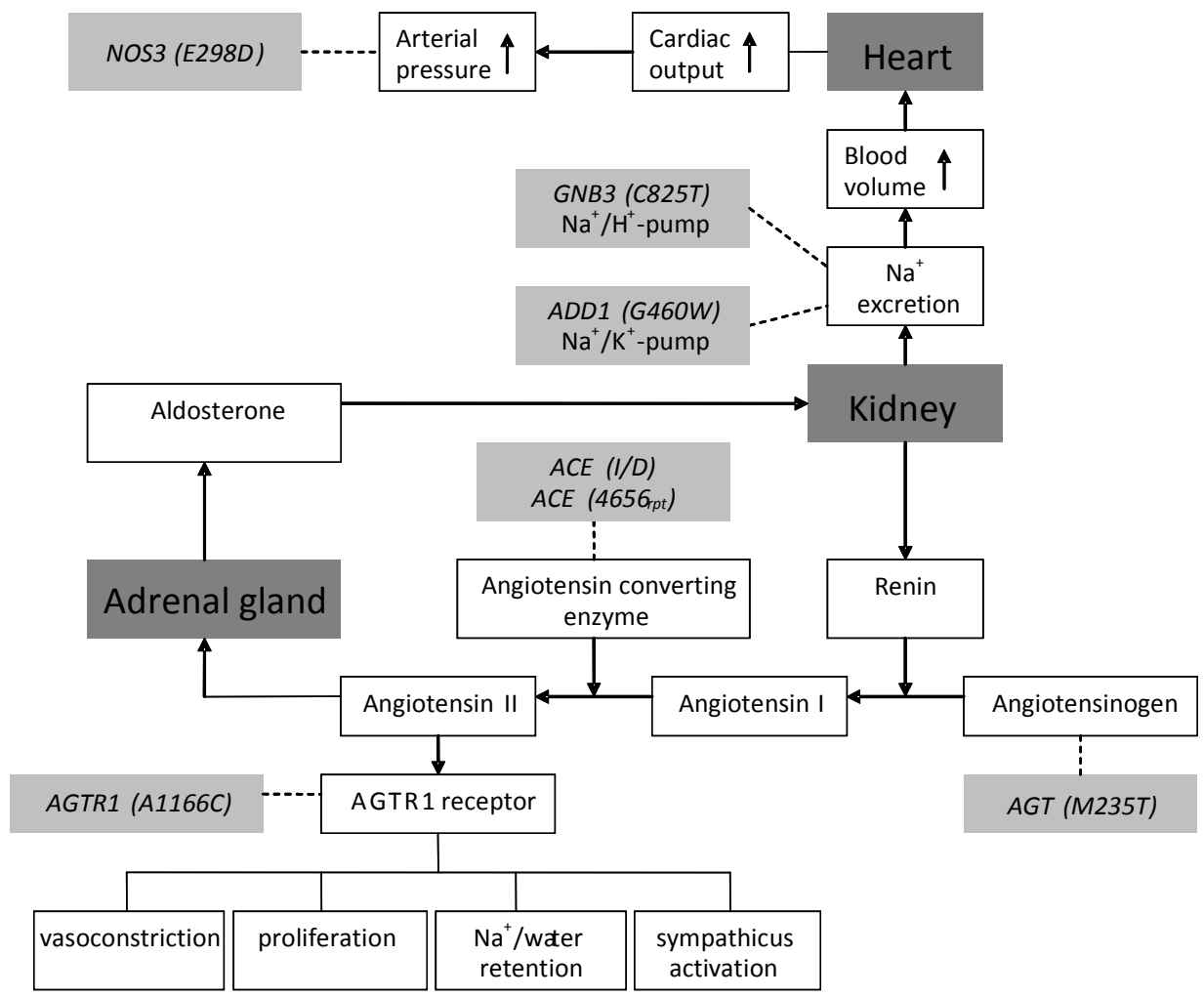

Figure 1.1 The renin-angiotensin system and several associated polymorphisms.

\section{Polymorphisms}

Polymorphisms are frequently occurring variations in the humane genome. By definition, the frequency of the allele with the lowest prevalence is higher than $1 \%$, but the occurrence can vary between populations. ${ }^{9}$ The Department of Internal Medicine of Maastricht University Medical Center has investigated the following polymorphisms related to the RAS in hypertensive and normotensive patients: ${ }^{18-21}$ angiotensin II (Angll) type 1 receptor [AGTR1 (A1166C)], angiotensinogen [AGT $(\mathrm{M} 235 \mathrm{~T})$ ], angiotensin-converting enzyme [ACE $\left(4656_{\mathrm{rpt}}\right)$ ], endothelial nitric oxide (NO) synthase [NOS3 (E298D)], G-protein $\beta 3$ subunit [GNB3 (C825T)] and $\alpha$-adducin [ADD1 $(\mathrm{G} 460 \mathrm{~W})$. $^{22}$ Figure 1.1 depicts the location of these polymorphisms, which function as follows: Patients homozygous for the C allele of the AGTR1 polymorphism exhibit increased sensitivity to Angll, which can - in combination with the DD genotype of the ACE (I/D) polymorphism - lead to an increased risk of cardiovascular complications. ${ }^{23,24}$ 
The T allele of the AGT polymorphism is associated with high plasma levels of AGT and increased responsiveness to AngII. ${ }^{11}$ The ACE (I/D) polymorphism was determined by detecting $A C E_{4656+C T}$. The $A C E_{4656+C T}$ polymorphism in the 3 '-untranslated region of the ACE gene consists of a repetition of two or three CT dinucleotides and is in complete linkage disequilibrium with the ACE (I/D) polymorphism. ${ }^{25,26}$ Increased ACE levels have been found In the presence of a 2 allele which is comparable to the $D$ allele of the I/D polymorphism, and they have been associated with an increased risk of cardiovascular complications. $^{27}$ The NOS3 (E298D) polymorphism is associated with reduced NO production in endothelial cells of the arterial wall, inducing elevation of the arterial pressure. $^{19,28}$ The T allele of the GNB3 (C825T) polymorphism is associated with increased intracellular signal transduction that stimulates the $\mathrm{Na}^{+} / \mathrm{H}^{+}$exchanger ${ }^{29}$ to increase $\mathrm{Na}^{+}$transport across renal tubules and cause chronic volume expansion that might lead to proliferation of vascular smooth muscle cells, vascular remodelling and increased peripheral arterial resistance. ${ }^{30}$ Finally, the ADD1 (G460W) polymorphism is of interest because the rare allele is also associated with increased $\mathrm{Na}^{+}$transport, though in this case the $\mathrm{Na}^{+} / \mathrm{K}^{+}$exchanger is stimulated, which also causes chronic volume expansion with related cardiovascular complications. ${ }^{31}$

\section{Patient care}

Collins et al. (1999) stated that genomics research will dramatically accelerate the development of new strategies for the diagnosis, prevention and treatment of disease, not just for single-gene disorders but for most of the more common complex diseases, such as CVD. ${ }^{32}$ It was thought that the completion of the Human Genome Project would lead naturally to the clinical application of medical genetics in both hospital and general practice. The clinical meaning of both diagnostics and therapeutics is strongly focused on the function of genes in both pathophysiological (e.g. CVD) and healthy circumstances. As a consequence, the expectation is that genetic knowledge will eventually have a major impact on daily clinical decisionmaking by every doctor. Therefore, doctors need to know the genetic background of a disease, not only for the treatment and prevention in an individual patient, but also as a consequence in all first-degree family members.

\section{Hypothesis}

At the start of our studies, we reasoned that the above-mentioned polymorphisms might be relevant individually or in combination as additional risk factors for CVD. We hypothesized that these polymorphisms would lead to better cardiovascular risk stratification, not only for an individual but probably also for all first-degree family members. Furthermore, it might offer opportunities for genetically tailored treatments. To explore this hypothesis, we studied the relationships between this set of polymorphisms and biological (risk factors) and clinical (intermediate endpoints) 
cardiovascular outcome parameters in a non-selected patient population. This led to the initiation of the HIPPOCRATES project.

\section{HIPPOCRATES}

The Hypertension: Interaction and Prevalence of POlymorphisms related to Cardiovascular Risk and the Association to Treatment Efficacy Study (HIPPOCRATES) was designed to compare genetic information (genotype) with clinical data on cardiovascular risk factors and morbidity (clinical phenotype) in primary care. We selected the six aforementioned polymorphisms - AGTR1 (A1166C), AGT (M235T), ACE $\left(4656_{\text {rpt }}\right.$ ), NOS3 (E298D), GNB3 (C825T) and ADD1 (G460W) - in this non-selected population for several reasons: (1) when HIPPOCRATES was designed, there was strong evidence in the literature for the role of these polymorphisms in the development of CVD, (2) these polymorphisms appeared very relevant to this study population, and (3) a complete infrastructure was available to determine these polymorphisms accurately and quickly.

Though our study had a cross-sectional design, we developed the project so as to facilitate the investigation of longitudinal relationships. A strong aspect of the HIPPOCRATES project was that the study subjects were primary care patients, and hence the entire range of low-to-high-risk patients was available. The subjects were derived from a rather small geographical area (and hence had similar social living conditions) that previously had been described in unpublished reports for the Heerlen/Kerkrade region as a population with a cardiovascular risk that was higher than that in the general Dutch population. All participants were recruited from one general practice in Kerkrade. This practice is located in a region with high burdens of CVD and cardiovascular risk factors, so the number of patients with CVD was higher than in other general practices. Consequently, it has well-implemented cardiovascular consulting hours and well-trained general practitioners and practice assistants with many years of experience in cardiovascular risk management.

We reasoned that this setting would provide an ideal environment for studying genetic associations of the aforementioned polymorphisms. The acronym HIPPOCRATES suggests that we focused on hypertension, but of course we did not restrict ourselves to this condition. To assess the effects of both genotype and cardiovascular risk factors on the arterial wall, we chose two intermediate endpoints: CIMT and carotid-femoral PWV (CF-PWV). Figure 1.2 summarizes the specific relationships that we intended to study in HIPPOCRATES. 


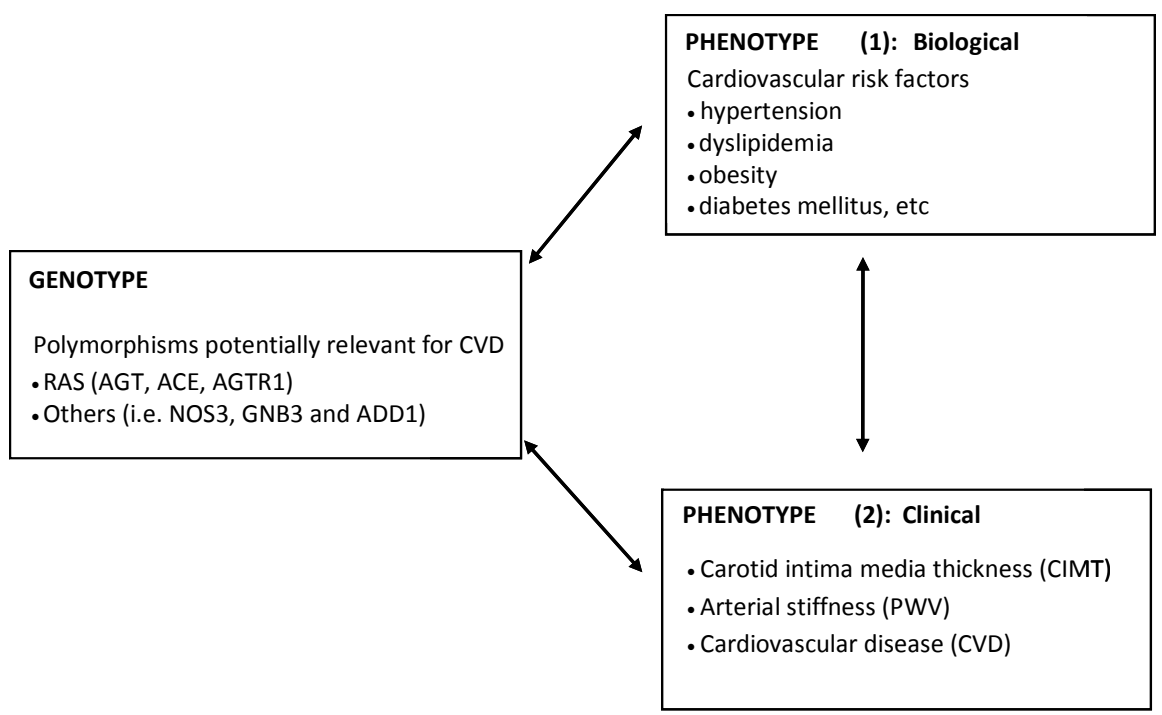

Figure 1.2 Specific relationships studied in the HIPPOCRATES project. Arrows indicate mutual associations. 
This thesis describes several studies that aimed to elucidate the contribution of six cardiovascular polymorphisms - AGTR1 (A1166C), AGT (M235T), ACE (4656 rpt $_{\text {) }}$, NOS3 (E298D), GNB3 (C825T) and ADD1 (G460W) - to cardiovascular risk assessment in primary care, by investigating the relationship between genotype, biological and clinical cardiovascular outcomes (phenotype).

Chapter 2 compares the burden of CVD in the Heerlen/Kerkrade region in the south of the Netherlands with those in a nearby region (Maastricht) and in the average Dutch population. We performed this comparison since there were indications that the prevalence of CVD was elevated in the Heerlen/Kerkrade region. Knowledge of interregional differences in cardiovascular risk factor profiles was necessary to assess the possible role of genetic factors in our study. Chapter $\mathbf{3}$ describes the results of our baseline cross-sectional data analyses in the HIPPOCRATES population. We first show the allele frequency distribution of our set of six polymorphisms and compare these data to that in a large Dutch control sample from the PHARMO RLS database. We then assess the contribution of these six polymorphisms to the occurrence of CVD. Chapter 4 reports on the contribution of the six cardiovascular polymorphisms to the occurrence of a first event of ischemic heart disease, which constitutes a specific phenotype of CVD, with the data presented according to gender and age. The study described in Chapter $\mathbf{5}$ investigated the relationship between the six polymorphisms and CIMT as an intermediate endpoint for preclinical atherosclerosis. Chapter 6 reports on the relationships between arterial stiffness as measured by CF-PWV measurements, the six polymorphisms and medication use. Since family history is closely related to the genetic background, we studied the practice and outcomes of family history-taking. Chapter 7 reviews the literature on family history-taking in primary care as a genetic tool for identifying individuals and families at an increased risk of multifactorial disorders, especially CVD. Finally, Chapter 8 summarizes the main findings, discusses possible clinical implications and provides suggestions for further research. 


\section{References}

1. Rosamond W, Flegal K, Friday G, Furie K, Go A, Greenlund K, Haase N, Ho M, Howard V, Kissela B, Kittner S, Lloyd-Jones D, McDermott M, Meigs J, Moy C, Nichol G, O'Donnell CJ, Roger V, Rumsfeld J, Sorlie P, Steinberger J, Thom T, Wasserthiel-Smoller S, Hong Y; American Heart Association Statistics Committee and Stroke Statistics Subcommittee. Heart disease and stroke statistics--2007 update: a report from the American Heart Association Statistics Committee and Stroke Statistics Subcommittee. Circulation 2007;115:e69-171.

2. Murray CJ, Lopez AD. Global mortality, disability, and the contribution of risk factors: Global Burden of Disease Study. Lancet 1997;349:1436-42.

3. Brown MS, Goldstein JL. A receptor-mediated pathway for cholesterol homeostasis. Science 1986; 232:34-47.

4. Spirito P, Seidman CE, McKenna WJ, Maron BJ. The management of hypertrophic cardiomyopathy. N Engl J Med 1997;336:775-85.

5. Marenberg ME, Risch N, Berkman LF, Floderus B, de Faire U. Genetic susceptibility to death from coronary heart disease in a study of twins. N Engl J Med 1994;330:1041-6.

6. Williams RR, Hunt SC, Heiss G, Province MA, Bensen JT, Higgins M, Chamberlain RM, Ware J, Hopkins PN. Usefulness of cardiovascular family history data for population-based preventive medicine and medical research (the Health Family Tree Study and the NHLBI Family Heart Study). Am J Cardiol 2001;87:129-35.

7. Lloyd-Jones DM, Nam BH, D'Agostino RB Sr, Levy D, Murabito JM, Wang TJ, Wilson PW, O'Donnell CJ. Parental cardiovascular disease as a risk factor for cardiovascular disease in middle-aged adults: a prospective study of parents and offspring. JAMA 2004;291:2204-11.

8. Morton NE. Outline of Genetic Epidemiology: S Karger Pub; 1982.

9. Khoury MJ, Beaty TH, Cohen BH. Fundamentals of Genetic Epidemiology. New York: Oxford University Press; 1993.

10. Carluccio M, Soccio M, De Caterina R. Aspects of gene polymorphisms in cardiovascular disease: the renin-angiotensin system. Eur J Clin Invest 2001;31:476-88.

11. Visvikis-Siest S, Marteau JB. Genetic variants predisposing to cardiovascular disease. Curr Opin Lipidol 2006;17:139-51.

12. Jeunemaitre X. Genetics of the human renin angiotensin system. J Mol Med 2008;86:637-41.

13. Benetos A, Gautier S, Ricard S, Topouchian J, Asmar R, Poirier O, Larosa E, Guize L, Safar M, Soubrier $\mathrm{F}$, Cambien F. Influence of angiotensin-converting enzyme and angiotensin II type 1 receptor gene polymorphisms on aortic stiffness in normotensive and hypertensive patients. Circulation 1996;94: 698-703.

14. Sayed-Tabatabaei FA, Houwing-Duistermaat JJ, van Duijn CM, Witteman JC. Angiotensin-converting enzyme gene polymorphism and carotid artery wall thickness: a meta-analysis. Stroke 2003;34: 1634-9.

15. Safar ME, London GM, Plante GE. Arterial stiffness and kidney function. Hypertension 2004;43:163-8.

16. Touboul PJ, Hennerici MG, Meairs S, Adams H, Amarenco P, Bornstein N, Csiba L, Desvarieux M, Ebrahim S, Fatar M, Hernandez Hernandez R, Jaff M, Kownator S, Prati P, Rundek T, Sitzer M, Schminke U, Tardif JC, Taylor A, Vicaut E, Woo KS, Zannad F, Zureik M. Mannheim carotid intimamedia thickness consensus (2004-2006). An update on behalf of the Advisory Board of the 3rd and 4th Watching the Risk Symposium, 13th and 15th European Stroke Conferences, Mannheim, Germany, 2004, and Brussels, Belgium, 2006. Cerebrovasc Dis 2007;23:75-80.

17. Laurent S, Cockcroft J, Van Bortel L, Boutouyrie P, Giannattasio C, Hayoz D, Pannier B, Vlachopoulos C, Wilkinson I, Struijker-Boudier H; European Network for Non-invasive Investigation of Large Arteries. Expert consensus document on arterial stiffness: methodological issues and clinical applications. Eur Heart J 2006;27:2588-605.

18. Beeks E, Janssen RG, Kroon AA, Keulen ET, Geurts JM, de Leeuw PW, de Bruin TW. Association between the alpha-adducin Gly460Trp polymorphism and systolic blood pressure in familial combined hyperlipidemia. Am J Hypertens 2001;14:1185-90. 
19. Veldman BA, Spiering W, Doevendans PA, Vervoort G, Kroon AA, de Leeuw PW, Smits P. The Glu298Asp polymorphism of the NOS 3 gene as a determinant of the baseline production of nitric oxide. J Hypertens 2002;20:2023-7.

20. Henskens LH, Spiering W, Stoffers HE, Soomers FL, Vlietinck RF, de Leeuw PW, Kroon AA. Effects of ACE I/D and AT1R-A1166C polymorphisms on blood pressure in a healthy normotensive primary care population: first results of the Hippocates study. J Hypertens 2003;21:81-6.

21. Spiering W, Zwaan IM, Kroon AA, de Leeuw PW. Genetic influences on $24 \mathrm{~h}$ blood pressure profiles in a hypertensive population: role of the angiotensin-converting enzyme insertion/deletion and angiotensin II type 1 receptor A1166C gene polymorphisms. Blood Press Monit 2005;10:135-41.

22. Spiering W, Kroon AA, Vreugdenhil HA, Geraedts JP, Daemen MJ, de Leeuw PW. The relationship between genetic polymorphisms and disease, illustrated by the renin-angiotensin-aldosterone system and cardiovascular disease. Ned Tijdschr Geneeskd 1998;142:1445-50.

23. Spiering W, Kroon AA, Fuss-Lejeune MM, Daemen MJ, de Leeuw PW. Angiotensin II sensitivity is associated with the angiotensin II type 1 receptor $A(1166) C$ polymorphism in essential hypertensives on a high sodium diet. Hypertension 2000;36:411-6.

24. Tiret L, Bonnardeaux A, Poirier O, Ricard S, Marques-Vidal P, Evans A, Arveiler D, Luc G, Kee F, Ducimetière $P$, et al. Synergistic effects of angiotensin-converting enzyme and angiotensin-II type 1 receptor gene polymorphisms on risk of myocardial infarction. Lancet 1994;344:910-3.

25. Villard E, Tiret L, Visvikis S, Rakotovao R, Cambien F, Soubrier F. Identification of new polymorphisms of the angiotensin l-converting enzyme (ACE) gene, and study of their relationship to plasma ACE levels by two-QTL segregation-linkage analysis. Am J Hum Genet 1996;58:1268-78.

26. Keavney B, McKenzie CA, Connell JM, Julier C, Ratcliffe PJ, Sobel E, Lathrop M, Farrall M. Measured haplotype analysis of the angiotensin-I converting enzyme gene. Hum Mol Genet 1998;7:1745-51.

27. Sayed-Tabatabaei FA, Oostra BA, Isaacs A, van Duijn CM, Witteman JC. ACE polymorphisms. Circ Res 2006;98:1123-33.

28. Casas JP, Cavalleri GL, Bautista LE, Smeeth L, Humphries SE, Hingorani AD. Endothelial nitric oxide synthase gene polymorphisms and cardiovascular disease: a HuGE review. Am J Epidemiol 2006; 164:921-35.

29. Zeltner R, Delles C, Schneider M, Siffert W, Schmieder RE. G-protein beta(3) subunit gene (GNB3) $825 \mathrm{~T}$ allele is associated with enhanced renal perfusion in early hypertension. Hypertension 2001; 37:882-6.

30. Siffert W. G protein polymorphisms in hypertension, atherosclerosis, and diabetes. Annu Rev Med 2005;56:17-28.

31. Manunta P, Bianchi G. Low-salt diet and diuretic effect on blood pressure and organ damage. J Am Soc Nephrol 2004;15 Suppl 1:S43-6.

32. Collins FS. Shattuck lecture--medical and societal consequences of the Human Genome Project. N Engl J Med 1999;341:28-37. 


\section{Chapter 2}

REGIONAL DIFFERENCES IN

CARDIOVASCULAR RISK FACTOR PROFILE

CANNOT FULLY EXPLAIN DIFFERENCES

IN CARDIOVASCULAR MORBIDITY IN THE

NeTHERLANDS: A COMPARISON OF TWO

URBAN AREAS

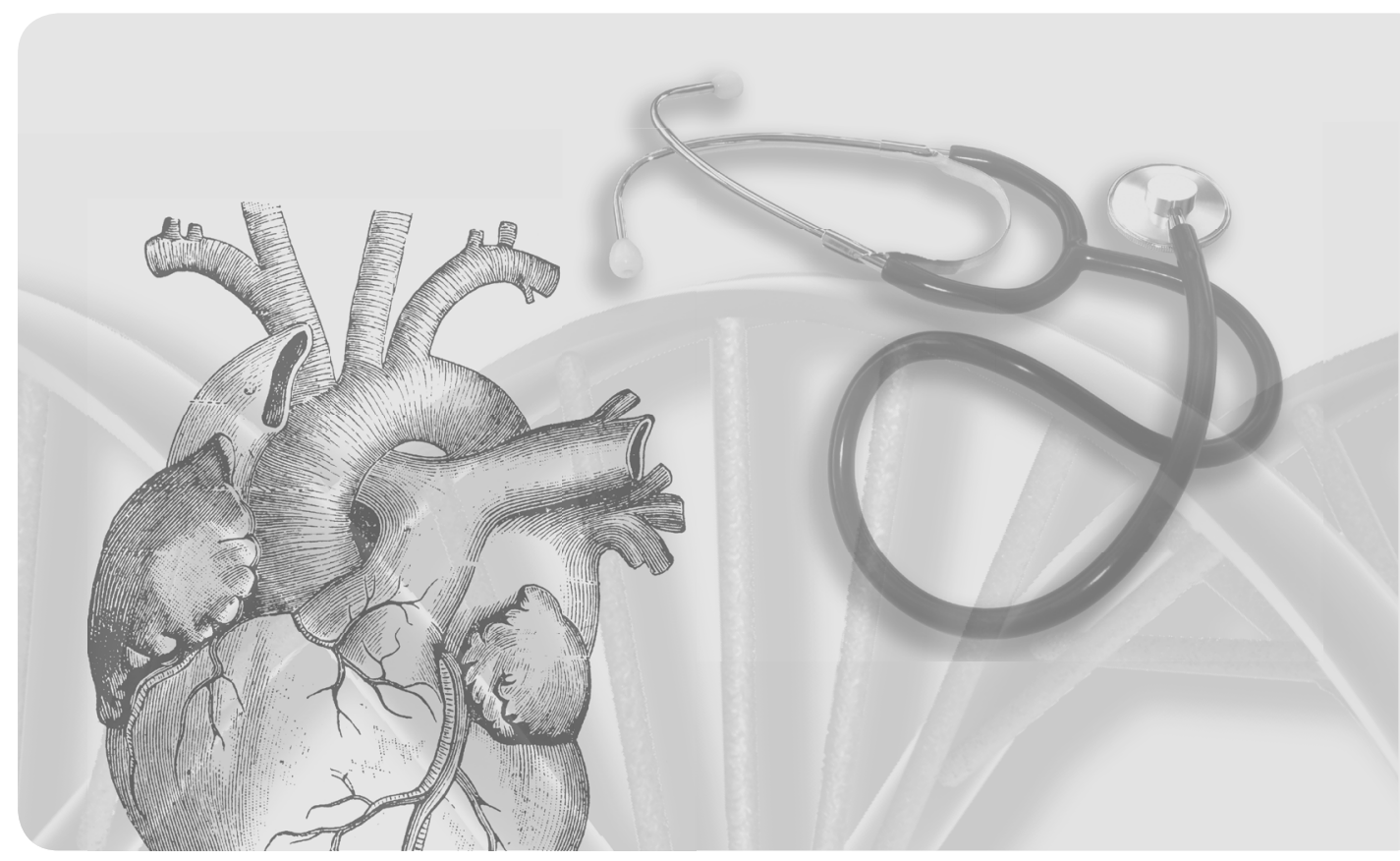

AW Plat, MJM te Wierik, AA Kroon, HJA Schouten, M van den Akker, CP van Schayck, $P W$ de Leeuw, KJ Hajema, HEJH Stoffers

The Netherlands Journal of Medicine 2005;63:309-315 


\section{Abstract}

\section{Background}

Our objective was to investigate whether a region in the south of the Netherlands (Heerlen/Kerkrade) had a high burden of cardiovascular disease in comparison with a nearby region (Maastricht) and the average Dutch population, respectively. We also wanted to determine if there are interregional differences in cardiovascular risk factor profile.

\section{Design}

Cross-sectional study.

\section{Method}

Data from a nationwide registry (CBS) were used to analyse cardiovascular mortality in the two regions and the average in the Netherlands. Data from a primary care morbidity registration network (RNH) were used to compare cardiovascular morbidity and cardiovascular risk factors in both regions. A standardisation procedure was carried out for age and sex. Data were analysed using logistic regression analyses.

\section{Results}

The overall cardiovascular mortality rate was higher in the Heerlen/Kerkrade region (7.8\%) compared with Maastricht $(6.1 \%$ o), $(O R=1.3$ [1.2-1.5]) and the average in the Netherlands $(5.7 \% \circ)$. Similarly, most cardiovascular morbidity rates for Heerlen/Kerkrade were more elevated compared with the RNH overall and with Maastricht. Prevalence rates of risk factors such as diabetes mellitus (7.2\%), (OR=1.5 [1.3-1.7]) and overweight (10.8\%), (OR=2.0 [1.8-2.2]) were significantly higher in the Heerlen/Kerkrade region compared with Maastricht. There were no differences with regard to hypertension (15.2\%), (OR=1.0 [0.9-1.1]).

\section{Conclusion}

Heerlen/Kerkrade is indeed a region with a high burden of cardiovascular disease. Differences in morbidity between Heerlen/Kerkrade and Maastricht cannot be fully explained by differences in cardiovascular risk factor profile. 


\section{Introduction}

Recently our group started the HIPPOCRATES project (Hypertension: Interaction and Prevalence of POlymorphisms related to Cardiovascular Risk and the Association to Treatment Efficacy Study). ${ }^{1}$ The main objective of this study is implementation of genetic polymorphisms in the assessment of cardiovascular risk in primary care. This study utilises the population of a general practice centre located in the southeast of Limburg, that is, an urbanised area around the cities of Heerlen and Kerkrade. From a population genetic point of view, this region is interesting in two aspects: (1) in unpublished Dutch reports a relatively high cardiovascular mortality has been described; (2) in and out migration figures are relatively low. Therefore, we were interested in the cardiovascular mortality of this region compared with the average in the Netherlands as well as with a region geographically nearby. Comparisons as these are usually limited to mortality data due to scarcity of national morbidity data.

However, morbidity data give a better estimation of the prevalence of cardiovascular disease (CVD). Fortunately, sources for regional morbidity data are available from general practice registration networks. ${ }^{2}$ Since in the Netherlands almost everyone is on the list of a general practitioner, morbidity registrations in these practices reflect the health status of a general population in a specific area. Our department coordinates such a primary care morbidity registration network. ${ }^{2}$ Consequently, we had the opportunity to compare the morbidity figures of various regions.

Moreover, we could explore the prevalence rates of some important cardiovascular risk factors also registered by this network (hypertension, diabetes mellitus, overweight and lipid disorders). Variation in risk factor profile might explain possible

differences in cardiovascular mortality and morbidity profile between regions. ${ }^{3,4}$ Comparing data on cardiovascular mortality and morbidity as well as risk factors could give insight into the specific cardiovascular profile of the study region. In this study the main question was whether the Heerlen/Kerkrade region does indeed have a high burden of CVD compared with a nearby region (Maastricht) and the average of the Netherlands. A second question was whether there were interregional differences in cardiovascular risk factor profile.

\section{Methods}

\section{Cardiovascular mortality}

From the official death certification data managed by Statistics Netherlands (CBS), the latest available mortality data (2000) were used on CVD and risk factors for Heerlen/Kerkrade and Maastricht. Diagnoses were coded according to the International Classification of Diseases (ICD-10). ${ }^{5}$ The validity of the death registry is 
generally considered sufficiently good for epidemiological use. ${ }^{6,7}$ The disease categories studied are presented in Table 2.1.

Table 2.1 Mortality and morbidity of categories of CVD and risk factors studied and their ICD-10 and ICPC codes.

\begin{tabular}{lcc}
\hline & $\begin{array}{c}\text { Mortality } \\
\text { (CBS } \\
\text { (CD-10 codes) }\end{array}$ & $\begin{array}{c}\text { Morbidity } \\
\text { (RNH }\end{array}$ \\
ICPC codes)
\end{tabular}

${ }^{\mathrm{a}}$ CBS: Statistics Netherlands; ${ }^{\mathrm{b}} \mathrm{RNH}$ : Registration Network Family Practices (RegistratieNet Huisarts-praktijken)

\section{Cardiovascular morbidity}

Cardiovascular morbidity rates were retrieved from the Registration Network Family Practices (RNH). This is a continuous and computerised database in which 63 general practitioners (GPs) working in 22 different practices in the south of the Netherlands participate. All relevant health problems are registered. A health problem is defined as 'anything that has required, does or may require healthcare management and has affected or could significantly affect a person's physical or emotional well-being' ${ }^{8}$ Health problems are only coded by the GPs if they are permanent (no recovery expected), chronic (duration longer than six months), recurrent (more than three recurrences within six months), or when they have lasting consequences for the functional status or prognosis of the patient. Problems are coded according to the International Classification of Primary Care (ICPC) using the criteria of the International Classification of Health Problems in Primary Care for diagnoses. ${ }^{9,10}$ The registered data are continuously updated and historically cumulated for each patient. Population membership only ends by migration or death. The quality of the data is ensured by instruction and training sessions, regional consensus groups, quality control experiments and by an automated thesaurus and automated checking for erroneous or missing entries. ${ }^{11}$ 
For this study, data from five general practices $(n=10,587)$ in Heerlen/Kerkrade (index population) and from three general practices $(n=8,742)$ in Maastricht (control population) were used. For both regions and the RNH overall $(n=56,976)$ prevalence rates were calculated. We compared the prevalence rates of Heerlen/Kerkrade with Maastricht. Age and sex distribution of the total RNH dataset was reported to be similar to that of the Netherlands. ${ }^{8}$ Comparison of the age and sex distribution of the total RNH dataset (2001) with the Netherlands (2001) still appeared to be the same. Age and sex specific data were drawn from the latest RNH dataset available (1 July 2001). The disease categories studied are presented in Table 2.1.

\section{Cardiovascular risk factors}

Prevalence rates of cardiovascular risk factors were also retrieved from the eight general practices in Heerlen/Kerkrade and Maastricht. Age and sex specific data were drawn from the latest RNH dataset available (1 July 2001). The risk factors studied are also presented in Table 2.1.

\section{Statistical analysis}

To compare the prevalence of cardiovascular mortality and morbidity between both regions (Heerlen/Kerkrade vs Maastricht), a standardisation procedure was carried out for age and sex, in which the standard population was the population of all RNH practices. To determine whether the observed differences between both regions were statistically significant, logistic regression analyses were performed, using the statistical software programme SPSS 9.0 for Windows. In the analyses regarding mortality, the dependent variable was presence or absence of a specific cause or causes of death; in those regarding morbidity and risk factors, the dependent variable was presence or absence of the disease category or risk factor. The independent variable was 'region' (Heerlen/Kerkrade vs. Maastricht) with potential confounders sex and age distribution. First, all variables were entered in the model, followed by all possible interaction terms (method: enter). The model was then further fitted, based on the statistical significance of the various interaction terms (region times age, region times sex, sex times age) according to the likelihood ratio test. In all analyses, age was entered as a categorical variable since this improved the Hosmer-Lemeshow goodness-of-fit tests considerably. ${ }^{12}$

\section{Results}

\section{General characteristics}

The general characteristics of the study populations are summarised in Table 2.2. With regard to mortality data (CBS), there were hardly any differences in age distribution 
between both regions. With regard to morbidity data (RNH), the population of Heerlen/Kerkrade was slightly older than that of Maastricht. Both CBS and RNH populations contained slightly more females than males. Overall, both study populations were very comparable regarding to age and sex.

Table 2.2 Sex and age distribution of the study populations for mortality and morbidity.

\begin{tabular}{|c|c|c|c|c|c|c|}
\hline & \multicolumn{3}{|c|}{ Mortality analyses ${ }^{a} \%$} & \multicolumn{3}{|c|}{ Morbidity analyses $^{\mathrm{a}} \%$} \\
\hline & Netherlands & Maastricht & $\begin{array}{l}\text { Heerlen/ } \\
\text { Kerkrade }\end{array}$ & RNH & Maastricht & $\begin{array}{l}\text { Heerlen/ } \\
\text { Kerkrade }\end{array}$ \\
\hline Characteristic & $(n=8,544,381)$ & $(n=67,975)$ & $(n=87,444)$ & $(n=56,976)$ & $(n=8,742)$ & $(n=10,587)$ \\
\hline \multicolumn{7}{|l|}{ Sex } \\
\hline Male & 48.2 & 47.3 & 47.7 & 48.1 & 46.9 & 48.3 \\
\hline Female & 51.8 & 52.7 & 52.3 & 51.9 & 53.1 & 51.7 \\
\hline \multicolumn{7}{|l|}{ Age (year) } \\
\hline $35-44$ & 29.6 & 27.2 & 27.8 & 27.5 & 28.8 & 26.5 \\
\hline $45-54$ & 26.7 & 25.4 & 25.1 & 26.4 & 23.7 & 25.9 \\
\hline $55-64$ & 18.5 & 18.9 & 18.9 & 19.6 & 18.7 & 19.5 \\
\hline $65-74$ & 14.0 & 15.8 & 16.0 & 15.4 & 16.4 & 15.9 \\
\hline $75-84$ & 8.6 & 9.8 & 9.8 & 9.0 & 9.6 & 10.0 \\
\hline$\geq 85$ & 2.6 & 2.8 & 2.4 & 2.1 & 2.8 & 2.1 \\
\hline
\end{tabular}

${ }^{\mathrm{a}}$ Based on CBS database 2000; ${ }^{\mathrm{b}}$ Based on RNH database 2001

\section{Cardiovascular mortality}

Mortality figures of some CVDs or risk factors were so small that no meaningful analyses could be performed. This was the case for 'other vascular disease' and 'peripheral arterial occlusive disease' and for all the risk factors. Table 2.3 shows standardised mortality rates of CVDs for both regions and the average in the Netherlands. The overall trend for all categories was that mortality rates were higher in Heerlen/Kerkrade compared with Maastricht. The most distinct difference was found for 'ischemic heart disease'. Figure 2.1 shows the age specific mortality rates for the two regions. For every age group, the mortality rate was higher in Heerlen/Kerkrade compared with Maastricht. However, the pattern of the mortality rates was comparable in the two regions.

Logistic regression analyses confirmed the statistical significance of the differences between the two regions. The variable 'region' had an independent association with mortality in the categories 'ischemic heart disease' (OR=1.4 [1.2-1.7]), 'other cardiovascular disease' (OR=1.2 [1.1-1.5]) and 'other heart disease' (OR=1.3 [1.1-1.7]). No independent association was observed for the mortality category 'stroke'. 
Table 2.3 Standardized mortality rates of CVDs for two urban regions $(n=155,419)$ and the Netherlands $(n=8,544,381)$.

\begin{tabular}{lcccc}
\hline & $\begin{array}{c}\text { Netherlands } \\
(\%)\end{array}$ & $\begin{array}{c}\text { Maastricht } \\
(\%)\end{array}$ & $\begin{array}{c}\text { Heerlen/Kerkrade } \\
(\%)\end{array}$ & $\begin{array}{c}\text { Significance of the } \\
\text { variable 'region' }\end{array}$ \\
\hline Mortality category & & & & \\
Ischemic heart disease & 2.0 & 2.2 & 3.1 & OR=1.4 (1.2-1.7) \\
Stroke & 1.4 & 1.5 & 1.8 & OR=1.2 \\
Other CV disease & $-{ }^{\mathrm{a}}$ & 2.9 & 2.9 & $\mathrm{OR}=1.2(1.1-1.5)^{\mathrm{b}, \mathrm{c}}$ \\
Other heart disease & $-\mathrm{a}^{\mathrm{a}, \mathrm{c}}$ & 1.6 & 2.2 & $\mathrm{OR}=1.3(1.1-1.7)^{\mathrm{b}, \mathrm{c}}$ \\
Overall CV diseases & 5.7 & 6.1 & 7.8 & $\mathrm{OR}=1.3(1.2-1.5)^{\mathrm{b}, \mathrm{c}}$ \\
\hline
\end{tabular}

${ }^{a}$ No comparable data available; ${ }^{b}$ Heerlen/Kerkrade versus Maastricht; ${ }^{c} 95 \%$ confidence interval. $\mathrm{CV}=$ cardiovascular.

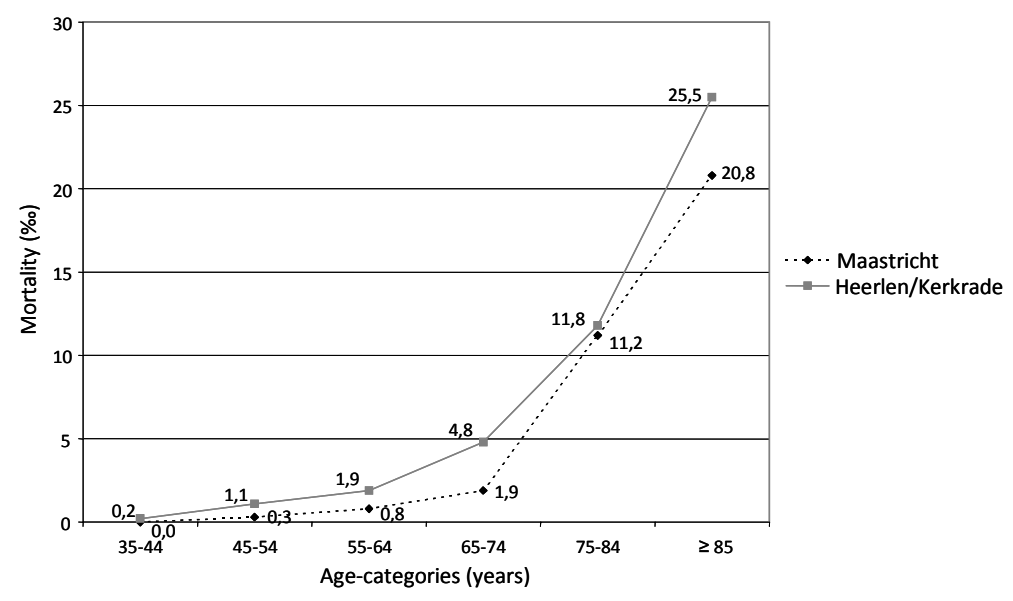

Figure 2.1 Age specific mortality rates for ischemic heart disease (CBS mortality data).

\section{Cardiovascular morbidity}

In Table 2.4 standardised prevalence rates of cardiovascular morbidity are presented for both regions. Overall, the Heerlen/Kerkrade region consistently showed a higher prevalence of cardiovascular morbidity in comparison with Maastricht. The most distinct differences between the regions were found with respect to 'ischemic heart disease' and 'other heart and vascular diseases', in which the main contribution came from 'other vascular disease'. Figure 2.2 shows the trend of the prevalence rates of ischemic heart disease in both regions. The prevalence rate of Heerlen/Kerkrade for every age group was consistently above Maastricht, except for the youngest and the oldest age category. For all other cardiovascular morbidity categories, the prevalence rate of Heerlen/Kerkrade lay consistently above Maastricht. Comparatively, the relative risk was the highest for peripheral arterial occlusive disease. Logistic regression analyses confirmed the statistical significance of the differences between both regions in most cases. The variable 'region' had an independent association with 
morbidity in the categories 'other heart and vascular disease' (OR=1.2 [1.1-1.3]), 'other vascular disease' (OR=1.2 [1.1-1.3]) and 'peripheral arterial occlusive disease' $(O R=1.4$ [1.2-1.7]). It was significant in interaction with age for 'ischemic heart disease', indicating that in all age categories the prevalence of ischemic heart disease was higher in Heerlen/Kerkrade than in Maastricht, except for the age category 35 to 44 and $\geq 85$. Differences in prevalence rates for stroke and 'other heart disease' were small, which was confirmed by the results of the logistic regression analysis (Table 2.4).

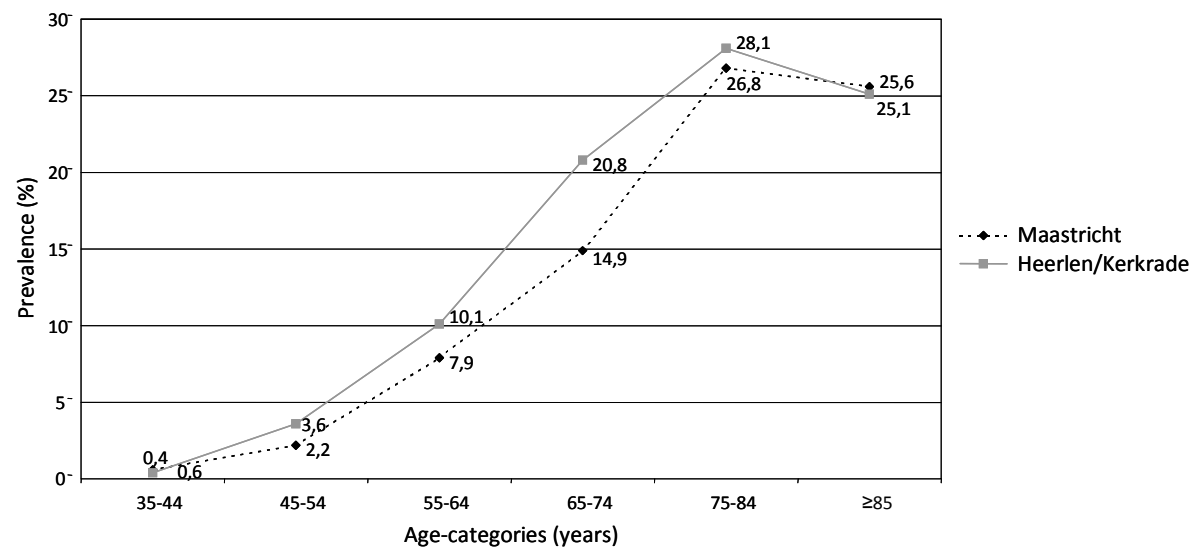

Figure 2.2 Age specific prevalence rates for ischemic heart disease (morbidity data from the RNH database).

\section{Cardiovascular risk factors}

In Table 2.4 also standardised prevalence rates of available cardiovascular risk factors are presented for both regions. The prevalence of the cardiovascular risk factors studied was higher in Heerlen/Kerkrade compared with Maastricht. This holds especially for 'diabetes mellitus', 'overweight' and 'lipid disorders'. Regarding 'hypertension', the difference was small.

Logistic regression analyses confirmed the statistical significance of the differences between both regions in most cases. With respect to the cardiovascular risk factors studied, the variable 'region' had an independent association with 'diabetes mellitus' $(\mathrm{OR}=1.5$ [1.3-1.7]) and with 'overweight' (OR=2.0 [1.8-2.2]). For 'lipid disorders', it was significant in interaction with age and sex, indicating that if age rises, more males develop lipid disorders in the region Heerlen/Kerkrade than in Maastricht. The difference in prevalence rates of hypertension was small, which was confirmed by the results of the logistic regression analysis. 
Table 2.4 Standardized prevalence rates of CVD and risk factors for two urban regions $(n=19329)$ and the $\mathrm{RNH}^{\#}$ overall ( $\mathrm{n}=56$ 976).

\begin{tabular}{|c|c|c|c|c|}
\hline & $\begin{array}{c}\text { RNH } \\
(\%)\end{array}$ & $\begin{array}{c}\text { Maastricht } \\
(\%)\end{array}$ & $\begin{array}{c}\text { Heerlen/Kerkrade } \\
(\%) \\
\end{array}$ & $\begin{array}{l}\text { Significance of the } \\
\text { variable 'region' }\end{array}$ \\
\hline \multicolumn{5}{|l|}{ Cardiovascular Disease category } \\
\hline Ischemic heart disease & 8.5 & 7.8 & 9.6 & In interaction with age \\
\hline Stroke & 3.7 & 3.9 & 4.0 & $\mathrm{OR}=1.0(0.9-1.2)^{\mathrm{b}, \mathrm{c}}$ \\
\hline Other heart and vascular disease & 19.6 & 20.1 & 22.3 & $\mathrm{OR}=1.2(1.1-1.3)^{\mathrm{b}, \mathrm{c}}$ \\
\hline - Other heart disease & 7.4 & 7.6 & 7.5 & $\mathrm{OR}=1.0(0.9-1.1)^{\mathrm{b}, \mathrm{c}}$ \\
\hline - Other vascular disease & 11.6 & 12.4 & 14.1 & $\mathrm{OR}=1 \cdot 2(1 \cdot 1-1 \cdot 3)^{\mathrm{b}, \mathrm{c}}$ \\
\hline - Peripheral arterial occlusive disease & 3.2 & 2.8 & 3.9 & $\mathrm{OR}=1 \cdot 4(1 \cdot 2-1 \cdot 7)^{\mathrm{b}, \mathrm{c}}$ \\
\hline $\begin{array}{l}\text { Overall diseases of the heart and } \\
\text { circulation system }\end{array}$ & 25.8 & 25.9 & 28.9 & $\mathrm{OR}=1.2(1.1-1.3)^{\mathrm{b}, \mathrm{c}}$ \\
\hline \multicolumn{5}{|l|}{ Cardiovascular Risk factor category } \\
\hline Hypertension & 14.6 & 15.3 & 15.2 & $\mathrm{OR}=1.0(0.9-1.1)^{\mathrm{b}, \mathrm{c}}$ \\
\hline Diabetes Mellitus (I \& II) & 6.3 & 5.0 & 7.2 & $\mathrm{OR}=1.5(1.3-1.7)^{\mathrm{b}, \mathrm{c}}$ \\
\hline Overweight $^{a}$ & 7.5 & 5.8 & 10.8 & $\mathrm{OR}=2.0(1.8-2.2)^{\mathrm{b}, \mathrm{c}}$ \\
\hline Lipid disorders & 6.4 & 5.5 & 8.0 & $\begin{array}{l}\text { In interaction with } \\
\text { age and sex }\end{array}$ \\
\hline
\end{tabular}

${ }^{\mathrm{a}} \mathrm{BMI} \geq 25 ;{ }^{\mathrm{b}} 95 \%$ confidence interval; ${ }^{\mathrm{c}}$ Heerlen/Kerkrade versus Maastricht; ${ }^{\#} \mathrm{RNH}$ : Registration Network Family Practices

\section{Discussion}

The present study showed that cardiovascular mortality rates were higher in the region Heerlen/Kerkrade compared with both the average in the Netherlands and in Maastricht in particular. Similarly, most cardiovascular morbidity rates for Heerlen/Kerkrade were more elevated compared with the RNH overall and more specifically with Maastricht. In accordance with these results prevalence rates of cardiovascular risk factors - in particular diabetes mellitus, overweight and lipid disorders, but not hypertension - were significantly higher in the Heerlen/ Kerkrade region.

Before discussing possible explanations and the relevance and implications of these findings, it is important to discuss in short the validity of the registration systems used. In the case of mortality data (CBS), validity depends on the accuracy of the registration of the primary cause of death. Several studies have assessed the validity of the Dutch mortality registration and confirmed the completeness of this registration. ${ }^{6,7,13}$ However, discrepancies have been found between the judgement of physicians and subsequent findings at autopsy and between physicians coding identical cases for research purposes. ${ }^{6,14}$ Using broad categories, as was done in this study, is known to lead to fewer discrepancies than analysing single disorders. ${ }^{14,15} \mathrm{We}$ have no reason to assume there are regional differences with regard to registration of death certificates by doctors. Regarding data on morbidity and risk factors (RNH), validity depends on the accuracy of the registration of the diagnostic problems by the general practitioners involved. The quality is ascertained by instruction and training 
sessions, regional consensus groups, quality control experiments and by an automated thesaurus and automated checking for erroneous or missing entries. ${ }^{8}$ There were no differences between the selected general practices in both regions with regard to participation in cardiovascular research projects over the last 13 years. Our results demonstrate that Heerlen/Kerkrade is indeed a region with a high burden of CVD, in comparison with Maastricht and the average in the Netherlands. Given the fact that five general practices in Heerlen/Kerkrade are included in the RNH overall, the estimates of the prevalence rates for cardiovascular morbidity in the RNH overall are probably higher than the average in the Netherlands. Consequently, average cardiovascular morbidity figures for the Netherlands will probably be lower than presented here.

Data from the Framingham study show that important cardiovascular risk factors such as hypertension, diabetes mellitus, overweight and lipid disorders have a mutual amplifying effect. ${ }^{16}$ Our results show a relatively high prevalence of diabetes mellitus, overweight and lipid disorders in Heerlen/Kerkrade and this will contribute to a higher prevalence rate of cardiovascular mortality and morbidity. However, the prevalence rates for hypertension did not differ in the two regions. A Dutch study using CBS data for the period 1950 to 1984 suggested that excess cardiovascular mortality appearing in the south of the Netherlands could be explained by Roman Catholic lifestyle and relatively lower income. ${ }^{17}$ Unpublished reports for the Heerlen/Kerkrade region and Maastricht on these cardiovascular risk factors as well as for alcohol use, showed inconsistent differences. No data were available on risk factors such as elevated homocysteine levels and unfavourable nutrition patterns. ${ }^{18-21}$

Our results are consistent with the complex relationship between cardiovascular morbidity and multiple cardiovascular risk factors. ${ }^{22}$ However, the excess risk observed in the Heerlen/Kerkrade region as compared with the Maastricht region can not be fully explained on the basis of a higher prevalence of risk factors. For instance, in subjects from Heerlen/Kerkrade with hypertension, the risk of coronary complications was substantially greater than that predicted from placebo-treated patient populations in major clinical trials. ${ }^{23}$ In the pathogenesis of CVD many factors, including genetic and environmental factors, play a role. ${ }^{24,25}$ Genetic factors that modulate the individual susceptibility to CVD are common, functionally different types of genes (polymorphisms). ${ }^{26-29}$ These polymorphisms generally have a modest effect at an individual level, but because of their high frequency in the population can be associated with a high attributable risk. ${ }^{30}$ Environmental factors can reveal or facilitate the phenotypic expression of such susceptibility genes. There is now accumulating evidence that most of the susceptibility genes for common diseases do not have a primary aetiological role in predisposition to disease, but rather act as response modifiers to exogenous factors such as stress, environment, disease, and drug intake. $^{30} \mathrm{~A}$ better characterisation of the interactions between environmental and 
genetic factors constitutes a key issue in the understanding of the pathogenesis of CVD. ${ }^{31-33}$ Therefore it is important to study all these factors on an individual level.

\section{Conclusion}

The Heerlen/Kerkrade region is indeed a region with a high burden of CVD. However, the differences in morbidity between Heerlen/Kerkrade and Maastricht cannot be fully explained by differences in cardiovascular risk factor profile. Therefore a better characterisation of the interactions between environmental and genetic factors is important in cardiovascular research in the Heerlen/ Kerkrade region. 


\section{References}

1. Henskens LH, Spiering W, Stoffers HE, Soomers FL, Vlietinck RF, de Leeuw PW, Kroon AA. Effects of ACE I/D and AT1R-A1166C polymorphisms on blood pressure in a healthy normotensive primary care population: first results of the Hippocrates study. J Hypertens 2003;21:81-6.

2. Metsemakers JF, Hoppener P, Knottnerus JA, Kocken RJ, Limonard CB. Computerized health information in the Netherlands: a registration network of family practices. Br J Gen Pract 1992; 42:102-6.

3. Kuulasmaa K, Tunstall-Pedoe H, Dobson A, Fortmann S, Sans S, Tolonen H, Evans A, Ferrario M, Tuomilehto J. Estimation of contribution of changes in classic risk factors to trends in coronary-event rates across the WHO MONICA Project populations. Lancet 2000;355: 675-87.

4. Nawawi HM, Nor IM, Noor IM, Karim NA, Arshad F, Khan R, Yusoff K. Current status of coronary risk factors among rural Malays in Malaysia. J Cardiovasc Risk 2002;9:17-23.

5. WHO. ICD-10: International statistical classification of diseases and related health problems. 10th ed. Geneva: World Health Organization; 1992.

6. Mackenbach JP, Van Duyne WM, Kelson MC. Certification and coding of two underlying causes of death in the Netherlands and other countries of the European Community. J Epidemiol Community Health 1987;41:156-60.

7. Schadé B. Reliability and validity of the classification of death in general practice. Scand J Prim Health Care 1987;5:109-12.

8. Metsemakers JFM. Unlocking patients' records in general practice for research, medical education and quality assurance. Maastricht: Rijksuniversiteit Limburg; 1994.

9. Lamberts H, Wood M, editors. ICPC: International Classification of Primary Care. Oxford: Oxford University Press; 1987.

10. Classification of Health Problems in Primary Care, 3rd edition. Oxford, Oxford University Press, 1983.Classification Committee of Wonca. Oxford: Oxford University Press; 1983.

11. van den Akker M, Franssen GHLM, Buntinx F, Metsemakers JFM, Knottnerus JA. The reliability of register-based patient characteristics. Archives of Public Health 1997;55:231-38.

12. Hosmer DW, Lemeshow S. Applied Logistic Regression. 2nd ed. New York: John Wiley and Sons; 2000:147-56.

13. Mackenbach JP, Snels IA, Friden-Kill LM. Diabetes mellitus as cause of death. Ned Tijdschr Geneeskd 1991;135:1492-6.

14. Kircher T, Nelson J, Burdo H. The autopsy as a measure of accuracy of the death certificate. N Engl J Med 1985;313:1263-9.

15. Messite J, Stellman SD. Accuracy of death certificate completion: the need for formalized physician training. JAMA 1996;275:794-6.

16. Kannel WB, McGee D, Gordon T. A general cardiovascular risk profile: the Framingham Study. Am J Cardiol 1976;38:46-51.

17. Mackenbach JP, Kunst AE, Looman CW. Cultural and economic determinants of geographical mortality patterns in The Netherlands. J Epidemiol Community Health 1991;45:231-7.

18. Nygard O, Nordrehaug JE, Refsum H, Ueland PM, Farstad M, Vollset SE. Plasma homocysteine levels and mortality in patients with coronary artery disease. N Engl J Med 1997;337:230-6.

19. Bots ML, Launer LJ, Lindemans J, Hoes AW, Hofman A, Witteman JC, Koudstaal PJ, Grobbee DE. Homocysteine and short-term risk of myocardial infarction and stroke in the elderly: the Rotterdam Study. Arch Intern Med 1999;159:38-44.

20. van der Bom JG, Bots ML, Grobbee DE. Cardiovascular risk factors. Review of possible causes of heart and vascular diseases. Ned Tijdschr Geneeskd 2002;146:1169-74.

21. van der Griend R, Biesma DH, Banga JD. Hyperhomocysteinaemia as a cardiovascular risk factor: an update. Neth J Med 2000;56:119-30. 
22. De Backer G, Ambrosioni E, Borch-Johnsen K, Brotons C, Cifkova R, Dallongeville J, Ebrahim S, Faergeman O, Graham I, Mancia G, Cats VM, Orth-Gomér K, Perk J, Pyörälä K, Rodicio JL, Sans S, Sansoy V, Sechtem U, Silber S, Thomsen T, Wood D; European Society of Cardiology Committee for Practice Guidelines. European guidelines on cardiovascular disease prevention in clinical practice: third joint task force of European and other societies on cardiovascular disease prevention in clinical practice (constituted by representatives of eight societies and by invited experts). Eur J Cardiovasc Prev Rehabil 2003;10:S1-S10.

23. Neal B, MacMahon S, Chapman N. Effects of ACE inhibitors, calcium antagonists, and other bloodpressure-lowering drugs: results of prospectively designed overviews of randomised trials. Blood Pressure Lowering Treatment Trialists' Collaboration. Lancet 2000;356:1955-64.

24. Sing CF, Stengard JH, Kardia SL. Genes, environment, and cardiovascular disease. Arterioscler Thromb Vasc Biol 2003;23:1190-6.

25. Smilde TJ, van Wissen S, Wollersheim H, Kastelein JJ, Stalenhoef AF. Genetic and metabolic factors predicting risk of cardiovascular disease in familial hyper-cholesterolemia. Neth J Med 2001;59: 184-95.

26. Wang JG, Staessen JA. Genetic polymorphisms in the renin-angiotensin system: relevance for susceptibility to cardiovascular disease. Eur J Pharmacol 2000;410:289-302.

27. Veldman BA, Spiering W, Doevendans PA, Vervoort G, Kroon AA, de Leeuw PW, Smits P. The Glu298Asp polymorphism of the NOS 3 gene as a determinant of the baseline production of nitric oxide. J Hypertens 2002;20:2023-7.

28. Spiering W, Kroon AA, Vreugdenhil HA, Geraedts JP, Daemen MJ, de Leeuw PW. [The relationship between genetic polymorphisms and disease, illustrated by the renin-angiotensin-aldosterone system and cardiovascular disease]. Ned Tijdschr Geneeskd 1998;142:1445-50.

29. Spiering W, Kroon AA, Fuss-Lejeune MM, Daemen MJ, de Leeuw PW. Angiotensin II sensitivity is associated with the angiotensin II type 1 receptor $A(1166) C$ polymorphism in essential hypertensives on a high sodium diet. Hypertension 2000;36:411-6.

30. Tiret L. Gene-environment interaction: a central concept in multifactorial diseases. Proc Nutr Soc 2002;61:457-63.

31. Stephens JW, Humphries SE. The molecular genetics of cardiovascular disease: clinical implications. J Intern Med 2003;253:120-7.

32. Herrmann SM, Paul M. Studying genotype-phenotype relationships: cardiovascular disease as an example. J Mol Med 2002;80:282-9.

33. D'Orleans-Juste P, Plante GE. ACE Inhibitors. Basel, Switzerland: Birkhäuser Verlag; 2001:11-27. 
34 


\section{Chapter 3}

\section{THE CONTRIBUTION OF SIX POLYMORPHISMS TO CARDIOVASCULAR RISK IN A DUTCH HIGH RISK PRIMARY CARE POPULATION: THE HIPPOCRATES PROJECT}

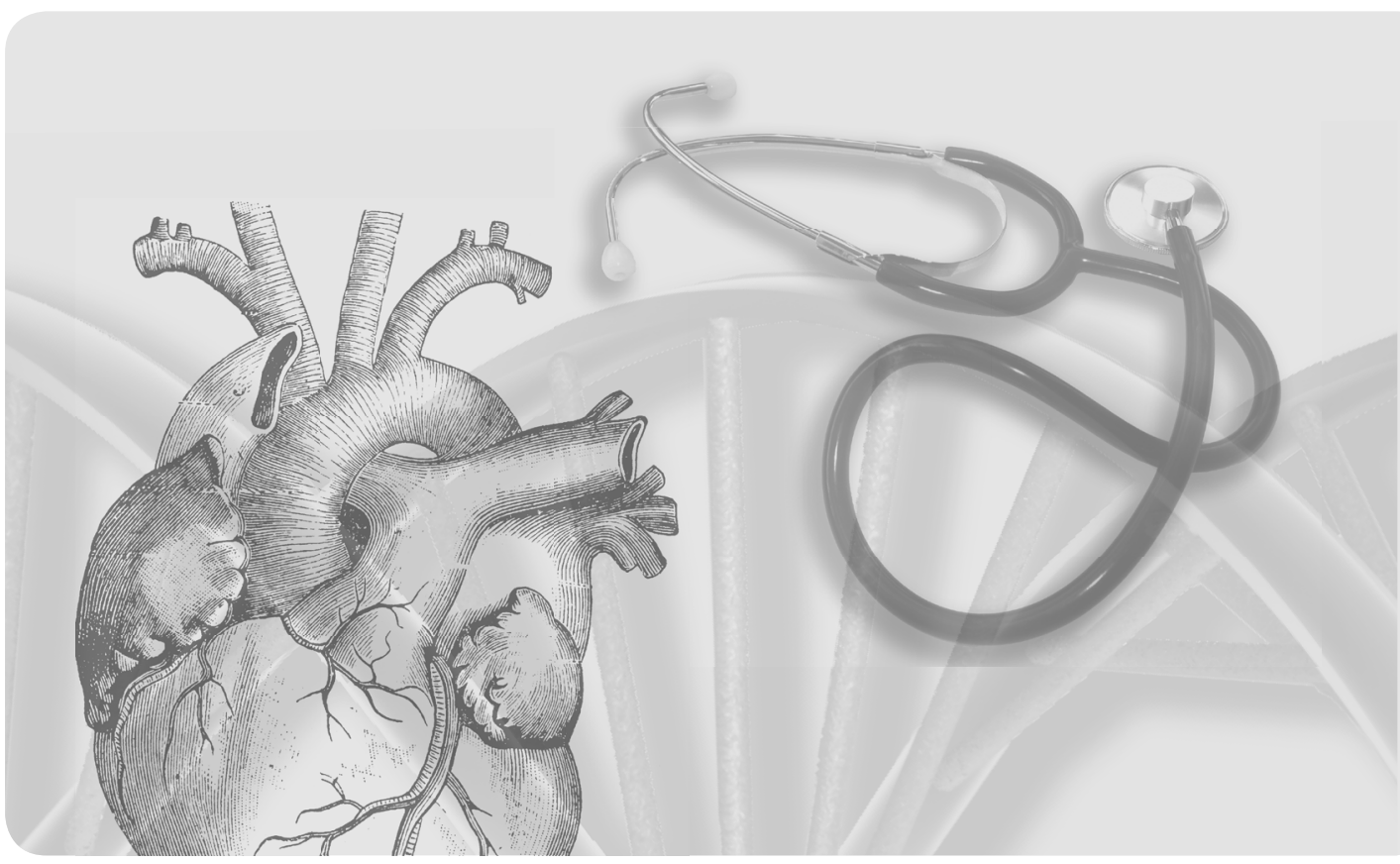

AW Plat, HEJH Stoffers, OH Klungel, CP van Schayck, PW de Leeuw, FL Soomers, PM Schiffers, ADM Kester, AA Kroon 


\section{Abstract}

This study was designed to examine the contribution of six cardiovascular polymorphisms to the occurrence of cardiovascular disease (CVD) in a Dutch primary care population with a high prevalence of cardiovascular risk factors. In this cross sectional case-control study, 232 patients with CVD and 571 event-free controls were studied. Patients were genotyped for the AGTR1 (A1166C), AGT (M235T), ACE (4656 rpt), NOS3 (E298D), GNB3 (C825T) and ADD1 (G460W) polymorphisms. Univariate and multivariate odds ratios (ORs) were calculated to assess the relationship between genotypes and CVD. Receiver operating characteristic (ROC) analysis was used to quantify the contribution of the polymorphisms to the prediction of CVD. No differences in either genotype or allele frequencies were found between CVD cases and controls. Multivariate analyses showed significant protective associations for the $T$ allele of AGT (OR=0.55 [0.34-0.84]) and for the T allele of ADD1 (OR=0.52 [0.31-0.82]). ROC analysis showed only a very small improvement of CVD risk prediction by adding the six polymorphisms to a model with traditional risk factors. Our data suggests that a major attribution of the six polymorphisms to the cardiovascular risk prediction in a primary care population such as HIPPOCRATES is unlikely. 


\section{Introduction}

Cardiovascular diseases are the leading cause of mortality and morbidity in the world. Smoking, obesity, gender, metabolic disorders and hypertension are traditional risk factors, which have been intensively investigated in population surveys. ${ }^{1}$ The appearance of cardiovascular genetics as a new discipline in medicine has led to the publication of numerous studies, investigating whether specific genetic polymorphisms may either cause cardiovascular disease (CVD) in a monogenetic or a polygenetic fashion or predispose subjects to various cardiovascular disorders. ${ }^{2}$ Among these, many studies have aimed to investigate the influence of genetic variability of the renin-angiotensin system (RAS) on the development of CVD. ${ }^{3}$ Among the many potential genes, those related to activation of the RAS or to an increased tendency to retain sodium rank high and so do genes which may cause reduced variability of nitric oxide (NO). To this date, the results from human studies on their role in the development of CVD are not beyond dispute. ${ }^{3}$ An important reason is that most of these observations have been obtained in selected populations. ${ }^{4}$

Earlier, we have suggested that the excess risk observed in the south-east region of the province of Limburg, the Netherlands, could not be fully explained on the basis of a higher prevalence of cardiovascular risk factors. ${ }^{5}$ Furthermore, a pilot study suggested a role for certain genetic variants of the RAS in healthy normotensive patients in this population. ${ }^{6}$ This prompted us to perform a genetic association study on CVD in a primary care population in this region. On the basis of the available literature at the start of the study, we restricted ourselves to the analysis of six polymorphisms. These were the angiotensinogen [AGT (M235T)], angiotensin converting enzyme [ACE $\left(4656_{\mathrm{rpt}}\right)$ ], and the angiotensin II type 1 receptor [AGTR1 (A1166C)] polymorphism, that are involved in the generation and action of angiotensin II (AngII). In addition, $\alpha$-adducin [ADD1 (G460W)], G-protein $\beta 3$ subunit [GNB3 (C825T)], and the endothelial nitric oxide synthase [NOS3 (E298D)] polymorphisms, as markers of sodium retaining tendency and altered NO availability, were selected, respectively. We hypothesized that the presence of one or more rare alleles of the aforementioned six polymorphisms would affect the occurrence of CVD in a high risk primary care population. Therefore, in this study we assessed the contribution of these six polymorphisms to the occurrence of CVD in patients with known CVD in comparison to control subjects without CVD.

\section{Methods}

\section{Study population}

The HIPPOCRATES (Hypertension: Interaction and Prevalence of POlymorphisms related to Cardiovascular Risk and the Association to Treatment Efficacy Study) is an 
ongoing study, in which the implementation of genetic polymorphisms in the assessment of cardiovascular risk in primary care is investigated. ${ }^{5-7}$ This study utilizes the population of one large general practice in Kerkrade, which is located in the southeast of the Netherlands, and is characterised with a high burden of CVD compared with the average of the Netherlands. ${ }^{5}$ This academic general practice takes part in the Registration Network Family Practices (RNH), which is a continuous and computerized morbidity registration network in which 63 general practitioners (GPs), working in 22 different practices, in the south of the Netherlands participate. All relevant health problems, including a full medical history of all cardiovascular events have been registered since $1990 .^{8,9}$ Medical problems are coded according to the International Classification of Primary Care (ICPC) using the criteria of the International Classification of Health Problems in Primary Care for diagnoses. ${ }^{10,11}$ The general practice in Kerkrade has a list of approximately 4400 patients, among whom are more than 2300 patients of 40 years and older. The practice has well implemented cardiovascular consulting hours. For HIPPOCRATES, all known patients aged $\geq 40$ years with CVD or hypertension were invited. From the group with neither CVD nor hypertension but with other cardiovascular risk factors, that is, smoking, alcohol, diabetes mellitus, dyslipidemia, overweight including obesity, a random 1:3 sample was taken. Of all patients without known CVD, hypertension or other cardiovascular risk factors, also a random 1:3 sample was taken. The initial classification was validated by a thorough assessment of the patients' records combined with additional measurements of risk factors for all subjects. The total HIPPOCRATES population consisted of 803 patients ( 382 males, 421 females), who were recruited between May 2003 and July 2005.

For the present study, 232 patients with known CVD were compared with 571 eventfree controls. The presence of CVD was defined as a diagnosis of ischemic heart disease, stroke, peripheral arterial occlusive disease or heart failure. Control subjects had no documented CVD. The study was approved by the Medical Ethics Committee of the Maastricht University Medical Center. Written informed consent was obtained from each of the participants.

\section{Clinical data collection}

All clinical measurements were performed in the practice by one of the authors (AWP; first measurement) and a nurse practitioner (second, third and fourth measurement with in-between periods of three months). The nurse practitioner measured weight and blood pressure. All persons were questioned on their smoking behaviour and alcohol consumption. Weight and height were measured. Body-mass index (BMI) was calculated as body weight divided by squared height. BMI values $\geq 27$ were considered to be too high. The size of the waist was measured. Blood pressure and heart rate were measured three times per visit after ten minutes rest in sitting position using a 
sphygmomanometer. Fasting blood samples were drawn to determine serum creatinine, total cholesterol, low-density lipoprotein (LDL) cholesterol, high-density lipoprotein (HDL) cholesterol, serum triglycerides and glucose levels and analyzed in one regional laboratory. Microalbuminuria was determined semiquantitatively in a first-morning urine sample.

\section{Definitions}

Hypertension was defined as a systolic blood pressure (SBP) $\geq 140 \mathrm{mmHg}$ and/or diastolic blood pressure (DBP) $\geq 90 \mathrm{mmHg}$ according to the Guidelines for Hypertension specified by the European Society of Hypertension ${ }^{12}$ or the use of antihypertensive drugs. The presence of dyslipidemia was defined as total cholesterol to HDL cholesterol ratio exceeding 4.0 or use of lipid lowering drugs. Diabetes mellitus was considered to be present in case of fasting plasma glucose levels $>6.9 \mathrm{mmol} / \mathrm{l}$ or the use of oral antidiabetic drugs or insuline. Creatinine values higher than $115 \mu \mathrm{mol} / \mathrm{I}$ (males) or $107 \mu \mathrm{mol} / \mathrm{l}$ (females) were considered to be a risk factor for CVD. Microalbuminuria was defined as albumin excretion above $20 \mathrm{mg} / \mathrm{l}$.

\section{Genetic analyses}

The various polymorphisms were determined at the Cardiovascular Genotyping (CAGT) Laboratory of the Department of Internal Medicine of the Maastricht University Medical Center. DNA was extracted from whole blood with the use of the QIAmp Blood Kit (Qiagen Inc., Valencia, California, USA). Genotyping of the angiotensin II type 1 receptor [AGTR1 (A1166C)/rs5186], angiotensinogen [AGT $(\mathrm{M} 235 \mathrm{~T}) / \mathrm{rs699}]$, angiotensin converting enzyme [ACE $\left.\left(4656_{\mathrm{rpt}}\right) / \mathrm{rs} 1799752\right]$, endothelial nitric oxide synthase [NOS3 (E298D)/rs1799983], G-protein $\beta 3$ subunit [GNB3 (C825T)/rs5443] and $\alpha$-adducin [ADD1 (G460W)/rs4961] polymorphisms was performed with a multiplex single base extension (SBE) assay (Multiplex SNaPshot,

Applied Biosystems, Foster City, USA) similar to previously published protocols. ${ }^{13}$ Briefly, in the first stage a multiplex PCR is carried out to amplify the gene fragments that contain the polymorphisms. In the second stage, the polymorphic positions are interrogated by a SBE reaction using fluorescently labelled ddNTPs. The oligos used for the single base extension have specific lengths, varying from 22-50 nt. After the SBE assay, the fragments are size-resolved on an ABI3100 Genetic Analyser: the size of the peaks identifies the locus (e.g. ADD1) and the color of the peak(s) identifies the genotype (e.g. Gly/Trp). Raw data were analyzed with Genescan Analysis software ( $v$ 3.7), then genotypes were scored independently by two researchers and entered in the database. In 27 patients, a second analysis was necessary to obtain all the genotypes. The ACE (I/D) polymorphism was determined by detecting $\mathrm{ACE}_{4656+C T}$ observed on the SNaPshot as ACE (4656 $6_{\mathrm{rpt}}$ ). The use of this SNaPshot method does not allow the direct determination of the insertion/deletion polymorphism. The $A C E_{4656+C T}$ polymorphism in the $3^{\prime}$-untranslated region of the ACE gene consists of a repetition of 
two or three CT dinucleotides and is in complete linkage disequilibrium with ACE (I/D). ${ }^{14,15}$ The multiplex assay was validated on a set of 100 DNA samples that had previously been genotyped with an alternative technique; this technique concerned a multilocus genotyping assay for candidate markers of CVD risk (Roche Molecular systems Inc., Pleasanton, USA) and has been described in detail previously. ${ }^{16}$ Only four samples gave a discordant result for the NOS3 polymorphism. All other genotypes were concordant. The discordant results have been adjusted.

\section{Genetic validation of control group}

To evaluate the validity of our control group, we compared the genotype- and allele frequencies with subjects who use antihypertensive drugs but without CVD in another general population sample in the Netherlands, that is, the PHARmacoMOrbidity Record Linkage System (PHARMO RLS), which has allele frequencies comparable with those found in large European healthy control groups. ${ }^{17,18}$ In short, PHARMO RLS links drug dispensing histories from a representative sample of Dutch community pharmacies to the national registrations of hospital discharges (LMR) from 1985 onwards. Currently, the base population of PHARMO covers more than 2.5 million community-dwelling inhabitants of several population-defined areas in the Netherlands. ${ }^{19,20}$

\section{Statistical analysis}

Statistical analysis was performed by using SPSS statistical software, version 13.0 (SPSS, Inc., Chicago, IL, USA). A $P$-value of 0.05 or less was considered statistically significant. Bonferroni correction was applied for multiple testing. Statistical significance for differences in quantitative variables between CVD patients and controls was tested by unpaired Student's $t$-tests. In case of categorical variables the chi-square test was used. Genotype and allele frequencies were calculated to test the Hardy-Weinberg equilibrium. Allele frequencies were analyzed using chi-square tests.

\section{Logistic regression analyses}

Both univariate and multivariate odds ratios (ORs) were calculated with a binarylogistic regression model (method: enter) to evaluate the relationship between polymorphisms and prevalent CVD. For that purpose, dummy variables were created using the homozygous wild-type genotype as reference category. Age and gender, both demographic variables, were incorporated in both the univariate as well as in the multivariate linear regression analyses. As indicated, we selected control subjects from different groups. Therefore, in the logistic regression analyses we had to adjust for this selection and dummy variables had to be created using the normotensive group without cardiovascular risk factors as the reference category. Adjustment for potential confounders was performed by incorporating smoking, alcohol, diabetes 
mellitus, waist circumference, serum creatinine, mean systolic and diastolic blood pressure, microalbuminuria and dyslipidemia into these models. To avoid collinearity, waist circumference was used instead of waist-to-hip ratio or BMI and condensed measures were used like diabetes and dyslipidemia as defined earlier. Recent research has shown that waist circumference is a better marker of abdominal fat accumulation than waist-to-hip ratio or $\mathrm{BMI}^{21}$, which is strongly associated with increased cardiovascular risk. ${ }^{22}$ The simultaneous contribution of the six polymorphisms to the prediction of CVD was tested, using a likelihood ratio test. If two or more polymorphisms reached statistical significance, interactions (effect modification) between two polymorphisms with respect to CVD were assessed. Again binary-logistic regression analysis (method: enter) was used, in which the alleles at risk, the interaction term between the alleles and the other covariates were incorporated. If an interaction term became statistically significant, the model was explored further.

\section{ROC analysis}

The quantitative impact of the six polymorphisms on the prediction of CVD was evaluated by comparison of the receiver operating characteristic (ROC) curve incorporating the traditional risk factors (that is, age, gender, smoking, alcohol, diabetes mellitus, waist circumference, serum creatinine, mean systolic and diastolic blood pressure, microalbuminuria, and dyslipidemia) and the polymorphisms versus the ROC curve without the polymorphisms, that is, based only on the traditional risk factors. The area under the curve (AUC) is a quantitative summary for the ROC curve. Values between 0.70 and 0.80 are considered acceptable, and those between 0.80 and 0.90 are considered excellent. ${ }^{23}$

\section{Results}

\section{General characteristics}

Characteristics of the study population are summarized in Table 3.1.

Both groups differed with respect to established cardiovascular risk factors. Subjects with CVD were more frequently older males and showed greater proportions of dyslipidemia, diabetes and microalbuminuria. They also had a higher waist-to-hip ratio and serum creatinine as compared with the control group. However, probably because of treatment in the CVD group, (that is antihypertensive and lipid-lowering drugs), diastolic blood pressure, heart rate, total and LDL cholesterol were lower in subjects with CVD. There were no significant differences with respect to smoking and alcohol use between both groups. 
Table 3.1 Characteristics of the study population $(n=803)$.

\begin{tabular}{|c|c|c|c|}
\hline & CVD patients $(n=232)$ & Controls $(n=571)$ & $\boldsymbol{P}$ \\
\hline Males, n (\%) & $142(61.2)$ & $240(42.0)$ & $<0.001^{\mathrm{a}}$ \\
\hline Age (years) & $69.5 \pm 9.6$ & $59.9 \pm 11.3$ & $<0.001$ \\
\hline \multicolumn{4}{|l|}{ Morbidity } \\
\hline History of ischemic heart disease, $n(\%)$ & $162(69.8)$ & & \\
\hline History of stroke, n (\%) & $77(33.2)$ & & \\
\hline Peripheral artery occlusive disease, $\mathrm{n}(\%)$ & $36(15.5)$ & & \\
\hline Heart failure, $n(\%)$ & $20(8.6)$ & & \\
\hline \multicolumn{4}{|l|}{ Risk factors } \\
\hline Body-mass index $\left(\mathrm{kg} / \mathrm{m}^{2}\right)$ & $29.0 \pm 4.8$ & $281 \pm 48$ & 0.011 \\
\hline Waist $(\mathrm{cm})$ & $1021 \pm 110$ & $95.1 \pm 14.2$ & $<0.001$ \\
\hline Systolic blood pressure (mmHg) & $1457 \pm 213$ & $140.1 \pm 21.0$ & 0.001 \\
\hline Diastolic blood pressure ( $\mathrm{mmHg}$ ) & $78.8 \pm 10.2$ & $80.7 \pm 10.2$ & 0.019 \\
\hline Heart rate (beats per minute) & $73.2 \pm 12.4$ & $75.4 \pm 11.4$ & 0.019 \\
\hline Current smoking, n (\%) & $52(22.4)$ & 107 (18.7) & $0.232^{a}$ \\
\hline Alcohol, n (\%) & $5(2.2)$ & $10(1.8)$ & $0.658^{\mathrm{a}}$ \\
\hline Hypertension, n (\%) & $182(78.4)$ & $339(59.4)$ & $<0.001^{a}$ \\
\hline Diabetes, $\mathrm{n}(\%)$ & $68(29.3)$ & $69(12.1)$ & $<0.001^{a}$ \\
\hline Dyslipidemia, n (\%) & $164(70.7)$ & $285(49.9)$ & $<0.001^{a}$ \\
\hline Microalbuminuria, n (\%) & $50(21.6)$ & $51(8.9)$ & $<0.001^{a}$ \\
\hline \multicolumn{4}{|l|}{ Biochemical } \\
\hline Creatinine $(\mu \mathrm{mol} / \mathrm{l})$ & $98.9 \pm 36.7$ & $91.9 \pm 14.8$ & $<0.001$ \\
\hline Total cholesterol (mmol/l) & $5.2 \pm 1.2$ & $5.7 \pm 1.0$ & $<0.001$ \\
\hline LDL-cholesterol (mmol/l) & $3.1 \pm 1.1$ & $3.5 \pm 0.9$ & $<0.001$ \\
\hline HDL-cholesterol (mmol/l) & $1.3 \pm 0.4$ & $1.6 \pm 0.4$ & $<0.001$ \\
\hline Triglycerides (mmol/l), fasting & $1.7 \pm 0.9$ & $1.5 \pm 0.8$ & $<0.001$ \\
\hline Glucose $(\mathrm{mmol} / \mathrm{l})$, fasting & $6.3 \pm 2.2$ & $5.7 \pm 1.5$ & $<0.001$ \\
\hline \multicolumn{4}{|l|}{ Medication } \\
\hline Antihypertensive, $\mathrm{n}(\%)$ & $191(82.3)$ & $221(38.7)$ & $<0.001^{a}$ \\
\hline Antidiabetic, $\mathrm{n}(\%)$ & $47(20.3)$ & $33(5.8)$ & $<0.001^{a}$ \\
\hline Antiplatelet, n (\%) & $166(71.6)$ & $40(7.0)$ & $<0.001^{a}$ \\
\hline Hypolipidemic, n (\%) & $121(52.2)$ & $47(8.2)$ & $<0.001^{a}$ \\
\hline
\end{tabular}

Values are given as mean \pm SD or as number of subjects (with corresponding percentages between brackets); CVD, cardiovascular disease; P, P values are the results of Student's $t$-test (continuous variables) or ${ }^{\text {a }}$ chi square test (categorical variables); HDL, high-density lipoprotein; LDL, low-density lipoprotein.

\section{Genetic Analyses}

Genotype and allele frequencies of all polymorphisms were in Hardy-Weinberg equilibrium. No differences in either genotype or allele frequencies were found between CVD cases and controls in the HIPPOCRATES population (Table 3.2). Comparison between the control subjects of the PHARMO and the HIPPOCRATES database showed that there were no differences in genotype- and allele frequencies between both populations. 
Table 3.2 Allele frequencies of polymorphisms in the HIPPOCRATES and the PHARMO population.

\begin{tabular}{|c|c|c|c|c|}
\hline \multirow{2}{*}{ Polymorphism } & & \multicolumn{2}{|c|}{ HIPPOCRATES } & \multirow{2}{*}{$\begin{array}{c}\text { PHARMO } \\
\text { Controls }(n=1,240)\end{array}$} \\
\hline & & CVD patients $(n=232)$ & Controls $(n=571)$ & \\
\hline \multirow[t]{2}{*}{ AGTR1 (A1166C) } & $A$ & 0.724 & 0.703 & 0.679 \\
\hline & $\mathrm{C}$ & 0.276 & 0.297 & 0.321 \\
\hline \multirow[t]{2}{*}{ AGT (M235T) } & $M$ & 0.634 & 0.606 & 0.590 \\
\hline & $\mathrm{T}$ & 0.366 & 0.394 & 0.410 \\
\hline \multirow[t]{2}{*}{ ACE $\left(4656_{r p t}\right)$} & C & 0.524 & 0.512 & 0.535 \\
\hline & G & 0.476 & 0.488 & 0.465 \\
\hline \multirow[t]{2}{*}{ NOS3 (E298D) } & G & 0.636 & 0.637 & 0.654 \\
\hline & $\mathrm{T}$ & 0.364 & 0.363 & 0.346 \\
\hline \multirow[t]{2}{*}{ GNB3 (C825T) } & C & 0.679 & 0.718 & 0.695 \\
\hline & $\mathrm{T}$ & 0.321 & 0.282 & 0.305 \\
\hline \multirow[t]{2}{*}{ ADD1 (G460W) } & G & 0.793 & 0.778 & 0.800 \\
\hline & $\mathrm{T}$ & 0.207 & 0.222 & 0.200 \\
\hline
\end{tabular}

\section{Logistic regression analyses}

Both univariate and multivariate ORs were calculated to evaluate the relationship between polymorphisms and CVD (Table 3.3). In the multivariate analysis, the simultaneous contribution of the six polymorphisms to the prediction of CVD was statistically significant (likelihood ratio test; $P<0.001$ ), showing a protective association for carriership of the $T$ allele of the AGT polymorphism (OR $=0.55$ [0.34-0.84]) and for carriership of the $T$ allele of the ADD1 polymorphism (OR=0.52 [0.31-0.82]). Both associations were still statistically significant after Bonferroni correction, that is, AGT $(P=0.02)$ and ADD1 $(P=0.01)$. In addition, we found a trend towards a protective effect for the rare-allele of the AGTR1 (OR=0.69 [0.47-1.01]). In all other polymorphisms, carriership of the rare allele of the investigated polymorphisms was not associated with an increased risk of CVD. Evaluation of possible interactions between AGT and ADD1 showed no statistically significant interaction terms.

Table 3.3 Odds ratios for prevalent cardiovascular disease according to the gene polymorphisms.

\begin{tabular}{lccc}
\hline Polymorphism & Rare allele* & On (95\% CI) \\
& & Univariate & Multivariate \\
\hline AGTR1 (A1166C) & $\mathrm{C}^{*}$ & $0.76(0.53-1.09)$ & $0.69(0.47-1.01)$ \\
AGT (M235T) & $\mathrm{T}^{*}$ & $0.67(0.46-0.96)^{\#}$ & $0.55(0.34-0.84)^{\#}$ \\
ACE (4656 & $\mathrm{G}_{\mathrm{rpt}}$ ) & $1.00(0.67-1.50)$ & $0.97(0.64-1.47)$ \\
NOS3 (E298D) & $\mathrm{T}^{*}$ & $1.10(0.76-1.59)$ & $1.20(0.82-1.76)$ \\
GNB3 (C825T) & $\mathrm{T}^{*}$ & $1.09(0.76-1.56)$ & $1.13(0.78-1.64)$ \\
ADD1 (G460W) & $\mathrm{T}^{*}$ & $0.69(0.48-1.01)$ & $0.52(0.31-0.82)^{\#}$ \\
\hline
\end{tabular}

* The wild-type alleles were used as reference category; multivariate adjustment was performed for age, gender, waist circumference, smoking, alcohol, diabetes mellitus, mean systolic and diastolic blood pressure, serum creatinine, microalbuminuria and dyslipidemia; ${ }^{\#} P \leq 0.05$; $\mathrm{Cl}$ denotes $95 \%$ confidence interval. 


\section{Cardiovascular risk prediction}

To quantify the contribution of the polymorphisms ROC curves were constructed for prediction of CVD by traditional risk factors only versus prediction of CVD by risk factors supplemented with the six polymorphisms, respectively (Figure 3.1). The area under the curve (AUC) for the first prediction was 0.83 [0.80-0.86] and for the second 0.84 [0.81-0.87], indicating that the six polymorphisms have hardly any additional influence on the assessment of CVD in this population. Adding only the AGT and ADD1 polymorphism, which showed a significant association in the multivariate analyses, did not change the AUC (0.84 [0.81-0.87]).

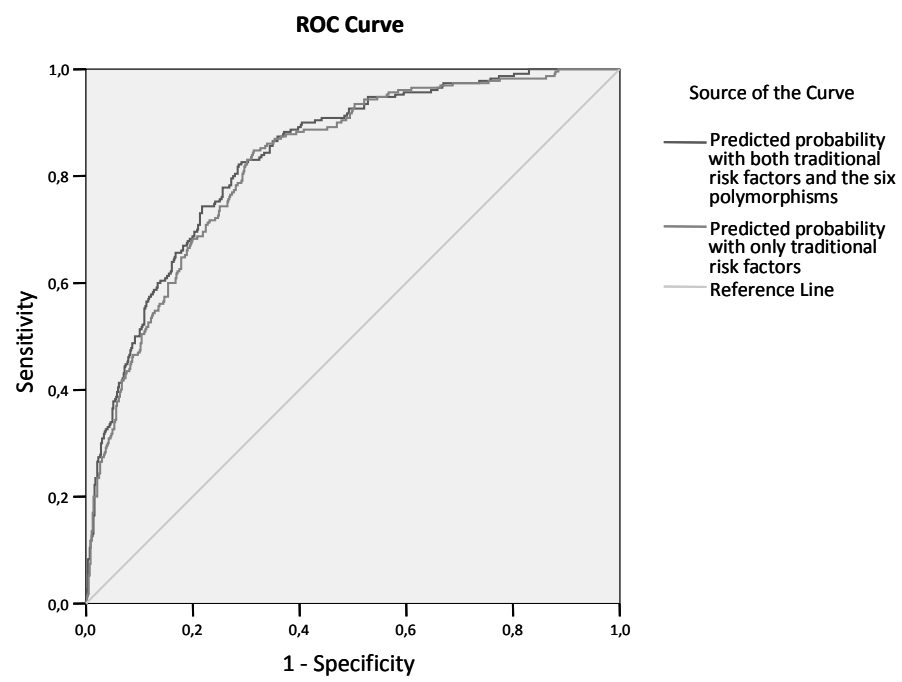

Figure 3.1 Receiver operating characteristic (ROC) analysis of the six cardiovascular polymorphisms for the prediction of cardiovascular disease in a primary care population; traditional risk factors were age, gender, waist circumference, smoking, alcohol, diabetes mellitus, mean systolic and diastolic blood pressure, serum creatinine, microalbuminuria and dyslipidemia.

\section{Discussion}

In this primary care study (HIPPOCRATES) no statistically significant differences in allele frequencies were found between CVD cases and controls with regard to the six polymorphisms. The allele frequencies were comparable to another Dutch database, PHARMO, consisting of subjects from other regions of the Netherlands. Multivariate analyses showed a statistically significant contribution of six polymorphisms $(P<0.001)$ to the presence of CVD, predominantly consisting of protective associations with carriership of the rare T alleles of AGT (OR=0.55 [0.34-0.84]) and of ADD1 (OR=0.52 [0.31-0.82]), and a borderline statistically significant association with CVD for the 
AGTR1 polymorphism (OR=0.69 [0.47-1.01]). Addition of all six or only the AGT and ADD1 polymorphisms to the traditional cardiovascular risk factors showed, however, only a $1 \%$ improvement of the prediction of CVD, as determined by ROC curve analysis.

\section{Allele frequencies}

To the best of our knowledge, no data on allele frequencies of RAS polymorphisms are available for a primary care population. Therefore, comparison of our allele frequencies with other studies is difficult. Moreover, allele frequencies differ from population to population. Therefore, the best comparison should be done on a similar population. However, a control group from the same population may not differ with respect to the genetic background compared to subjects with CVD. Therefore, we compared our allele frequencies with frequencies from the PHARMO cohort, which has comparable allele frequencies with those found in large European healthy control groups. $^{17,18}$ Consequently, we found an equal allele frequency for all six polymorphisms in HIPPOCRATES and PHARMO control subjects. Besides, if we compared the observed allele frequencies in HIPPOCRATES of cases and controls with those found in larger European studies (with at least 500 cases and 500 controls), comparable allele frequencies were found (data not presented). This comparability of the allele frequencies indicates that the observed high cardiovascular risk in the HIPPOCRATES population is probably not related to marked differences in genetic make up of the investigated polymorphisms. ${ }^{17,18,24-26}$

\section{Polymorphisms}

\section{Angiotensinogen (M235T) polymorphism}

The observed decreased risk for CVD for carriers of the rare T allele of the AGT polymorphism needs further explanation. From literature we know that angiotensinogen (AGT) is significantly elevated in patients with the AGT (M235T) polymorphism and is particularly associated with hypertension, coronary heart disease and myocardial infarction. ${ }^{27,28}$ Recently, Xu et al. performed a meta-analysis on the AGT (M235T) polymorphism studying 43 association studies on coronary artery disease including a total of 13,478 cases and 17,024 controls. ${ }^{29}$ This meta-analysis showed that overall the effect of this polymorphism is weak, showing both protective and harmful associations. ${ }^{29}$ A possible explanation for the observed decreased risk for CVD in our study might be a low-renin state. The protective association for the T allele of AGT under these conditions may be related to lower angiotensin levels. This was confirmed by a study performed by Fernández-Arcás et al., who indeed found a suppressed RAS in carriers of the T allele of AGT. ${ }^{30}$ In addition, misclassification of the AGT (M235T) genotype should also be considered, as has been indicated recently. ${ }^{31}$ However, this is less likely an explanation in our study, since the extensive validation 
process of the multiplex assay did not result in discordant cases for the AGT (M235T) polymorphism.

\section{Alpha-adducin (G460W) polymorphism}

The ADD1 (G460W) polymorphism is associated with salt sensitivity, or high sodium intake, and an increased risk of cardiovascular events and mortality. ${ }^{32}$ The results of our study, that is, decreased risk for CVD for carriers of the T allele of ADD1, are not in line with these findings. A possible explanation may be related to the treatment status of the subjects. Earlier, it has been reported that there is an interaction between carriers of the rare T allele of ADD1 and diuretic therapy. ${ }^{33}$ Hypertensive subjects carrying the rare $\mathrm{T}$ allele, who were treated with diuretics, were at lower risk of myocardial infarction and stroke compared with subjects treated with other antihypertensive therapies. We checked our database for the use of diuretics and found no association with diuretics. So, although attractive, the concurrent use of diuretics does not explain our findings. Our finding of a protective association for the rare allele of ADD1 is however not an isolated unique observation. Tobin et al., also found such a protective association for ADD1 in a multilocus case-control study in which patients with myocardial infarction were compared with healthy controls. ${ }^{18}$ They suggested that this was attributable to the premature death of T allele carriers or to a protective effect of this allele through a cellular mechanism different from its effect leading to hypertension. ${ }^{18}$ Since the design of both our study and the one of Tobin et al., was cross sectional, we think this need to be evaluated in future prospective studies.

\section{Angiotensin II type 1 receptor (A1166C) polymorphism}

Over the last decade, the angiotensin II type I receptor (A1166C) polymorphism has been intensively investigated for its possible role in hypertension and CVD. ${ }^{34}$ An explanation for the borderline significant protective association with the rare $\mathrm{C}$ allele of the AGTR1 polymorphism may be found in the fact that these subjects have a poor cardiovascular prognosis and as a consequence were not included in our study. Although the data collection for this study already started in 1990, this possibility can not be excluded completely. Importantly, the data of this AGTR1 polymorphism were of borderline significance, and the relevance should not be overstretched therefore.

\section{Strengths and limitations}

A unique aspect of a primary care population is that the whole range of low-to-highrisk patients is available. Moreover, our population was selected using strict inclusion criteria and was derived from a rather small area, including subjects with similar social living conditions. Although our study has an exploratory character, we performed this study with a clear a priori hypothesis, therefore reducing multiple hypothesis testing. Albeit even after Bonferroni correction for multiple testing the statistical significant 
associations maintained. We realize that our population was not designed to obtain realistic ROC estimates; the ROC results should be interpreted as indicative of the contribution of genetic information, not as quantitatively accurate. The last decades, investigators developed multivariable risk prediction algorithms to predict the risk for occurrence of CVD. ${ }^{35,36}$ For instance, the Framingham risk score uses age, gender, total and HDL cholesterol levels, blood pressure, smoking and diabetes mellitus as variables to predict risk. ${ }^{37}$ When ROC analyses were performed, containing these traditional risk factors, in various epidemiological cohorts, the area under the curve (AUC) ranged from 0.66 to $0.88 .{ }^{35}$ In our analyses we found an AUC of 0.83 for the prediction of CVD by traditional cardiovascular risk factors. This indicates that our multivariate model was already an excellent standard even before the six polymorphisms were added and compared. ${ }^{23}$ This may be why the ROC analysis with the addition of six polymorphisms only improved the predictive value of traditional cardiovascular risk factors by approximately 1 per cent.

One may argue the presence of other limitations of our study. Firstly, we only studied the effect of one polymorphism per gene, which does not exclude the role of other polymorphic alleles, which are not in linkage disequilibrium. Another limitation, as is for many genetic association studies, is sample size. It has been emphasized that sample sizes of thousands are required to have adequate power to detect genes conferring ORs as low as 1.2 , with minor allele frequencies in the range of $5-10 \% .{ }^{38}$ In our study the actual allele frequencies of the rare alleles ranged between 0.21 and 0.48, and the ORs for prevalent CVD were much larger than 1.2, indicating that the sample size of our study, at least for the AGT and the ADD1 polymorphism, was acceptable.

In conclusion, although pilot data suggested a role for genetics in explaining the cardiovascular risk in the HIPPOCRATES population, and although we observed practically no differences in allele frequencies of six RAS related polymorphisms between patients with CVD and the control group, and although some alleles showed a protective effect, these findings were of little clinical significance for the group as a whole. This does not exclude relevance of our findings for an individual patient with regard to other (intermediate) endpoints. Anyhow, our data suggest that a major contribution of the genetic background, that is, the studied six polymorphisms, to the cardiovascular risk prediction in this south Netherlands primary care population is unlikely. 


\section{References}

1. Yusuf S, Hawken S, Ounpuu S, Dans T, Avezum A, Lanas F, McQueen M, Budaj A, Pais P, Varigos J, Lisheng L; INTERHEART Study Investigators. Effect of potentially modifiable risk factors associated with myocardial infarction in 52 countries (the INTERHEART study): case-control study. Lancet 2004; 364:937-52.

2. Chen Y, Rollins J, Paigen B, Wang X. Genetic and genomic insights into the molecular basis of atherosclerosis. Cell Metab 2007;6:164-79.

3. Jeunemaitre X. Genetics of the human renin angiotensin system. J Mol Med 2008;86:637-41.

4. Hegele RA. SNP judgments and freedom of association. Arterioscler Thromb Vasc Biol 2002;22: 1058-61.

5. Plat AW, te Wierik MJ, Kroon AA, Schouten HJ, van den Akker M, van Schayck CP, de Leeuw PW, Hajema KJ, Stoffers HE. Regional differences in cardiovascular risk factor profile cannot fully explain differences in cardiovascular morbidity in the Netherlands: a comparison of two urban areas. Neth J Med 2005;63:309-15.

6. Henskens LH, Spiering W, Stoffers HE, Soomers FL, Vlietinck RF, de Leeuw PW, Kroon AA. Effects of ACE I/D and AT1R-A1166C polymorphisms on blood pressure in a healthy normotensive primary care population: first results of the Hippocates study. J Hypertens 2003;21:81-6.

7. van Onna M, Kroon AA, Houben AJ, Koster D, Zeegers MP, Henskens LH, Plat AW, Stoffers HE, de Leeuw PW. Genetic risk of atherosclerotic renal artery disease: the candidate gene approach in a renal angiography cohort. Hypertension 2004;44:448-53.

8. Metsemakers JF, Knottnerus JA, van Schendel GJ, Kocken RJ, Limonard CB. Unlocking patients' records in general practice for research, medical education and quality assurance: the Registration Network Family Practices. Int J Biomed Comput 1996;42:43-50.

9. Landwehr JSTM, Akker Mvd, Metsemakers JFM, Buntinx F. Comorbidity of chronic cardiovascular disorders. A cross-sectional analysis in a large general practice population in the Netherlands. Archiv Public Health 2000;58:213-31.

10. Classification of Health Problems in Primary Care, 3rd edition. Oxford, Oxford University Press, 1983.Classification Committee of Wonca. Oxford: Oxford University Press; 1983.

11. Lamberts H, Wood M, editors. ICPC: International Classification of Primary Care. Oxford: Oxford University Press; 1987.

12. Cifkova R, Erdine S, Fagard R, Farsang C, Heagerty AM, Kiowski W, Kjeldsen S, Lüscher T, Mallion JM, Mancia G, Poulter N, Rahn KH, Rodicio JL, Ruilope LM, van Zwieten P, Waeber B, Williams B, Zanchetti A; ESH/ESC Hypertension Guidelines Committee. Practice guidelines for primary care physicians: 2003 ESH/ESC hypertension guidelines. J Hypertens 2003;21:1779-86.

13. Knaapen AM, Ketelslegers HB, Gottschalk RW, Janssen RG, Paulussen AD, Smeets HJ, Godschalk RW, Van Schooten FJ, Kleinjans JC, Van Delft JH. Simultaneous genotyping of nine polymorphisms in xenobiotic-metabolizing enzymes by multiplex PCR amplification and single base extension. Clin Chem 2004;50:1664-8.

14. Villard E, Tiret L, Visvikis S, Rakotovao R, Cambien F, Soubrier F. Identification of new polymorphisms of the angiotensin I-converting enzyme (ACE) gene, and study of their relationship to plasma ACE levels by two-QTL segregation-linkage analysis. Am J Hum Genet 1996;58:1268-78.

15. Keavney B, McKenzie CA, Connell JM, Julier C, Ratcliffe PJ, Sobel E, Lathrop M, Farrall M. Measured haplotype analysis of the angiotensin-I converting enzyme gene. Hum Mol Genet 1998;7:1745-51.

16. Veldman BA, Spiering W, Doevendans PA, Vervoort G, Kroon AA, de Leeuw PW, Smits P. The Glu298Asp polymorphism of the NOS 3 gene as a determinant of the baseline production of nitric oxide. J Hypertens 2002;20:2023-7.

17. Visvikis S, Sass C, Pallaud C, Grow MA, Zannad F, Siest G, Erlich HA, Cheng S. Familial studies on the genetics of cardiovascular diseases: the Stanislas cohort. Clin Chem Lab Med 2000;38:827-32.

18. Tobin MD, Braund PS, Burton PR, Thompson JR, Steeds R, Channer K, Cheng S, Lindpaintner K, Samani NJ. Genotypes and haplotypes predisposing to myocardial infarction: a multilocus case-control study. Eur Heart J 2004;25:459-67.

19. Herings R. PHARMO: a record linkage system for postmarketing surveillance of prescription drugs in The Netherlands. Utrecht: Utrecht University; 1993. 
20. Van Wijk BL, Klungel $\mathrm{OH}$, Heerdink ER, de Boer A. The association between compliance with antihypertensive drugs and modification of antihypertensive drug regimen. J Hypertens 2004;22: 1831-7.

21. Després JP, Lemieux I, Bergeron J, Pibarot P, Mathieu P, Larose E, Rodés-Cabau J, Bertrand OF, Poirier $P$. Abdominal obesity and the metabolic syndrome: contribution to global cardiometabolic risk. Arterioscler Thromb Vasc Biol 2008;28:1039-49.

22. Ryan $\mathrm{DH}$. The relationship among risk factor clustering, abdominal obesity, and residual risk for cardiovascular events. Rev Cardiovasc Med 2007;8:9-16.

23. Hosmer DW, Lemeshow S. Applied Logistic Regression. 2nd ed. New York: J Wiley; 2000.

24. Keavney B, McKenzie C, Parish S, Palmer A, Clark S, Youngman L, Delépine M, Lathrop M, Peto R, Collins R. Large-scale test of hypothesised associations between the angiotensin-converting-enzyme insertion/deletion polymorphism and myocardial infarction in about 5000 cases and 6000 controls. International Studies of Infarct Survival (ISIS) Collaborators. Lancet 2000;355:434-42.

25. Sethi AA, Tybjaerg-Hansen A, Gronholdt ML, Steffensen R, Schnohr P, Nordestgaard BG. Angiotensinogen mutations and risk for ischemic heart disease, myocardial infarction, and ischemic cerebrovascular disease. Six case-control studies from the Copenhagen City Heart Study. Ann Intern Med 2001;134:941-54.

26. Renner W, Hoffmann MM, Grunbacher G, Winkelmann BR, Boehm BO, Marz W. G-protein beta3 subunit (GNB3) gene polymorphisms and cardiovascular disease: The Ludwigshafen Risk and Cardiovascular Health (LURIC) study. Atherosclerosis 2007;192:108-12.

27. Jeunemaitre $X$, Soubrier F, Kotelevtsev YV, Lifton RP, Williams CS, Charru A, Hunt SC, Hopkins PN, Williams RR, Lalouel JM, et al. Molecular basis of human hypertension: role of angiotensinogen. Cell 1992;71:169-80.

28. Winkelmann BR, Russ AP, Nauck M, Klein B, Böhm BO, Maier V, Zotz R, Matheis G, Wolf A, Wieland H, Gross W, Galton DJ, März W. Angiotensinogen M235T polymorphism is associated with plasma angiotensinogen and cardiovascular disease. Am Heart J 1999;137:698-705.

29. $\mathrm{Xu} \mathrm{MQ}, \mathrm{Ye} \mathrm{Z}, \mathrm{Hu} F B, \mathrm{He}$ L. Quantitative assessment of the effect of angiotensinogen gene polymorphisms on the risk of coronary heart disease. Circulation 2007;116:1356-66.

30. Fernández-Arcás N, Dieguez-Lucena JL, Muñoz-Morán E, Ruiz-Galdón M, Espinosa-Caliani S, ArandaLara P, Rius-Diaz F, Gaitán-Arroyo MJ, De Teresa-Galván E, Reyes-Engel A. Both alleles of the M235T polymorphism of the angiotensinogen gene can be a risk factor for myocardial infarction. Clin Genet 2001;60:52-7.

31. Lizanecz E, Pasztor ET, Mohacsi A, Papp Z, Edes I, Toth A. Mistyping of angiotensinogen M235T alleles. Hypertens Res 2006;29:197-201.

32. Bianchi G, Ferrari P, Staessen JA. Adducin polymorphism: detection and impact on hypertension and related disorders. Hypertension 2005;45:331-40.

33. Psaty BM, Smith NL, Heckbert SR, Vos HL, Lemaitre RN, Reiner AP, Siscovick DS, Bis J, Lumley T, Longstreth WT Jr, Rosendaal FR. Diuretic therapy, the alpha-adducin gene variant, and the risk of myocardial infarction or stroke in persons with treated hypertension. JAMA 2002;287:1680-9.

34. Baudin B. Polymorphism in angiotensin II receptor genes and hypertension. Exp Physiol 2005;90: 277-82.

35. Prediction of mortality from coronary heart disease among diverse populations: is there a common predictive function? Heart 2002;88:222-8.

36. Conroy RM, Pyörälä K, Fitzgerald AP, Sans $S$, Menotti $A$, De Backer $G$, De Bacquer D, Ducimetière $P$, Jousilahti P, Keil U, Njølstad I, Oganov RG, Thomsen T, Tunstall-Pedoe H, Tverdal A, Wedel H, Whincup $P$, Wilhelmsen L, Graham IM; SCORE project group. Estimation of ten-year risk of fatal cardiovascular disease in Europe: the SCORE project. Eur Heart J 2003;24:987-1003.

37. Third Report of the National Cholesterol Education Program (NCEP) Expert Panel on Detection, Evaluation, and Treatment of High Blood Cholesterol in Adults (Adult Treatment Panel III) final report. Circulation 2002;106:3143-421.

38. Ioannidis JP, Trikalinos TA, Ntzani EE, Contopoulos-loannidis DG. Genetic associations in large versus small studies: an empirical assessment. Lancet 2003;361:567-71. 


\section{Chapter 4}

\section{THE INFLUENCE OF SIX CARDIOVASCULAR POLYMORPHISMS ON A FIRST EVENT OF ISCHEMIC HEART DISEASE IS MODIFIED BY GENDER AND AGE}

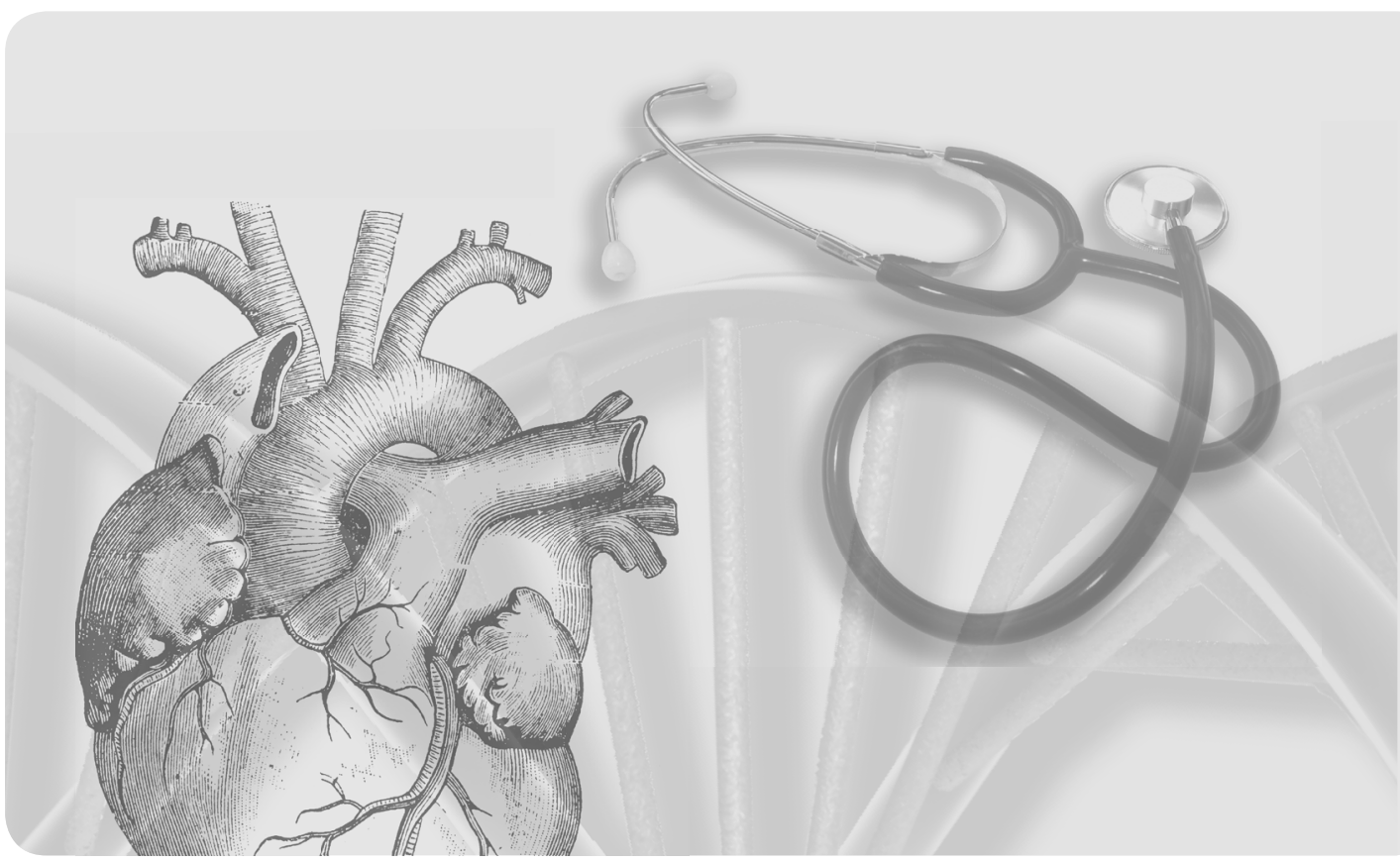

AW Plat, HEJH Stoffers, PW de Leeuw, CP van Schayck, FL Soomers, ADM Kester, K Aretz, AA Kroon 


\section{Abstract}

This case-control study aimed to examine the contribution of six cardiovascular polymorphisms to the occurrence of a first event of ischemic heart disease (IHD) in a primary care population with a high burden of cardiovascular disease (CVD) including hypertension. Furthermore, we specified the data for gender and age. Patients with a first event of IHD ( $n=157)$ were compared with event free controls $(n=571)$. Both groups were genotyped for the AGTR1 (A1166C), AGT (M235T), ACE (4656rpt), NOS3 (E298D), GNB3 (C825T) and ADD1 (G460W) polymorphisms. To assess the association between a first ischemic event and these polymorphisms, univariate and multivariate odds ratios (ORs) were calculated. Sliding mean analyses were performed to show age specific associations. Multivariate ORs indicated a protective association for the carrier status of the $T$ allele of $A G T$, overall $(O R=0.69$ [0.34-0.90]) and for males (OR=0.58 [0.27-0.89]). Sliding mean analyses showed for males a continuous protective association with IHD of the T allele of AGT with increasing age, whereas in females an increased risk for IHD was observed with a maximum OR of 1.6 at the age of 56 years. In conclusion, in this population the T allele of the AGT polymorphism is protective for a first event of IHD in males. 


\section{Introduction}

The renin-angiotensin system (RAS) plays an important role in vascular homeostasis. The biochemical cascade concerns the sequential cleavage of angiotensinogen (AGT) by renin to angiotensin I, and subsequently by angiotensin converting enzyme (ACE) to angiotensin II (Ang II). Besides regulating blood pressure, the vasoactive peptide Ang II has a number of other actions, eventually leading to formation of atherosclerotic lesions. ${ }^{1-3}$ Therefore, it is commonly accepted that components of the RAS play a role in atherosclerosis and thromboembolic events, e.g. ischemic heart disease (IHD) and stroke. ${ }^{4-6}$ Many studies have attempted to relate genetic variants of components of RAS to cardiovascular disease (CVD). ${ }^{7}$ Among the many potential genes, those related to activation of the RAS or to an increased tendency to retain sodium rank high and so do genes which may cause reduced availability of nitric oxide (NO). To this date, however, findings from association studies involving the RAS genes remain inconsistent and controversial. ${ }^{6,8}$ Important reasons for this inconsistency is that most of these observations have been obtained in selected populations and the variability of cardiovascular endpoints. ${ }^{8}$

This prompted us to perform a genetic association study on IHD in a primary care population. On the basis of the available literature at the start of the study, we restricted ourselves to the analysis of six polymorphisms. These were the angiotensinogen [AGT (M235T)], angiotensin converting enzyme [ACE (4656 $6_{\mathrm{rpt}}$ )], and the angiotensin II type 1 receptor [AGTR1 (A1166C)] polymorphism, that are involved in the generation and action of Angll. In addition, $\alpha$-adducin [ADD1 (G460W)], G-protein $\beta 3$ subunit [GNB3 (C825T)], and the endothelial nitric oxide synthase [NOS3 (E298D)] polymorphisms, as markers of sodium retaining tendency and altered NO availability, were selected, respectively. The selection criterium for IHD was narrowed down to a first event of IHD. To further reduce the variability of the association with the first event of IHD, we specified the data for gender and age. ${ }^{8-10}$ We hypothesized that the presence of one or more rare alleles of aforementioned six polymorphisms would affect the occurrence of a first event, and that these associations are modified by gender and age. To do so, in the present study, we assessed the contribution of these parameters to patients with a first event of IHD in comparison to control subjects without IHD.

\section{Methods}

\section{Participants}

For the present study we used data from the HIPPOCRATES project. The HIPPOCRATES (Hypertension: Interaction and Prevalence of POlymorphisms related to Cardiovascular Risk and the Association to Treatment Efficacy Study) is an ongoing 
study, in which the implementation of genetic polymorphisms in the assessment of cardiovascular risk in primary care is investigated. ${ }^{11-13}$ This study utilizes the population of one large general practice in Kerkrade, which is located in the southeast of the Netherlands, and is characterised with a high burden of CVD compared with the average of the Netherlands. ${ }^{13}$ This academic general practice takes part in the Registration Network Family Practices (RNH), which is a continuous and computerized database in which 63 general practitioners (GPs), working in 22 different practices, in the south of the Netherlands participate. All relevant health problems, including a full medical history of all cardiovascular events have been registered since $1990 .^{14,15}$ Medical problems are coded according to the International Classification of Primary Care (ICPC) using the criteria of the International Classification of Health Problems in Primary Care for diagnoses. ${ }^{16,17}$ The general practice in Kerkrade has a list of approximately 4400 patients, among whom are more than 2300 patients of 40 years and older. The practice has well implemented cardiovascular consulting hours. For HIPPOCRATES, all known patients aged $\geq 40$ years with CVD or hypertension were invited. From the group with other cardiovascular risk factors, that is, smoking, alcohol, diabetes mellitus, hypercholesterolemia, overweight including obesity, a random 1:3 sample was taken. Of all patients without known CVD, hypertension or other cardiovascular risk factors, also a random 1:3 sample was taken. The initial classification was validated by a thorough assessment of the patients' records combined with additional measurements of risk factors for all subjects. The total HIPPOCRATES population consisted of 803 patients (382 males, 421 females), who were recruited between May 2003 and July 2005.

The study population for the present cross sectional case-control study consisted of 728 Caucasian subjects: 157 patients with a known first event of IHD (cases) and 571 event-free subjects without documented CVD (controls). IHD was defined as having a diagnosis of angina pectoris, myocardial infarction, or heart failure. A first event was defined as the first diagnosis of IHD which was present in the medical registration. An event-free control subject had no IHD, stroke, peripheral artery occlusive disease, or heart failure.

\section{Clinical data collection}

Data on risk factors were collected from the RNH from the period before the first event till one year after the event. The latter was done, since data on risk factors are not immediately available due to delay of data entry of medical problems in the registration. Overweight was defined as having a body-mass index (BMI) $\geq 27$ (ICPC: T82, T83). Data on smoking behaviour (P17) and alcohol consumption (P15) were collected. Hypertension was defined as a systolic blood pressure (SBP) $\geq 140 \mathrm{mmHg}$ and/or diastolic blood pressure (DBP) $\geq 90 \mathrm{mmHg}$ (diagnosis $\mathrm{K} 86$ or $\mathrm{K} 87$, respectively) according to the Guidelines for Hypertension specified by the European Society of Hypertension $^{18}$ or use of antihypertensive drugs. Hypercholesterolemia was defined 
as having a diagnosis of T93 (dyslipidemia) or use of lipid-lowering drugs. Diabetes mellitus was considered to be present in case of fasting plasma glucose levels $>6.9$ $\mathrm{mmol} / \mathrm{l}$ (diagnosis T90) or the use of oral antidiabetic drugs or insulin. The computerized medication lists were analysed for antihypertensive, antidiabetic, antiplatelet, and hypolipidemic medication. All relevant data on medication were collected in the period before the first event. All patients gave written informed consent to participate in the study. The study was approved by the Medical Ethics Committee of the Maastricht University Medical Center.

\section{Genetic analyses}

The various polymorphisms were determined at the Cardiovascular Genotyping (CAGT) laboratory of the Department of Internal Medicine of the Maastricht University Medical Center. DNA was extracted from whole blood with the use of the QIAmp Blood Kit (Qiagen Inc. Valencia, USA). Genotyping of the angiotensin II type 1 receptor [AGTR1 (A1166C)/rs5186], angiotensinogen [AGT (M235T)/rs699], angiotensin converting enzyme [ACE $\left.\left(4656_{\mathrm{rpt}}\right) / \mathrm{rs} 1799752\right]$, endothelial nitric oxide synthase [NOS3 (E298D)/rs1799983], G-protein $\beta 3$ subunit [GNB3 (C825T)/rs5443] and $\alpha$-adducin [ADD1 $(\mathrm{G} 460 \mathrm{~W}) / \mathrm{rs} 4961]$ polymorphisms was performed with a multiplex single base extension (SBE) assay (Multiplex SNaPshot, Applied Biosystems, Foster City, USA) similar to previously published protocols. ${ }^{19}$ Briefly, in the first stage a multiplex PCR is carried out to amplify the gene fragments that contain the polymorphisms. In the second stage, the polymorphic positions are interrogated by a SBE reaction using fluorescently labeled ddNTPs. The oligos used for the single base extension have specific lengths, varying from 22-50 nt. After the SBE assay, the fragments are size-resolved on an ABI3100 Genetic Analyser: the size of the peaks identifies the locus (e.g. ADD1) and the color of the peak(s) identifies the genotype (e.g. Gly/Trp). Raw data were analysed with Genescan Analysis software (v 3.7), then genotypes were scored independently by two researchers and entered in the database. In 27 patients, a second analysis was necessary to obtain all the genotypes. The ACE insertion/deletion (I/D) polymorphism was determined by detecting $\mathrm{ACE}_{4656+C T}$ observed on the SNaPshot as ACE $\left(4656_{\text {rpt }}\right)$. The use of this SNaPshot method does not allow the direct determination of the I/D polymorphism. The $\mathrm{ACE}_{4656+\mathrm{CT}}$ polymorphism in the 3 '-untranslated region of the ACE gene consists of a repetition of two or three $\mathrm{CT}$ dinucleotides and is in complete linkage disequilibrium with ACE (I/D) polymorphism. ${ }^{20,21}$ The multiplex assay was validated on a set of 100 DNA samples that had previously been genotyped with an alternative technique; this technique concerned a multilocus genotyping assay for candidate markers of CVD risk (Roche Molecular systems Inc., Pleasanton, USA) and has been described in detail previously. ${ }^{22}$ Only four samples gave a discordant result for the ecNOS polymorphism. All other genotypes were concordant. The discordant results have been adjusted. 


\section{Statistical analyses}

Statistical analysis was performed by using SPSS statistical software, version 13.0 (SPSS, Inc., Chicago, IL, USA). A P-value of 0.05 or less was considered statistically significant. Bonferroni correction was applied for multiple testing. Statistical significance for differences in quantitative variables between males and females with IHD and event free male and female controls was tested in case of continuous variables by one-way analysis of variance (ANOVA) and the chi-square test was used in case of categorical variables. Genotype and allele frequencies were calculated to test the Hardy-Weinberg equilibrium. Allele frequencies were analyzed using chi-square tests. Only differences in allele frequencies larger than 0.04 between and within males and females were tested for significance.

\section{Logistic regression analyses}

Both univariate and multivariate odds ratios (ORs) were calculated with a binarylogistic regression model (method: enter) to evaluate the relationship between polymorphisms and a first event of IHD. For that purpose, dummy variables were created using the homozygous wild-type genotype as reference category. For females only univariate ORs could be calculated, due to the low number of patients that were available to perform meaningful multivariate regression analyses. Age and gender were incorporated in both the univariate as well as in the multivariate logistic regression analyses. As indicated, control subjects were selected from different groups. Therefore, in the logistic regression analyses we had to adjust for this selection and dummy variables had to be created using the normotensive group without cardiovascular risk factors as the reference category. Adjustment for potential confounders was performed by incorporating smoking, alcohol, overweight, diabetes mellitus and hypercholesterolemia into these models. The simultaneous contribution of the six polymorphisms to the prediction of a first event of IHD was tested, using a likelihood ratio test. If two or more polymorphisms reached statistical significance, interactions (effect modification) between two polymorphisms with respect to a first event of IHD were assessed. Again binary-logistic regression analysis (method: enter) was used, in which the alleles at risk, the interaction term between the alleles and the other covariates were incorporated. If an interaction term became statistically significant, the model was explored further.

\section{Sliding means analyses}

To explore the influence of increasing age on the risk of a first event of IHD within males or females the sliding means technique for ORs was applied. ${ }^{23}$ According to this approach, subgroups of 328 subjects were formed based on increasing age. Each subgroup differed from the preceding or succeeding subgroup by ten individuals. For each subgroup a binary-logistic regression analysis (method: enter) was carried out, to explore the relation between carriership of the rare allele and a first event of IHD. 
Covariates were not incorporated because the number of patients available per data point did not allow meaningful regression analyses. For both males and females a curve was fitted using STATA Graph 8.2 (Lowess smoothing technique). ${ }^{23}$ Differences between males and females were tested by comparing the area under the curve $(A \cup C)$, which represents the mean OR calculated for the relevant polymorphism in the univariate analyses.

\section{Results}

\section{General characteristics}

Baseline characteristics of the study population are summarized in Table 4.1. Overall, the first event group differed from the control group with respect to established cardiovascular risk factors, except for the occurrence of hypertension and diabetes. For both male and female cases, the mean age at which the first cardiovascular event occurred was below 60 years. On average, male cases smoked more cigarettes and used more alcohol. Cases with a first IHD event used more often antihypertensive, antidiabetic, antiplatelet, and hypolipidemic medication as compared to controls. There was no statistically significant difference between male and female cases in terms of the presence of overweight, hypertension, diabetes and hypercholesterolemia. The control group contained more females than males; their mean age was comparable with the first event group.

Table 4.1 Characteristics of the HIPPOCRATES study population $(n=728)$.

\begin{tabular}{|c|c|c|c|c|c|}
\hline & \multicolumn{2}{|c|}{ First event of IHD } & \multicolumn{2}{|c|}{ Controls } & \multirow[b]{2}{*}{$\boldsymbol{P}$} \\
\hline & $\begin{array}{c}\text { Male } \\
(n=105)\end{array}$ & $\begin{array}{c}\text { Female } \\
(n=52)\end{array}$ & $\begin{array}{c}\text { Male } \\
(n=240)\end{array}$ & $\begin{array}{l}\text { Female } \\
(n=331)\end{array}$ & \\
\hline Age (years) & $57.6 \pm 10.4$ & $58.5 \pm 11.3$ & $59.3 \pm 11.3$ & $60.4 \pm 11.4$ & 0.135 \\
\hline \multicolumn{6}{|l|}{ Risk factors } \\
\hline Overweight, n (\%) & $28(26.7)$ & $18(34.6)$ & $32(13.3)$ & $46(13.9)$ & $<0.001^{a}$ \\
\hline Smoking, n (\%) & $66(62.9)$ & $22(42.3)$ & $41(17.1)$ & $50(15.1)$ & $<0.001^{a}$ \\
\hline Alcohol, n (\%) & $8(7.6)$ & $0(0.0)$ & $5(2.1)$ & $1(0.3)$ & $<0.001^{a}$ \\
\hline Hypertension, n (\%) & $47(44.8)$ & 27 (51.9) & $88(36.7)$ & $135(40.8)$ & $0.169^{a}$ \\
\hline Diabetes, n (\%) & $14(13.3)$ & $7(13.5)$ & $20(8.3)$ & $26(7.9)$ & $0.240^{\mathrm{a}}$ \\
\hline Hypercholesterolemia, n (\%) & $31(29.5)$ & $12(23.1)$ & $22(9.2)$ & $22(6.6)$ & $<0.001^{a}$ \\
\hline \multicolumn{6}{|l|}{ Medication } \\
\hline Antihypertensive, $\mathrm{n}(\%)$ & $93(88.6)$ & $45(86.5)$ & $86(35.8)$ & $135(40.8)$ & $<0.001^{\mathrm{a}}$ \\
\hline Antidiabetic, n (\%) & $19(18.1)$ & $7(13.5)$ & $13(5.4)$ & $20(6.0)$ & $<0.001^{\mathrm{a}}$ \\
\hline Antiplatelet, n (\%) & $67(63.8)$ & $26(50.0)$ & $15(6.3)$ & $25(7.6)$ & $<0.001^{a}$ \\
\hline Hypolipidemic, n (\%) & $53(50.5)$ & $19(36.5)$ & $16(6.7)$ & $31(9.4)$ & $<0.001^{\mathrm{a}}$ \\
\hline
\end{tabular}

Values are given as mean $\pm S D$ or as number of subjects (with corresponding percentages between brackets); IHD, ischemic heart disease; $P, P$-values are the results of one-way analysis of variance (continuous variables) and ${ }^{a}$ chi square test (categorical variables) for overall differences between males and females with a first event of IHD event free male and female controls. 


\section{Genetic analyses}

Genotype and allele frequencies of all polymorphisms were in Hardy-Weinberg equilibrium. No statistically significant differences in allele frequencies were found between cases and controls, except between male cases with IHD and male controls for GNB3 $(P=0.03)$ and between male and female controls for ecNOS $(P=0.04)$ (Table 4.2). Additionally, for AGT a borderline statistically significant difference in allele frequency was observed $(P=0.08)$ between males with IHD and male controls. Other differences in allele frequency, that is, larger than 0.04 between and within males and females, were not statistically significant.

Table 4.2 Allele frequencies of cardiovascular polymorphisms in a primary care population.

\begin{tabular}{|c|c|c|c|c|c|c|c|}
\hline \multirow{2}{*}{\multicolumn{2}{|c|}{ Gene polymorphism }} & \multirow{2}{*}{\multicolumn{3}{|c|}{ First event of IHD }} & \multirow{2}{*}{\multicolumn{3}{|c|}{ Controls }} \\
\hline & & & & & & & \\
\hline \multirow{2}{*}{ AGTR1 (A1166C) } & A & 0.729 & 0.719 & 0.750 & 0.703 & 0.704 & 0.702 \\
\hline & $\mathrm{C}$ & 0.271 & 0.281 & 0.250 & 0.297 & 0.296 & 0.298 \\
\hline \multirow[t]{2}{*}{ AGT (M235T) } & M & 0.653 & 0.652 & 0.654 & 0.606 & 0.583 & 0.622 \\
\hline & $\mathrm{T}$ & 0.347 & 0.348 & 0.346 & 0.394 & 0.417 & 0.378 \\
\hline \multirow[t]{2}{*}{ ACE $\left(4656_{r p t}\right)$} & C & 0.545 & 0.562 & 0.510 & 0.512 & 0.510 & 0.514 \\
\hline & G & 0.455 & 0.438 & 0.490 & 0.488 & 0.490 & 0.486 \\
\hline \multirow[t]{2}{*}{ ecNOS (E298D) } & G & 0.650 & 0.676 & 0.596 & 0.637 & 0.671 & 0.612 \\
\hline & $\mathrm{T}$ & 0.350 & 0.324 & 0.404 & 0.363 & $0.329^{*}$ & $0.388^{*}$ \\
\hline \multirow[t]{2}{*}{ GNB3 (C825T) } & C & 0.672 & 0.657 & 0.702 & 0.718 & 0.738 & 0.704 \\
\hline & $\mathrm{T}$ & 0.328 & $0.343^{+}$ & 0.298 & 0.282 & $0.262^{+}$ & 0.296 \\
\hline \multirow[t]{2}{*}{ ADD1 (G460W) } & G & 0.780 & 0.786 & 0.769 & 0.778 & 0.790 & 0.770 \\
\hline & $\mathrm{T}$ & 0.220 & 0.214 & 0.231 & 0.222 & 0.210 & 0.230 \\
\hline
\end{tabular}

IHD, ischemic heart disease; ${ }^{*}$ Male versus female controls: $P=0.04{ }^{\dagger}{ }^{\dagger}$ Males with IHD versus male controls: $P=0.03$.

\section{Logistic regression analyses}

Both univariate and multivariate ORs for a first IHD event were calculated (Table 4.3). In the multivariate analysis, the simultaneous contribution of the six polymorphisms to the prediction of a first event was statistically significant for all subjects and males, respectively (likelihood ratio test; $P<0.001$ ), showing a protective association for carriership of the $T$ allele of the AGT polymorphism (OR=0.58 [0.27-0.89]). After Bonferroni correction, this association was still statistically significant $(P=0.04)$. In addition, we found a trend towards a protective effect for AGTR1 (OR=0.65 [0.42-1.01]), which was also observed for females in the univariate analysis (OR=0.56 [0.29-1.09]). In all other polymorphisms, carriership of the rare allele of the investigated polymorphisms was not associated with an increased risk of IHD. Evaluation of possible interactions between AGT and AGTR1 showed no statistically significant interaction terms for both males and females together or for males alone. 


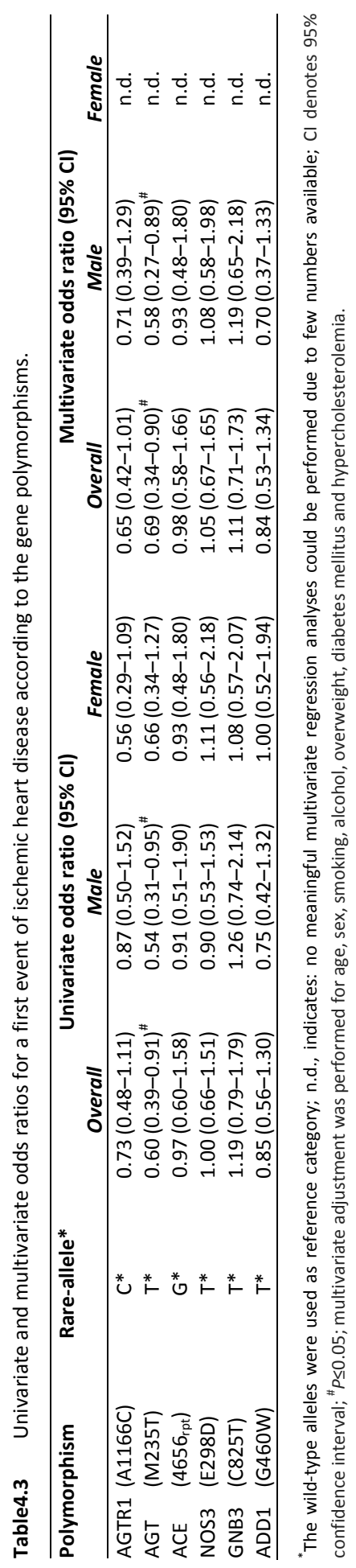




\section{Sliding means analyses}

For AGT the effect of increasing age was explored by the sliding means technique for ORs (Figure 4.1). For males a protective trend was observed, whereas in females the T allele is harmful till the age of approximately 65 . This observed difference between males and females was statistically significant $(P<0.001)$. The maximum $O R$ for the Lowess-curve in female cases was estimated 1.6 at the age of 56 years old.

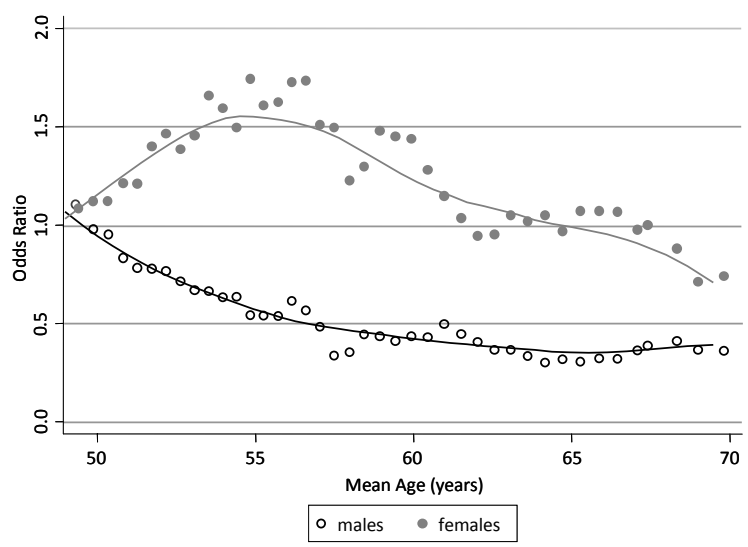

Figure 4.1 Sliding OR analysis of the interaction between carriership of the T allele of AGT and age for males and females with respect to the risk of a first event of ischemic heart disease. Each endpoint represents the unadjusted OR (T allele versus MM genotype) of 328 individuals according to age and gender and differs from the preceding or succeeding point by 10 individuals. The observed difference between males and females is statistically significant $(P<0.001)$.

\section{Discussion}

In the present study, no statistically significant differences in allele frequencies were found between cases and controls, except for a higher frequency of the T allele of GNB3 $(P=0.03)$ in male cases compared to male controls and a higher frequency of the T allele of ecNOS $(P=0.04)$ in female controls compared to male controls. However, multivariate analyses showed a protective association for carriership of the T allele of $A G T$, overall (OR=0.69 [0.34-0.90]) and for males ( $O R=0.58$ [0.27-0.89]). Sliding mean analyses indicated a statistically significant, but opposite age-associated trend for this polymorphism between males and females.

\section{Gender and age}

Gender-specific associations of cardiovascular phenotypes with a variety of candidate genes have been reported previously. ${ }^{24-28}$ In most cases, they appear as rather 
unexpected findings and are difficult to explain in terms of straightforward pathophysiological mechanisms. These kind of results are often marked as type I errors, due to sample stratification with consequent multiple comparisons and in some cases a small number of individuals in a subgroup. ${ }^{29}$ Our study is certainly not protected from such a risk. However, a few considerations may support the plausibility of a gender-specific association. First of all, gender was a statistically significant co-variate in the overall multivariate analyses, irrespective of correction for multiple testing. Secondly, it is known from literature, that hypertension and IHD are age-dependent ${ }^{30,31}$, and that females develop both conditions at an older age..$^{30-33}$ However, in our study population the age at onset for IHD is approximately the same for both males and females (Table 4.1). Since, age-related phenotypes (e.g. overweight, hypertension, diabetes and hypercholesterolemia) are present to the same extent for both male and female cases, a gender-specific association is plausible in our study.

The influence of age on the association of cardiovascular polymorphisms with cardiovascular phenotypes has not yet been completely elucidated. Several authors have underlined the importance of taking into account pathophysiological changes related to ageing when analysing the phenotypic effect of genetic variants. ${ }^{34,35}$ For instance, Province et al., found in a study in which they investigated the association of higher blood pressure values with ADD1 (G460W), that only in older individuals this association was observed. They discussed that this is probably due to a reduced efficiency of compensatory mechanisms at an older age. ${ }^{34}$

\section{Angiotensinogen (M235T) polymorphism}

The opposing associations of the T allele of AGT with IHD for males and females need further explanation. Recently, a meta-analysis by Sethi et al., including 127 studies $(n=45,267)$ stratified by gender, concluded that the M235T polymorphism did not predict risk of IHD or myocardial infarction, neither for males nor females. ${ }^{36}$ However, when looking in detail in their data these authors also showed a harmful association for women homozygous for the T allele and a protective association for males. These data were however not statistically significant. Another recent study performed by Sekuri et al., found that patients with the TT genotype had a decreased risk of premature coronary heart disease. ${ }^{37}$ Such an association was reported earlier for myocardial infarction. ${ }^{38}$ However, in both studies no subgroup analysis was performed on gender.

A speculative explanation for our observations might be a low-renin state, which can be enhanced by the GNB3 (C825T) polymorphism and older age. ${ }^{39-41}$ A protective association for the T allele of AGT may under these conditions be related to lower angiotensin levels. This was confirmed by a study performed by Fernández-Arcás et al., who indeed found a suppressed RAS in carriers of the T allele of AGT. ${ }^{38}$ In combination with the higher frequency of the T allele of GNB3 in males, this could 
translate to the observed ORs. This is also suggested by Schunkert et al., who hypothesized that the difference between males and females is rather a genetic alternation than an effect induced by for instance blood pressure. ${ }^{39}$ Another explanation might be the recently indicated misclassification of the AGT (M235T) genotype. ${ }^{42}$ However, in our study the validation process of our multiplex assay did not reveal discordant results for this polymorphism.

\section{Strengths and limitations}

The present study has several limitations. Firstly, we only studied the effect of one polymorphism per gene, which does not exclude the role of other polymorphic alleles, which are not in linkage disequilibrium. Another limitation for the present study as is for many genetic association studies is sample size. It has been emphasized that sample sizes of thousands are required to have adequate power to detect genes conferring ORs as low as 1.2 , with minor allele frequencies in the range of $5-10 \% .{ }^{43}$ In our study the actual allele frequencies of the rare alleles ranged between 0.22 and 0.55 , and the ORs for a first event were much larger than 1.2, indicating that the sample size of our study, at least for the AGT polymorphism, was acceptable. Furthermore, one could object that the definition of IHD included heart failure. However, in primary care the diagnosis heart failure is mostly caused by an event of angina pectoris or myocardial infarction. Nevertheless, the association maintained after exclusion of this type of event.

Our study has also some strong aspects, including a primary care population in which the whole range of low-to-high-risk patients is available. Although our study has an exploratory character, we performed this study with a clear a priori hypothesis, therefore reducing multiple hypothesis testing. Additionally, our population was selected using strict inclusion criteria and was derived from a rather small area, including subjects with similar social living conditions.

In conclusion, this study provides evidence that in this primary care population the $T$ allele of the AGT polymorphism is protective for males with a first event of IHD. Our data confirm that age and gender are not simply confounders in genetic epidemiology but represent a key to a better understanding of the underlying mechanisms of pathological phenotypes. 


\section{References}

1. Griendling KK, Murphy TJ, Alexander RW. Molecular biology of the renin-angiotensin system. Circulation 1993;87:1816-28.

2. Weiss D, Sorescu D, Taylor WR. Angiotensin II and atherosclerosis. Am J Cardiol 2001;87:25C-32C.

3. Ferrario CM, Richmond RS, Smith R, Levy P, Strawn WB, Kivlighn S. Renin-angiotensin system as a therapeutic target in managing atherosclerosis. Am J Ther 2004;11:44-53.

4. Dzau VJ. Cell biology and genetics of angiotensin in cardiovascular disease. J Hypertens Suppl 1994;12:S3-10.

5. Yusuf S, Sleight P, Pogue J, Bosch J, Davies R, Dagenais G. Effects of an angiotensin-converting-enzyme inhibitor, ramipril, on cardiovascular events in high-risk patients. The Heart Outcomes Prevention Evaluation Study Investigators. N Engl J Med 2000;342:145-53.

6. Carluccio M, Soccio M, De Caterina R. Aspects of gene polymorphisms in cardiovascular disease: the renin-angiotensin system. Eur J Clin Invest 2001;31:476-88.

7. Visvikis-Siest S, Marteau JB. Genetic variants predisposing to cardiovascular disease. Curr Opin Lipidol 2006;17:139-51.

8. Hegele RA. SNP judgments and freedom of association. Arterioscler Thromb Vasc Biol 2002;22: 1058-61.

9. Vineis $\mathrm{P}, \mathrm{McMichael}$ AJ. Bias and confounding in molecular epidemiological studies: special considerations. Carcinogenesis 1998;19:2063-7.

10. Campbell H, Rudan I. Interpretation of genetic association studies in complex disease. Pharmacogenomics J 2002;2:349-60.

11. Henskens LH, Spiering W, Stoffers HE, Soomers FL, Vlietinck RF, de Leeuw PW, Kroon AA. Effects of ACE I/D and AT1R-A1166C polymorphisms on blood pressure in a healthy normotensive primary care population: first results of the Hippocrates study. J Hypertens 2003;21:81-6.

12. van Onna M, Kroon AA, Houben AJ, Koster D, Zeegers MP, Henskens LH, Plat AW, Stoffers HE, de Leeuw PW. Genetic risk of atherosclerotic renal artery disease: the candidate gene approach in a renal angiography cohort. Hypertension 2004;44:448-53.

13. Plat AW, te Wierik MJ, Kroon AA, Schouten HJ, van den Akker M, van Schayck CP, de Leeuw PW, Hajema KJ, Stoffers HE. Regional differences in cardiovascular risk factor profile cannot fully explain differences in cardiovascular morbidity in the Netherlands: a comparison of two urban areas. Neth J Med 2005;63:309-15.

14. Metsemakers JF, Knottnerus JA, van Schendel GJ, Kocken RJ, Limonard CB. Unlocking patients' records in general practice for research, medical education and quality assurance: the Registration Network Family Practices. Int J Biomed Comput 1996;42:43-50.

15. Landwehr JSTM, Akker Mvd, Metsemakers JFM, Buntinx F. Comorbidity of chronic cardiovascular disorders. A cross-sectional analysis in a large general practice population in the Netherlands. Archiv Public Health 2000;58:213-31.

16. Classification of Health Problems in Primary Care, 3rd edition. Oxford, Oxford University Press, 1983.Classification Committee of Wonca. Oxford: Oxford University Press; 1983.

17. Lamberts $\mathrm{H}$, Wood M, editors. ICPC: International Classification of Primary Care. Oxford: Oxford University Press; 1987.

18. Cifkova R, Erdine S, Fagard R, Farsang C, Heagerty AM, Kiowski W, Kjeldsen S, Lüscher T, Mallion JM, Mancia G, Poulter N, Rahn KH, Rodicio JL, Ruilope LM, van Zwieten P, Waeber B, Williams B, Zanchetti A; ESH/ESC Hypertension Guidelines Committee. Practice guidelines for primary care physicians: 2003 ESH/ESC hypertension guidelines. J Hypertens 2003;21:1779-86.

19. Knaapen AM, Ketelslegers HB, Gottschalk RW, Janssen RG, Paulussen AD, Smeets HJ, Godschalk RW, Van Schooten FJ, Kleinjans JC, Van Delft JH. Simultaneous genotyping of nine polymorphisms in xenobiotic-metabolizing enzymes by multiplex PCR amplification and single base extension. Clin Chem 2004;50:1664-8.

20. Villard E, Tiret L, Visvikis S, Rakotovao R, Cambien F, Soubrier F. Identification of new polymorphisms of the angiotensin I-converting enzyme (ACE) gene, and study of their relationship to plasma ACE levels by two-QTL segregation-linkage analysis. Am J Hum Genet 1996;58:1268-78. 
21. Keavney B, McKenzie CA, Connell JM, Julier C, Ratcliffe PJ, Sobel E, Lathrop M, Farrall M. Measured haplotype analysis of the angiotensin-I converting enzyme gene. Hum Mol Genet 1998;7:1745-51.

22. Veldman BA, Spiering W, Doevendans PA, Vervoort G, Kroon AA, de Leeuw PW, Smits P. The Glu298Asp polymorphism of the NOS 3 gene as a determinant of the baseline production of nitric oxide. J Hypertens 2002;20:2023-7.

23. Hosmer DW, Lemeshow S. Applied Logistic Regression. 2nd ed. New York: J Wiley; 2000.

24. O'Donnell CJ, Lindpaintner K, Larson MG, Rao VS, Ordovas JM, Schaefer EJ, Myers RH, Levy D. Evidence for association and genetic linkage of the angiotensin-converting enzyme locus with hypertension and blood pressure in men but not women in the Framingham Heart Study. Circulation 1998;97:1766-72.

25. Higaki J, Baba S, Katsuya T, Sato N, Ishikawa K, Mannami T, Ogata J, Ogihara T. Deletion allele of angiotensin-converting enzyme gene increases risk of essential hypertension in Japanese men: the Suita Study. Circulation 2000;101:2060-5.

26. Wang JG, Staessen JA, Barlassina C, Fagard R, Kuznetsova T, Struijker-Boudier HA, Zagato L, Citterio L, Messaggio $E$, Bianchi $G$. Association between hypertension and variation in the alpha- and betaadducin genes in a white population. Kidney Int 2002;62:2152-9.

27. Brand E, Wang JG, Herrmann SM, Staessen JA. An epidemiological study of blood pressure and metabolic phenotypes in relation to the Gbeta3 C825T polymorphism. J Hypertens 2003;21:729-37.

28. Shin J, Lobmeyer MT, Gong Y, Zineh I, Langaee TY, Yarandi H, Schofield RS, Aranda JM Jr, Hill JA, Pauly $\mathrm{DF}$, Johnson JA. Relation of beta(2)-adrenoceptor haplotype to risk of death and heart transplantation in patients with heart failure. Am J Cardiol 2007;99:250-5.

29. Hingorani A. Resolving inconsistency in the results of genetic association studies of cardiovascular disease. Clin Sci (Lond) 2004;107:251-3.

30. Reckelhoff JF. Gender differences in the regulation of blood pressure. Hypertension 2001;37: 1199-208.

31. Yusuf S, Hawken S, Ounpuu S, Dans T, Avezum A, Lanas F, McQueen M, Budaj A, Pais P, Varigos J, Lisheng L; INTERHEART Study Investigators. Effect of potentially modifiable risk factors associated with myocardial infarction in 52 countries (the INTERHEART study): case-control study. Lancet 2004;364:937-52.

32. Lerner DJ, Kannel WB. Patterns of coronary heart disease morbidity and mortality in the sexes: a 26year follow-up of the Framingham population. Am Heart J 1986;111:383-90.

33. Goldberg RJ, O'Donnell C, Yarzebski J, Bigelow C, Savageau J, Gore JM. Sex differences in symptom presentation associated with acute myocardial infarction: a population-based perspective. Am Heart J 1998;136:189-95.

34. Province MA, Arnett DK, Hunt SC, Leiendecker-Foster C, Eckfeldt JH, Oberman A, Ellison RC, Heiss G, Mockrin SC, Williams RR. Association between the alpha-adducin gene and hypertension in the HyperGEN Study. Am J Hypertens 2000;13:710-8.

35. Castellano M. Genetic association studies on gender- and age-related phenotypes: the case of GNB3 gene. J Hypertens 2003;21:683-5.

36. Sethi AA, Nordestgaard BG, Tybjaerg-Hansen A. Angiotensinogen gene polymorphism, plasma angiotensinogen, and risk of hypertension and ischemic heart disease: a meta-analysis. Arterioscler Thromb Vasc Biol 2003;23:1269-75.

37. Sekuri C, Cam FS, Ercan E, Tengiz I, Sagcan A, Eser E, Berdeli A, Akin M. Renin-angiotensin system gene polymorphisms and premature coronary heart disease. J Renin Angiotensin Aldosterone Syst 2005; 6:38-42.

38. Fernández-Arcás N, Dieguez-Lucena JL, Muñoz-Morán E, Ruiz-Galdón M, Espinosa-Caliani S, ArandaLara P, Rius-Diaz F, Gaitán-Arroyo MJ, De Teresa-Galván E, Reyes-Engel A. Both alleles of the M235T polymorphism of the angiotensinogen gene can be a risk factor for myocardial infarction. Clin Genet 2001;60:52-7.

39. Schunkert H, Hense HW, Doring A, Riegger GA, Siffert W. Association between a polymorphism in the $\mathrm{G}$ protein beta3 subunit gene and lower renin and elevated diastolic blood pressure levels. Hypertension 1998;32:510-3.

40. Zeltner R, Delles C, Schneider M, Siffert W, Schmieder RE. G-protein beta(3) subunit gene (GNB3) $825 \mathrm{~T}$ allele is associated with enhanced renal perfusion in early hypertension. Hypertension 2001; 37:882-6. 
41. Siffert W. G protein polymorphisms in hypertension, atherosclerosis, and diabetes. Annu Rev Med 2005;56:17-28.

42. Lizanecz E, Pasztor ET, Mohacsi A, Papp Z, Edes I, Toth A. Mistyping of angiotensinogen M235T alleles. Hypertens Res 2006;29:197-201.

43. Ioannidis JP, Trikalinos TA, Ntzani EE, Contopoulos-loannidis DG. Genetic associations in large versus small studies: an empirical assessment. Lancet 2003;361:567-71. 


\section{Chapter 5}

GENDER-SPECIFIC EFFECT OF

THE $\boldsymbol{\alpha}$-ADDUCIN (G460W) AND

AGTRI (AII66C) POLYMORPHISM

ON CAROTID INTIMA MEDIA

THICKNESS

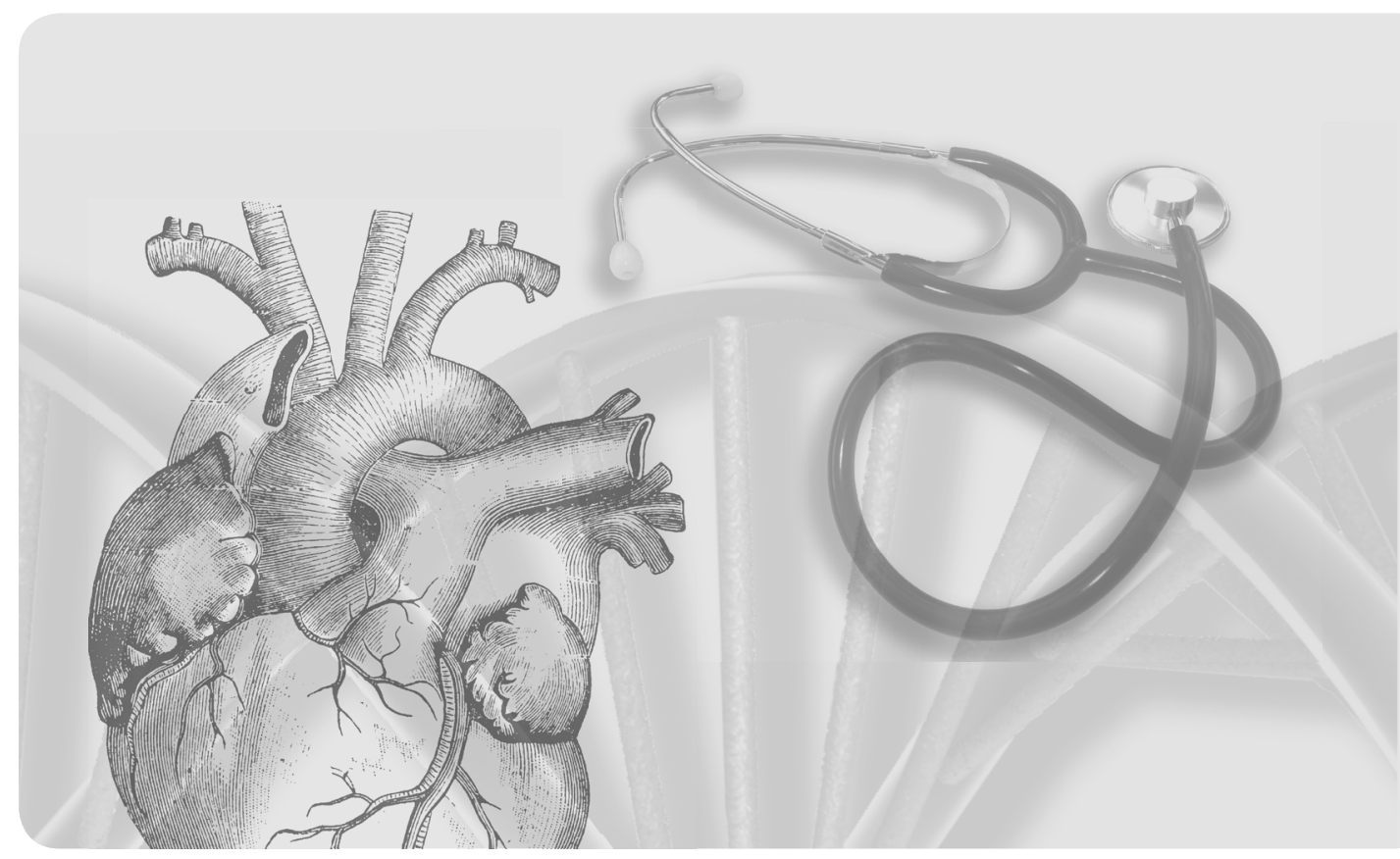

AW Plat, HEJH Stoffers, PW de Leeuw, CP van Schayck,

FL Soomers, ADM Kester, K Aretz, AA Kroon

Submitted 


\section{Abstract}

\section{Objective}

In a primary care population covering a broad spectrum of cardiovascular risk (HIPPOCRATES project) the relationship between carotid intima media thickness (CIMT) and six cardiovascular polymorphisms was analysed in a cross sectional study.

\section{Methods}

CIMT was assessed in 618 patients, who were genotyped for the AGTR1 (A1166C), AGT (M235T), ACE $\left(4656_{\mathrm{rpt}}\right.$ ), NOS3 (E298D), GNB3 (C825T) and ADD1 (G460W) polymorphisms. Linear regression analyses were performed to assess the relationship between CIMT and the polymorphisms.

\section{Results}

The study population included 289 males (46.8\%) and 329 (53.2\%) females of whom 52.3\% were treated with cardiovascular medication. CIMT increased for both males and females with age $(P<0.001)$ after correction for the arterial diameter. CIMT was significantly associated with age, female gender, use of cardiovascular medication, waist circumference and dyslipidemia. After correction for these covariates, multivariate linear regression analyses showed that only in females the C allele of AGTR1 was associated with a thicker CIMT ( $P=0.03)$. The T allele of ADD1 was associated with a smaller CIMT in both males and females, but this only reached statistical significance in females $(P=0.03)$.

\section{Conclusion}

Although the effect of both genetic variants on CIMT was small, this study showed a statistically significant effect of AGTR1 and ADD1 in females. However, our findings should be viewed as hypothesis generating and require further confirmation in prospective epidemiological primary care studies. 


\section{Introduction}

Carotid intima media thickness (CIMT) is often increased in patients with cardiovascular risk factors, such as hypertension, diabetes mellitus and hypercholesterolemia. ${ }^{1,2}$ It has also been suggested that an increased CIMT is an independent predictor of future myocardial infarction, stroke and peripheral artery disease. ${ }^{1-3}$ Consequently, CIMT is regarded as a surrogate marker for pre-clinical atherosclerosis. ${ }^{1,4}$ Current research has shown that CIMT is not only associated with traditional cardiovascular risk factors, but also with certain genetic variants. Among the many potential genes, those related to activation of the renin-angiotensin system (RAS) or to an increased tendency to retain sodium rank high, and so do genes which may cause reduced availability of nitric oxide (NO). Indeed, some studies suggest that certain genetic polymorphisms of the RAS may be important modifiers of CIMT. ${ }^{5,6}$ Most of these observations, however, have been obtained in selected populations and this prompted us to address such associations in a primary care population. On the basis of the available literature at the start of the study, we restricted ourselves to the analysis of only six polymorphisms. These were the angiotensinogen [AGT (M235T)], angiotensin converting enzyme [ACE $\left(4656_{\mathrm{rpt}}\right)$ ] and the angiotensin II type 1 receptor [AGTR1 (A1166C)] polymorphism, because these genes are involved in the generation and action of angiotensin II (Ang II). ${ }^{7-9}$ In addition, we assessed the role of polymorphisms which may be related to an enhanced reabsorption of sodium, that is, the G-protein $\beta 3$ subunit [GNB3 (C825T)] and $\alpha$-adducin [ADD1 (G460W)] polymorphism. ${ }^{10,11}$ Finally, we looked at the endothelial nitric oxide synthase [NOS3 (E298D)] polymorphism because this may be associated with altered NO availability. ${ }^{12}$ We hypothesized that the presence of one or more rare alleles of the aforementioned polymorphisms would affect CIMT values. Therefore, in the present study, we aimed to assess the association of these six polymorphisms with CIMT.

\section{Methods}

\section{Study population}

For this study we used data from the HIPPOCRATES project. The HIPPOCRATES project (Hypertension: Interaction and Prevalence of POlymorphisms related to Cardiovascular Risk and the Association to Treatment Efficacy Study) is an ongoing study, in which the implementation of genetic polymorphisms in the assessment of cardiovascular risk in primary care is investigated. ${ }^{13-15}$ All participants for this project were recruited from one general practice in Kerkrade, The Netherlands, between May 2003 and July 2005. This academic general practice takes part in the Registration Network Family Practices (RNH), which is a continuous and computerized database. All relevant health problems, including a full medical history of all cardiovascular events have been registered since $1990 .{ }^{16}$ Medical problems are coded according to 
the International Classification of Primary Care (ICPC) using the criteria of the International Classification of Health Problems in Primary Care for diagnoses. ${ }^{17,18}$ The general practice in Kerkrade has a list of approximately 4400 patients, among whom are more than 2300 patients of 40 years and older. The practice is located in a region with a high burden of cardiovascular disease (CVD) and cardiovascular risk factors and, therefore, it has well implemented cardiovascular consulting hours. For the HIPPOCRATES project, all known patients aged at least 40 years with CVD and hypertension were invited. From the group with cardiovascular risk factors other than hypertension, that is, smoking, alcohol, diabetes mellitus, hypercholesterolemia, overweight including obesity, a random 1:3 sample was taken. Of all patients without known CVD, hypertension or other cardiovascular risk factors, also a random 1:3 sample was taken. Classification was validated by thorough analysis of the patients' records combined with additional measurements of risk factors for all patients. The total HIPPOCRATES population consisted of 803 patients (382 males, 421 females). During their first visit, participants were asked permission to measure their CIMT. Included patients did not differ in baseline characteristics from those who did not consent (185 patients). CIMT was measured succesfully in all 618 patients: 289 males and 329 females. These were included in the present study. The study was approved by the Medical Ethics Committee of the Maastricht University Medical Center. All patients gave written informed consent to participate in the study.

\section{Clinical data collection}

All clinical measurements were performed in the practice by one of the authors (AWP; first measurement) and a nurse practitioner (second, third and fourth measurement with in between periods of three months). The nurse practitioner measured weight, blood pressure and heart rate. All persons were questioned on their smoking behaviour and alcohol consumption. Weight and height of all patients were measured. Body-mass index (BMI) was calculated as body weight divided by squared height. The size of the waist circumference was measured. Blood pressure and heart rate were measured after ten minutes rest in sitting position, using a sphygmomanometer. Fasting blood samples were drawn to determine serum creatinine, total cholesterol, low-density lipoprotein-cholesterol (LDL-c), high-density lipoprotein-cholesterol (HDL-c), serum triglycerides and glucose levels and were analyzed in one regional laboratory. Microalbuminuria was determined semi quantitatively in a first morning urine sample.

\section{Treatment status}

The computerized medication lists were analyzed for antihypertensive, hypolipidemic, antiplatelet and antidiabetic medication. Furthermore, all persons were questioned about their medication use at the start of the study. Cardiovascular medication was based on the anatomical therapeutic classification (ATC) and defined as having at least 
one prescription of antihypertensive (ATC level 2: C02, C03, C04, C07, C08, C09), hypolipidemic (ATC level 2: C10), or antiplatelet (ATC level 5: B01AC) medication in the selected study period. This definition was chosen since these drugs are most frequently prescribed for the prevention of CVD in primary care. Combination therapy was defined as having at least two different prescriptions of antihypertensive, hypolipidemic or antiplatelet medication used concomitantly during the study period. Antidiabetic medication was defined as having at least one prescription of A10 (ATC level 2) in the study period.

\section{Definitions}

Hypertension was defined as a systolic blood pressure (SBP) at least $140 \mathrm{mmHg}$, diastolic blood pressure (DBP) at least $90 \mathrm{mmHg}$ or both according to the Guidelines for Hypertension specified by the European Society of Hypertension. ${ }^{19}$ Mean arterial pressure (MAP) was calculated as $\mathrm{MAP}=(2 \times \mathrm{DBP}+\mathrm{SBP}) / 3$. The presence of dyslipidemia was defined as the total cholesterol to HDL-C ratio exceeding 4.0. Diabetes mellitus was considered to be present in case of fasting plasma glucose levels above $6.9 \mathrm{mmol} / \mathrm{l}$. Creatinine clearance was calculated by the Cockcroft-Gault formula. Microalbuminuria was defined as albumin excretion above $20 \mathrm{mg} / \mathrm{l}$.

\section{Carotid IMT}

CIMT measurements were performed by one of the authors (AWP) at the Circulation Laboratory of the Department of Internal Medicine of the Maastricht University Medical Center. To measure CIMT, high-resolution B-mode ultrasonography was performed with ESAOTE PICUS 3 equipped with a 7.5- $\mathrm{MHz}$. linear array transducer. The left and right common carotid arteries were examined in anterolateral, posterolateral and medialateral directions. Measurements were performed $1 \mathrm{~cm}$ proximal to the beginning of the dilatation of the carotid bulb. The mean CIMT of the far wall of the common carotid artery was measured automatically over $1 \mathrm{~cm}$, during seven heartbeats and was accepted as correct as the mean SD $<0.05$, according to the Mannheim Carotid Intima Media Thickness Consensus. ${ }^{1}$ In order to correct for asymmetry of the arterial vessel and to enhance reproducibility, CIMT was measured at four different angles and mean values were calculated for both the left and the right carotid artery. The internal diameter of the carotid artery was defined as the distance between the media-adventitia interfaces of the near and far arterial wall. Carotid atheromatous plaques were defined as focal structures encroaching into the arterial lumen and where its thickness was at least $50 \%$ greater than that of the adjacent sites. ${ }^{1}$ For this article, plaques were not analyzed.

\section{Genetic analyses}

The various polymorphisms were determined at the Cardiovascular Genotyping (CAGT) Laboratory of the Department of Internal Medicine of the Maastricht 
University Medical Center. DNA was extracted from whole blood with the use of the QIAmp Blood Kit (Qiagen Inc., Venlo, the Netherlands). Genotyping of the angiotensin II type 1 receptor [AGTR1 (A1166C)/rs5186], angiotensinogen [AGT (M235T)/rs699], angiotensin converting enzyme [ACE $\left.\left(4656_{\mathrm{rpt}}\right) / \mathrm{rs} 1799752\right]$, endothelial nitric oxide synthase [NOS3 (E298D)/rs1799983], G-protein $\beta 3$ subunit [GNB3 (C825T)/rs5443] and $\alpha$-adducin [ADD1 (G460W)/rs4961] polymorphisms was performed with a multiplex single base extension (SBE) assay (Multiplex SNaPshot, Applied Biosystems, Foster City, California, USA) similar to previously published protocols. ${ }^{20}$ Briefly, in the first stage a multiplex PCR is carried out to amplify the gene fragments that contain the polymorphisms. In the second stage, the polymorphic positions are interrogated by a SBE reaction using fluorescently labeled ddNTPs. The oligos used for the single base extension have specific lengths, varying from 22-50 nt. After the SBE assay, the fragments are size-resolved on an ABI3100 Genetic Analyser (Applied Biosystems): the size of the peaks identifies the locus (e.g. ADD1) and the color of the peak(s) identifies the genotype (e.g. Gly/Trp). Raw data were analyzed with Genescan Analysis software ( $v$ 3.7), then genotypes were scored independently by two researchers and entered in the database. In 27 patients, a second analysis was necessary to obtain all the genotypes. The ACE (I/D) polymorphism was determined by detecting $\mathrm{ACE}_{4656+C T}$ observed on the SNaPshot as ACE (4656 $6_{\text {rpt }}$ ). The use of this SNaPshot method does not allow the direct determination of the insertion/deletion polymorphism. The $A_{C E} E_{4656+C T}$ polymorphism in the $3^{\prime}$-untranslated region of the ACE gene consists of a repetition of two or three CT dinucleotides and is in complete linkage disequilibrium with ACE (I/D). ${ }^{21,22}$ The multiplex assay was validated on a set of 100 DNA samples that had previously been genotyped with an alternative technique; this technique concerned a multilocus genotyping assay for candidate markers of CVD risk (Roche Molecular

systems Inc., Alameda, California, USA) and has been described in detail previously. ${ }^{23}$ Only four samples gave a discordant result for the NOS3 polymorphism. All other genotypes were concordant. The discordant results have been adjusted.

\section{Statistical analysis}

Statistical analysis was performed using SPSS statistical software, version 13.0 (SPSS, Inc., Chicago, IL, USA). A P-value of 0.05 or less was considered statistically significant. Statistical significance for differences in quantitative variables was tested by Student's $t$-test or Mann-Whitney $U$ test when appropriate. In case of categorical variables, the chi-square test was used. Overall mean CIMT values were calculated by taking the average of the left and right mean CIMT values. Correction for gender differences in arterial diameter was provided by calculation of the CIMT/internal carotid diameter ratio. Since we expected potential differences between males and females, we analyzed data with respect to gender separately.

A power calculation indicated that the HIPPOCRATES population was large enough to calculate differences between groups. Assuming allele frequencies ranging between 0.51 and 0.79 , a total group number of 590-635 would be sufficient to detect a clinical 
significant difference in CIMT of $0.035 \mathrm{~mm}$ with a power of $80 \%(\alpha=0.05)$. Genotype and actual allele frequencies were calculated to test the Hardy-Weinberg equilibrium. Furthermore, allele frequencies were analyzed using chi-square tests. Differences in frequency between groups larger than 0.04 were tested for significance. Significant co-variables for the relationship between CIMT and polymorphisms were traced by multivariate linear regression analysis using backward model selection. To avoid collinearity, waist circumference was used instead of waist-to-hip ratio or BMI and condensed measures were used like diabetes and dyslipidemia as defined earlier. Recent research has shown that waist circumference is a better marker of abdominal fat accumulation than waist-to-hip ratio or $\mathrm{BMI}^{24}$, which is strongly associated with increased cardiovascular risk. ${ }^{25}$ MAP was used because it is constant along the arterial tree and hence reflects accurately the impact of pressure on the carotid segments. $P$ values for co-variables to stay in the model were set at 0.10 . Because of the skewed distribution of CIMT, log transformation was applied to achieve normality for further analysis. The contribution of all co-variables to CIMT was calculated as the estimated effect on population mean CIMT. Univariate and multivariate linear regression analyses were performed to evaluate the relationship between polymorphisms and CIMT. For that purpose, the homozygous wild-type genotype was used as reference category. Age and gender, both demographic variables, were incorporated in both the univariate as well as the multivariate linear regression analyses. As indicated, we selected patients from different groups. Therefore, in the regression analyses, we had to adjust for this selection by creating dummy variables using the normotensive group without cardiovascular risk factors as the reference category. Adjustment for potential confounders was performed by incorporating age, gender, waist circumference, dyslipidemia and use of cardiovascular medication into the model (enter procedure). The simultaneous contribution of the six polymorphisms to the prediction of increased CIMT was determined, using the overall F-test. If two or more polymorphisms reached statistical significance, interactions (effect modification) between these polymorphisms with respect to CIMT were assessed. Again linear regression analysis was used, in which the alleles at risk, the interaction term between the alleles and the other covariates were incorporated. If an interaction became statistically significant, the model was explored further.

\section{Results}

\section{Characteristics of the participants}

Baseline characteristics of the study population are summarized in Table 5.1. There were slightly more females (53.2\%) than males (46.8\%). Overall, $52.3 \%$ of these patients were treated with cardiovascular medication. Males more often had a history of ischemic heart disease, used more antiplatelet and hypolipidemic medication as compared to females. Additionally, they used more often alcohol, they had a larger 
waist circumference and a lower HDL-c. Their creatinine clearance was higher as compared with females and they had more often microalbuminuria. The observed difference in CIMT between males and females (Table 5.1) was not statistically significant, except for the age category $50-59(P=0.02)$. However, females have a higher CIMT / diameter ratio than males, because the internal diameter of their carotid artery is smaller (Table 5.1). For both males and females this ratio increased with age (Figure $5.1 ; P<0.001$ ).

Table 5.1 Characteristics of the HIPPOCRATES study population $(n=618)$.

\begin{tabular}{|c|c|c|c|c|}
\hline & Overall (618) & Males (289) & Females (329) $P$ & \\
\hline Age (years) & $60.5 \pm 10.6$ & $60.8 \pm 10.4$ & $60.3 \pm 10.8$ & 0.592 \\
\hline \multicolumn{5}{|l|}{ Morbidity } \\
\hline History of ischemic heart disease, $\mathrm{n}(\%)$ & 117 (18.9) & $78(27.0)$ & 39 (11.9) & $<0.001^{\mathrm{a}}$ \\
\hline History of stroke, n (\%) & $39 \quad 6.3)$ & $24(8.3)$ & $15(4.6)$ & $0.056^{\mathrm{a}}$ \\
\hline Peripheral artery occlusive disease, $\mathrm{n}(\%)$ & $23(3.7)$ & $12(4.2)$ & $11(3.3)$ & $0.596^{a}$ \\
\hline Heart failure, $\mathrm{n}(\%)$ & $12(1.9)$ & $7(2.4)$ & $5(1.5)$ & $0.417^{\mathrm{a}}$ \\
\hline \multicolumn{5}{|l|}{ Risk factors } \\
\hline Body-mass index $\left(\mathrm{kg} / \mathrm{m}^{2}\right)$ & $27.8 \pm 4.5$ & $27.5 \pm 3.9$ & $28.0 \pm 5.0$ & 0.171 \\
\hline Waist $(\mathrm{cm})$ & $95.1 \pm 13.0$ & $100.0 \pm 10.9$ & $93.4 \pm 14.9$ & $<0.001$ \\
\hline MAP (mmHg) & $103.3 \pm 12.1$ & $102.9 \pm 11.3$ & $103.7 \pm 12.8$ & 0.393 \\
\hline Heart rate (beats per minute) & $74.3 \pm 11.2$ & $72.3 \pm 12.0$ & $76.1 \pm 10.1$ & $<0.001$ \\
\hline Current smoking, $\mathrm{n}(\%)$ & $117(18.9)$ & $59(20.4)$ & $58(17.6)$ & $0.378^{\mathrm{a}}$ \\
\hline Alcohol, n (\%) & $14(2.3)$ & $11(3.8)$ & $3(0.9)$ & $0.016^{a}$ \\
\hline Diabetes, n (\%) & $85(13.8)$ & $40(13.8)$ & $45(13.7)$ & $0.953^{a}$ \\
\hline Dyslipidemia, n (\%) & $342(55.3)$ & $166(57.4)$ & $176(53.5)$ & $0.275^{a}$ \\
\hline Microalbuminuria, n (\%) & $66(10.7)$ & $41(14.2)$ & $25(7.6)$ & $0.008^{a}$ \\
\hline \multicolumn{5}{|l|}{ Biochemical } \\
\hline Creatinine clearance $^{c}(\mathrm{ml} / \mathrm{min})$ & $77.9 \pm 22.7$ & $83.4 \pm 23.4$ & $73.0 \pm 20.9$ & $<0.001^{\text {b }}$ \\
\hline Total cholesterol (mmol/l) & $5.6 \pm 1.1$ & $5.4 \pm 1.0$ & $5.7 \pm 1.1$ & 0.001 \\
\hline LDL-cholesterol (mmol/l) & $3.4 \pm 1.0$ & $3.3 \pm 0.9$ & $3.4 \pm 1.0$ & 0.721 \\
\hline HDL-cholesterol (mmol/l) & $1.5 \pm 0.4$ & $1.3 \pm 0.4$ & $1.7 \pm 0.5$ & $<0.001$ \\
\hline Triglycerides (mmol/l) & $1.6 \pm 0.9$ & $1.6 \pm 0.9$ & $1.5 \pm 0.8$ & 0.077 \\
\hline Glucose $(\mathrm{mmol} / \mathrm{l})$ & $5.7 \pm 1.5$ & $5.8 \pm 1.4$ & $5.6 \pm 1.6$ & $0.003^{b}$ \\
\hline \multicolumn{5}{|l|}{ Medication } \\
\hline Antihypertensive, n (\%) & $293(47.4)$ & $146(50.5)$ & $147(44.7)$ & $0.147^{\mathrm{a}}$ \\
\hline Hypolipidemic, n (\%) & $124(20.1)$ & 69 (23.9) & $55(16.7)$ & $0.027^{\mathrm{a}}$ \\
\hline Antiplatelet, n (\%) & $144(23.3)$ & $85(29.4)$ & $59(17.9)$ & $0.001^{\mathrm{a}}$ \\
\hline Antidiabetic, n (\%) & $48(7.8)$ & $21(7.3)$ & $27(8.2)$ & $0.663^{a}$ \\
\hline \multicolumn{5}{|l|}{ Arterial measurements } \\
\hline Carotid atheromatous plaques, n (\%) & $92(14.9)$ & 39 (13.5) & $53(16.1)$ & $0.362^{a}$ \\
\hline Carotid intima media thickness $(\mu \mathrm{m})$ & $684 \pm 137$ & $680 \pm 142$ & $688 \pm 132$ & $0.342 b$ \\
\hline Internal diameter of carotid artery $(\mathrm{mm})^{\mathrm{d}}$ & $6.2 \pm 0.9$ & $6.5 \pm 0.8$ & $5.9 \pm 0.8$ & $<0.001$ \\
\hline Carotid IMT / diameter ratio & $0.091 \pm 0.02$ & $0.086 \pm 0.02$ & $0.095 \pm 0.01$ & $<0.001 \mathrm{~b}$ \\
\hline
\end{tabular}

Values are given as mean $\pm \mathrm{SD}$ or as number of patients (with corresponding percentages in brackets); $P, \mathrm{P}$ values are the results of ${ }^{a}$ chi square test (categorical variables) or Student's $t$-test or ${ }^{b}$ Mann-Whitney $U$ test (continuous variables) for differences between males and females; ${ }^{c}$ creatinine clearance by the Cockcroft-Gault formula; ${ }^{d}$ The distance between the media-adventitia interfaces of the near and far arterial wall; MAP, mean arterial pressure; HDL, high-density lipoprotein; LDL, low-density lipoprotein. 


\section{Allele frequencies}

Genotype and allele frequencies of all polymorphisms were in Hardy-Weinberg equilibrium. No statistically significant differences in allele frequencies were found between males and females, except for NOS3 $(P=0.01)$. For this polymorphism, females had a higher frequency of the T allele (Table 5.2).

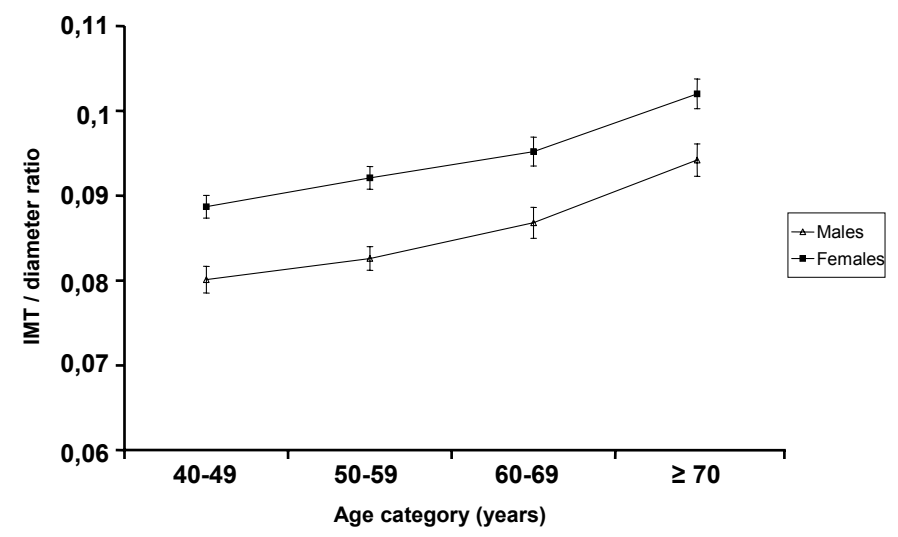

Figure 5.1 Carotid intima media thickness corrected for the internal diameter of the carotid artery by age categories (years) for males $(n=289)$ and females $(n=329)(P<0.001)$. Values are means \pm standard error.

Table $\mathbf{5 . 2}$ Allele frequencies of polymorphisms.

\begin{tabular}{lcccc}
\hline Gene polymorphism & & Overall $(\mathrm{n}=618)$ & Male $(\mathrm{n}=289)$ & Female $(\mathrm{n}=329)$ \\
\hline AGTR1 (A1166C) & A & 0.708 & 0.713 & 0.704 \\
AGT (M235T) & C & 0.292 & 0.287 & 0.296 \\
& M & 0.607 & 0.611 & 0.603 \\
ACE (4656 $r$ $)$ & T & 0.393 & 0.389 & 0.397 \\
& C & 0.515 & 0.512 & 0.517 \\
ecNOS (E298D) & G & 0.485 & 0.488 & 0.483 \\
GNB3 (C825T) & G & 0.642 & 0.678 & 0.611 \\
& T & 0.358 & $0.322^{*}$ & $0.389^{*}$ \\
ADD1 (G460W) & C & 0.710 & 0.711 & 0.708 \\
& T & 0.290 & 0.289 & 0.292 \\
& G & 0.786 & 0.798 & 0.775 \\
\hline
\end{tabular}

*Males versus females $(P=0.01)$

\section{Intima media thickness and cardiovascular polymorphisms}

Stepwise regression analysis identified age, gender, waist circumference, dyslipidemia and use of cardiovascular medication as significant co-variables for the association between the six polymorphisms and CIMT (Table 5.3). In the univariate linear 
regression analyses, an association was found between CIMT and carriers of the T allele of ADD1. This association was statistically significant for the overall group (Figure 5.2, $P=0.01$ ), but when males and females were analyzed separately, only in females statistical significance was reached $(P=0.02)$ with or without correction for internal carotid diameter. After correction for all co-variates using multivariate linear regression analyses (Table 5.4), we assessed for the overall group an independent significant relationship between CIMT and ADD1 ( $P=0.01)$. However, the simultaneous contribution of all six polymorphisms to the change in CIMT (overall F-test) was not statistically significant, except for females $(P=0.04)$, due to a statistically significant harmful association for carriers of the $C$ allele of AGTR1 $(P=0.03)$ and a protective association for carriers of the T allele of ADD1 $(P=0.03)$. For all other polymorphisms, carriers of the rare allele were not statistically significant associated with CIMT. Furthermore, there were no other statistically significant differences for these associations between males and females (Table 5.4). For females, a multivariate post hoc evaluation of possible interactions between presence of the C allele of AGTR1 and homozygosity of the G allele of ADD1 showed overall an increase of $36 \mu \mathrm{m}$ in CIMT [36.6 (-6.2-76.2)]. This interaction was of borderline statistical significance $(P=0.09)$. The CIMT in females with both $C^{*} / G G$ was statistically significant thicker than females with both $\mathrm{AA} / \mathrm{T}^{*}(P=0.04$, Figure 5.3$)$.

Table 5.3 Relevant co-variables for the association between CIMT and six cardiovascular polymorphisms. Results of multivariate linear regression analysis using backward model selection in 618 participants.

\begin{tabular}{lc}
\hline & CIMT $(\boldsymbol{\mu m})$ \\
\hline Coefficient of determination $\left(\mathrm{R}^{2}\right)$ & 0.5 \\
Intercept & 266 \\
Estimated effect on population mean $(95 \% \mathrm{Cl})^{*}$ & \\
Gender $(0,1)^{* *}$ & $23.7(5.5-43.0)^{\#}$ \\
Age (years) & $5.5(4.1-6.9)^{\#}$ \\
Presence of cardiovascular morbidity $(0,1)$ & $-8.2(-30.8,15.9)$ \\
Use of cardiovascular medication $(0,1)$ & $33.6(9.0,59.2)^{\#}$ \\
Antidiabetic medication $(0,1)$ & $18.0(-26.8,65.9)$ \\
Current smoking $(0,1)^{\dagger}$ & $9.0(-12.8,31.5)$ \\
Alcohol $(0,1)^{+}$ & $-38.6(-89.4,17.3)$ \\
Diabetes $(0,1)^{\dagger}$ & $-20.2(-53.2,14.5)$ \\
Waist $(\mathrm{cm})$ & $27.9(13.8,35.1)^{\#}$ \\
Creatinine clearance $(\mathrm{ml} / \mathrm{min})$ & $0.1(-0.7,0.7)$ \\
Microalbuminuria $(0,1)^{\dagger}$ & $-18.9(-45.6,9.0)$ \\
Dyslipidemia $(0,1)^{+}$ & $15.9(1.4,34.4)^{\#}$ \\
Heart rate $($ beats per minute) & $0.1(-0.7-1.4)$ \\
MAP $(10$ mmHg) & $0.6(-6.9-6.9)$ \\
\hline
\end{tabular}

CIMT, carotid intima media thickness; " population mean is $684.23 \mu \mathrm{m}$; Cl denotes $95 \%$ confidence interval; ${ }^{* *}$ Males were coded as 0 and females as $1{ }^{\dagger}$ Variables were coded 0 or 1 if the condition was absent or present; MAP, mean arterial pressure; ${ }^{\#} P \leq 0.05$. 


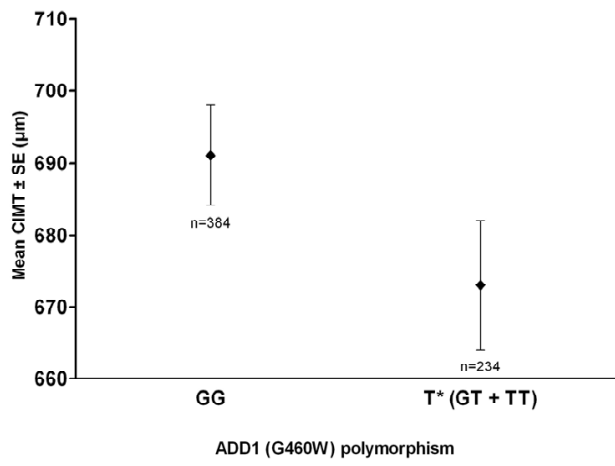

Figure 5.2 Carotid intima media thickness $(\mu \mathrm{m})$ for carriers of the normal $(G G)$ as of the rare allele $\left(T^{*}\right)$ for the ADD1 (G460W) polymorphism $(P=0.01)$. Values are unadjusted means \pm standard error.

Table 5.4 Linear regression model for six polymorphisms and carotid intima media thickness for all patients and for males and females separately.

\begin{tabular}{|c|c|c|c|c|}
\hline \multirow[t]{2}{*}{ Polymorphism } & \multirow[t]{2}{*}{ Rare allele* } & \multicolumn{3}{|c|}{ Multivariate analysis $(95 \% \mathrm{Cl})^{\ddagger \dagger}$} \\
\hline & & Overall (618) & Male (289) & Female (329) \\
\hline AGTR1 (A1166C) & $\mathrm{C}^{*}$ & $10.3(-6.8,27.2)$ & $0.1(-25.5,26.5)$ & $25.1(3.4,47.4)^{\#}$ \\
\hline AGT (M235T) & $\mathrm{T}^{*}$ & $9.0(-8.2,26.5)$ & $14.5(-12.2,41.6)$ & $0.7(-21.5,24.4)$ \\
\hline ACE $\left(4656_{\mathrm{rpt}}\right)$ & $\mathrm{G}^{*}$ & $-4.8(-23.5,14.5)$ & $-8.8(-37.2,20.8)$ & $-5.5(-30.8,20.1)$ \\
\hline NOS3 (E298D) & $\mathrm{T}^{*}$ & $6.2(-10.9,23.7)$ & $8.3(-16.9,34.4)$ & $3.4(-19.6,26.5)$ \\
\hline GNB3 (C825T) & $T^{*}$ & $-4.1(-20.2,12.4)$ & $11.7(-14.2,38.0)$ & $-19.6(-41.1,2.1)$ \\
\hline ADD1 (G460W) & $\mathrm{T}^{*}$ & $-22.9(-38.6,-6.1)^{\#}$ & $-19.6(-44.3,6.9)$ & $-23.5(-44.3,-2.7)^{\#}$ \\
\hline
\end{tabular}

* The wild-type alleles were used as reference category; $¥$ Data presented as unstandardized $\beta$ coefficient $(95 \% \mathrm{Cl}):$ the $\beta$ represents the change in carotid intima media thickness $(\mu \mathrm{m})$ for each unit change in continuous risk factors and for a change (absent or present) in dichotomous risk factors; $\mathrm{Cl}$ denotes $95 \%$ confidence interval; + Multivariate adjustment was performed for age, gender, waist, dyslipidemia and use of cardiovascular medication; \# $P \leq 0.05$.

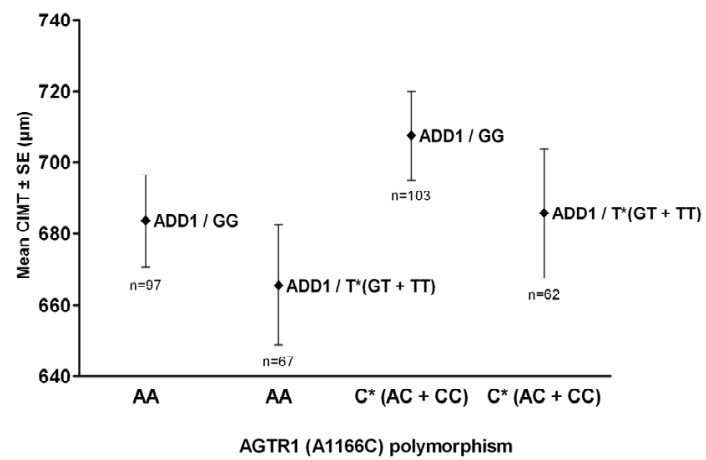

Figure 5.3 Carotid intima media thickness $(\mu \mathrm{m})$ for carriers of the normal versus the rare alleles of the AGTR1 (A1166C) and ADD1 (G460W) polymorphism. AGTR1 / AA plus ADD1 / T* versus AGTR1 / $C^{*}$ plus ADD1 /GG $(P=0.04)$. Values are unadjusted means \pm standard error. 


\section{Discussion}

To the best of our knowledge, this is the first study on CIMT and cardiovascular polymorphisms in a primary care population reflecting current daily practice. In the present study, we found that with increasing age, females show a greater CIMT compared to males if correction for the diameter of the artery is applied $(P<0.001)$. Other variables that were statistically significant associated with CIMT were use of cardiovascular medication, waist circumference and dyslipidemia, which was in accordance with previous findings. ${ }^{2,26}$ In multivariate linear regression analyses a statistically significant harmful association of the C allele of AGTR1 with CIMT was found for females only $(P=0.03)$. For the T allele of ADD1 a protective association was found in males and females, but statistical significance was only reached in females $(P=0.03)$. Post-hoc analyses revealed a potential synergism between AGTR1 and ADD1 in relation to CIMT (Figure 5.3).

\section{CIMT and gender differences}

In most studies male gender is associated with increased $\mathrm{CIMT} .{ }^{2,27,28}$ Females have most often the thinnest $\mathrm{CIMT}{ }^{2,27,28}$ For the CIMT/internal carotid diameter ratio, the same kind of results are observed, though this ratio yields the weakest associations. ${ }^{29}$ Our study results are not in line with these findings, especially if we look at CIMT values corrected for differences in arterial diameter (Table 5.1). A possible explanation might be that males are treated more than females with cardiovascular risk-reducing therapies (Table 5.1).

\section{Angiotensin II type I receptor (A1166C) polymorphism}

The observed association between carriers of the rare C allele of AGTR1 and higher CIMT has been reported by other authors. ${ }^{30,31}$ The mechanism for this association remains unclear, because the AGTR1 polymorphisms is located in the 3 '-untranslated region ( $3^{\prime}$-UTR) of the chromosome $3 q 22^{32}$ and, therefore, the amino-acid sequence of the receptor is not altered. However, recently, the $3^{\prime}$-UTR site has been shown to be involved in microRNA gene silencing. ${ }^{33}$ MicroRNAs are single-stranded RNA molecules of about 21-23 nucleotides in length, which regulate gene expression. They are processed from primary transcripts and their main function is to down-regulate gene expression (gene silencing). The $\mathrm{C}$ allele carriers have impaired microRNA binding and a consequent impairment of translation attenuation, resulting in increased receptor density. Such AGTR1 receptor alterations have a number of possible effects which may influence CIMT, including increased extracellular matrix (ECM) formation, smooth muscle cell (SMC) migration, oxidation of LDL-C and the formation of reactive oxygen species (ROS), eventually initiating the inflammation process in the vascular cells. ${ }^{34}$ Previously, we have shown that there is also an 
increase in angiotensin $\|$ sensitivity. ${ }^{35}$ So, these mechanisms might explain the observed higher CIMT for C allele carriers of the AGTR1 polymorphism. Evidence for gender differences with respect to these mechanisms was not present in the literature.

\section{Alpha-adducin (G460W) polymorphism}

Several studies have reported an association between ADD1 (G460W) polymorphism, salt sensitivity, or high sodium intake, and an increased risk of cardiovascular events and mortality. ${ }^{36,37}$ Moreover, the risk of cardiovascular events and mortality was shown to be increased in T allele carriers with high systolic blood pressure. ${ }^{38}$ Recently, in the Rotterdam study and in another study in young adult males performed by Sarzani et al., an increased CIMT was found for carriers of the T allele. ${ }^{39,40}$ Balkestein et al., found that the T allele of ADD1 was associated with increased femoral artery IMT, but only in the context of the ACE DD genotype. ${ }^{41}$ The results of our study are not in line with these findings, that is, female carriers of the T-allele are associated with a lower CIMT, indicating that they are at lower risk for developing CVD in comparison with females with the GG genotype. Additionally, compared with males, female carriers of the T-allele have a signicantly lower risk to develop CVD, though we realize that in the overall analysis correction for gender yielded an overall protective association for T-allele carriers. A possible explanation may be related to the treatment status of the patients. Previously, it has been reported that there is an interaction between carriers of the rare T allele of ADD1 and diuretic therapy. ${ }^{42}$ Hypertensive patients carrying the rare $T$ allele, who were treated with diuretics, were at lower risk of myocardial infarction and stroke compared to patients treated with other antihypertensive therapies. We checked our database for the use of diuretics and found no association with diuretics. So, although attractive, the concurrent use of diuretics does not explain our findings. Another explanation might be the use of combination therapy which may modify the behavior of the CIMT. We checked our database, if carriers of the T-allele of the ADD1 polymorphism more often used combination therapies and found no association with combination therapy. Our finding of a protective association with outcome for the rare allele of ADD1 is however not an isolated unique observation. Tobin et al., also found such a protective association for ADD1 in a multilocus case-control study in which patients with myocardial infarction were compared with healthy controls. They suggested that this protective effect is likely to be through a cellular mechanism different from its effect leading to hypertension. ${ }^{43}$ Other authors also indicated that the duration of treatment with medication reduces the increase in $\mathrm{CIMT}^{44,45}$ This may in our cross-sectional study indeed be an alternative explanation for the observed protective effect of the T allele of ADD1. Carriers of the rare T allele for the ADD1 (G460W) polymorphism are probably treated at earlier age and, consequently, longer with medication leading to reduced $\mathrm{CIMT}^{46}$ We checked our database for treatment duration and found no 
statistically significant difference in treatment duration between carriers of the normal (GG) and and rare T allele of the ADD1 (G460W) polymorphism. However, we realize that our design is cross-sectional. This implicates two major problems. First of all, CIMT is influenced by cardiovascular medication, and secondly, channeling plays an important role, that is, the most severe cardiovascular patients are treated more intensively. In a cross-sectional design the contribution of these two factors can not be distinguized and, therefore, we think duration of treatment needs to be evaluated in future prospective studies.

\section{Endothelial nitric oxide synthase (E298D) polymorphism}

Although we found a statistically significant higher frequency of the rare T allele for the NOS3 (E298D) polymorphism in females, our multivariate linear regression analyses indicated that NOS3 did not contribute to higher CIMT. Homozygosity of the rare T allele of NOS3 has been shown to be associated with coronary heart disease, carotid atherosclerosis and endothelial function. ${ }^{47}$ Recent studies found statistically significant associations between increased CIMT and NOS3. In additional analyses for NOS3, both univariate and multivariate, for homozygosity of the rare allele, we could not confirm these findings, though the allele frequency of the rare $T$ allele in our population was similar or higher as compared with other studies. ${ }^{48,49}$

\section{Strengths and limitations}

Several limitations of our study need to be discussed. Firstly, we only studied the effect of one polymorphism per gene, which does not exclude the role of other polymorphic alleles that are not in linkage disequilibrium. Secondly, we used a recessive model of inheritance. Although based on results of other studies, we realize this choice is arbitrary. Thirdly, one could object to averaging CIMT values from the left and right side, like we did. There is evidence for a significant difference between left and right CIMT, with higher values on the left side. ${ }^{50}$ When we analyzed our data for left and right CIMT values separately, this did not alter our results. Fourthly, for reasons of comparability, we analyzed mean CIMT values, although the gender differences in CIMT values only were statistically significant when they were corrected for gender differences in internal carotid diameter, except for the age category 50-59. Analyses using CIMT/diameter ratio did not alter our results. Other studies have shown that the cross-sectional area of IMT (CSA-IMT) is also an important correction for measurements of CIMT. However, analyses using the CSA-IMT did again not alter our results. Fifthly, one could argue that we did not correct for multiple testing. We had, however, a clear a priori hypothesis, which limited the number of hypotheses tested. Finally, as is for many genetic association studies, a limitation of the present study is sample size. ${ }^{51}$ Therefore, as stated by Ginsburg et al., these findings should be replicated in at least one independent cohort. ${ }^{52}$ However, at the start of our study in 2002 such a confirmation cohort was not included. 


\section{Perspectives}

Recently it has been shown that CIMT is an important surrogate marker of atherosclerosis in the clinical trial setting. ${ }^{53}$ Therefore, we think the results of our study are of utmost importance, since our results reflect the use of CIMT in daily practice and not the controlled setting of a clinical trial. Therefore, we were able to assess the influence on CIMT of several factors, including the six polymorphisms. Furthermore, we used a relatively unselected population from primary care, in which the whole spectrum of cardiovascular risk was present and well defined. From the perspective of prevention this is clinically relevant, because the general practitioner is first responsible for the long-term cardiovascular risk management of his patients. Furthermore, results from studies among unselected populations may lead to better cardiovascular risk stratification, not only for the index patient, but possibly for (first degree) family members as well. Eventually, it might offer opportunities for genetically-tailored treatment.

\section{Conclusion}

This study in a primary care population showed statistically significant associations between AGTR1 and CIMT in females and between ADD1 and CIMT for both males and females, but only statistically significant in females. The observed protective association of the T allele of ADD1 with CIMT under pharmacological therapy warrants further study on the role of this polymorphism. Our findings should be viewed as hypothesis generating and require further confirmation in prospective epidemiological primary care studies. 


\section{References}

1. Touboul PJ, Hennerici MG, Meairs S, Adams H, Amarenco P, Bornstein N, Csiba L, Desvarieux M, Ebrahim S, Fatar M, Hernandez Hernandez R, Jaff M, Kownator S, Prati P, Rundek T, Sitzer M, Schminke U, Tardif JC, Taylor A, Vicaut E, Woo KS, Zannad F, Zureik M. Mannheim carotid intimamedia thickness consensus (2004-2006). An update on behalf of the Advisory Board of the 3rd and 4th Watching the Risk Symposium, 13th and 15th European Stroke Conferences, Mannheim, Germany, 2004, and Brussels, Belgium, 2006. Cerebrovasc Dis 2007;23:75-80.

2. Lorenz MW, Markus HS, Bots ML, Rosvall M, Sitzer M. Prediction of clinical cardiovascular events with carotid intima-media thickness: a systematic review and meta-analysis. Circulation 2007;115:459-67.

3. O'Leary DH, Polak JF, Kronmal RA, Manolio TA, Burke GL, Wolfson SK, Jr. Carotid-artery intima and media thickness as a risk factor for myocardial infarction and stroke in older adults. Cardiovascular Health Study Collaborative Research Group. N Engl J Med 1999;340:14-22.

4. Roman MJ, Naqvi TZ, Gardin JM, Gerhard-Herman M, Jaff M, Mohler E. American society of echocardiography report. Clinical application of noninvasive vascular ultrasound in cardiovascular risk stratification: a report from the American Society of Echocardiography and the Society for Vascular Medicine and Biology. Vasc Med 2006;11:201-11.

5. Fox CS, Polak JF, Chazaro I, Cupples A, Wolf PA, D'Agostino RA, O'Donnell CJ; Framingham Heart Study. Genetic and environmental contributions to atherosclerosis phenotypes in men and women: heritability of carotid intima-media thickness in the Framingham Heart Study. Stroke 2003;34: 397-401.

6. Manolio TA, Boerwinkle E, O'Donnell CJ, Wilson AF. Genetics of ultrasonographic carotid atherosclerosis. Arterioscler Thromb Vasc Biol 2004;24:1567-77.

7. Tiret L, Bonnardeaux A, Poirier O, Ricard S, Marques-Vidal P, Evans A, Arveiler D, Luc G, Kee F, Ducimetière $P$, et al. Synergistic effects of angiotensin-converting enzyme and angiotensin-II type 1 receptor gene polymorphisms on risk of myocardial infarction. Lancet 1994;344:910-3.

8. Visvikis-Siest S, Marteau JB. Genetic variants predisposing to cardiovascular disease. Curr Opin Lipidol 2006;17:139-51.

9. Sayed-Tabatabaei FA, Oostra BA, Isaacs A, van Duijn CM, Witteman JC. ACE polymorphisms. Circ Res 2006;98:1123-33.

10. Zeltner R, Delles C, Schneider M, Siffert W, Schmieder RE. G-protein beta(3) subunit gene (GNB3) $825 \mathrm{~T}$ allele is associated with enhanced renal perfusion in early hypertension. Hypertension 2001;37:882-6.

11. Manunta P, Bianchi G. Low-salt diet and diuretic effect on blood pressure and organ damage. J Am Soc Nephrol 2004;15 Suppl 1:S43-6.

12. Casas JP, Cavalleri GL, Bautista LE, Smeeth L, Humphries SE, Hingorani AD. Endothelial nitric oxide synthase gene polymorphisms and cardiovascular disease: a HuGE review. Am J Epidemiol 2006; 164:921-35.

13. Plat AW, te Wierik MJ, Kroon AA, Schouten HJ, van den Akker M, van Schayck CP, de Leeuw PW, Hajema KJ, Stoffers HE. Regional differences in cardiovascular risk factor profile cannot fully explain differences in cardiovascular morbidity in the Netherlands: a comparison of two urban areas. Neth J Med 2005;63:309-15.

14. van Onna M, Kroon AA, Houben AJ, Koster D, Zeegers MP, Henskens LH, Plat AW, Stoffers HE, de Leeuw PW. Genetic risk of atherosclerotic renal artery disease: the candidate gene approach in a renal angiography cohort. Hypertension 2004;44:448-53.

15. Henskens LH, Spiering W, Stoffers HE, Soomers FL, Vlietinck RF, de Leeuw PW, Kroon AA. Effects of ACE I/D and AT1R-A1166C polymorphisms on blood pressure in a healthy normotensive primary care population: first results of the Hippocates study. J Hypertens 2003;21:81-6.

16. Landwehr JSTM, Akker Mvd, Metsemakers JFM, Buntinx F. Comorbidity of chronic cardiovascular disorders. A cross-sectional analysis in a large general practice population in the Netherlands. Archiv Public Health 2000;58:213-31.

17. Lamberts H, Wood M, editors. ICPC: International Classification of Primary Care. Oxford: Oxford University Press; 1987. 
18. Classification of Health Problems in Primary Care, 3rd edition. Oxford, Oxford University Press, 1983. Classification Committee of Wonca. Oxford: Oxford University Press; 1983.

19. Cifkova R, Erdine S, Fagard R, Farsang C, Heagerty AM, Kiowski W, Kjeldsen S, Lüscher T, Mallion JM, Mancia G, Poulter N, Rahn KH, Rodicio JL, Ruilope LM, van Zwieten P, Waeber B, Williams B, Zanchetti A; ESH/ESC Hypertension Guidelines Committee. Practice guidelines for primary care physicians: 2003 ESH/ESC hypertension guidelines. J Hypertens 2003;21:1779-86.

20. Knaapen AM, Ketelslegers HB, Gottschalk RW, Janssen RG, Paulussen AD, Smeets HJ, Godschalk RW, Van Schooten FJ, Kleinjans JC, Van Delft JH. Simultaneous genotyping of nine polymorphisms in xenobiotic-metabolizing enzymes by multiplex PCR amplification and single base extension. Clin Chem 2004;50:1664-8.

21. Villard E, Tiret L, Visvikis S, Rakotovao R, Cambien F, Soubrier F. Identification of new polymorphisms of the angiotensin I-converting enzyme (ACE) gene, and study of their relationship to plasma ACE levels by two-QTL segregation-linkage analysis. Am J Hum Genet 1996;58:1268-78.

22. Keavney B, McKenzie CA, Connell JM, Julier C, Ratcliffe PJ, Sobel E, Lathrop M, Farrall M. Measured haplotype analysis of the angiotensin-I converting enzyme gene. Hum Mol Genet 1998;7:1745-51.

23. Veldman BA, Spiering W, Doevendans PA, Vervoort G, Kroon AA, de Leeuw PW, Smits P. The Glu298Asp polymorphism of the NOS 3 gene as a determinant of the baseline production of nitric oxide. J Hypertens 2002;20:2023-7.

24. Després JP, Lemieux I, Bergeron J, Pibarot P, Mathieu P, Larose E, Rodés-Cabau J, Bertrand OF, Poirier $P$. Abdominal obesity and the metabolic syndrome: contribution to global cardiometabolic risk. Arterioscler Thromb Vasc Biol 2008;28:1039-49.

25. Ryan $\mathrm{DH}$. The relationship among risk factor clustering, abdominal obesity, and residual risk for cardiovascular events. Rev Cardiovasc Med 2007;8:9-16.

26. Kastelein JJ, de Groot E. Ultrasound imaging techniques for the evaluation of cardiovascular therapies. Eur Heart J 2008;29:849-58.

27. Li C, Engstrom G, Berglund G, Janzon L, Hedblad B. Incidence of ischemic stroke in relation to asymptomatic carotid artery atherosclerosis in subjects with normal blood pressure. A prospective cohort study. Cerebrovasc Dis 2008;26:297-303.

28. Tzou WS, Douglas PS, Srinivasan SR, Bond MG, Tang R, Li S, Chen W, Berenson GS, Stein JH. Distribution and predictors of carotid intima-media thickness in young adults. Prev Cardiol 2007;10:181-9.

29. Bots ML, Grobbee DE, Hofman A, Witteman JC. Common carotid intima-media thickness and risk of acute myocardial infarction: the role of lumen diameter. Stroke 2005;36:762-7.

30. Pontremoli R, Ravera M, Viazzi F, Nicolella C, Berruti V, Leoncini G, Giacopelli F, Bezante GP, Sacchi G, Ravazzolo R, Deferrari G. Genetic polymorphism of the renin-angiotensin system and organ damage in essential hypertension. Kidney Int 2000;57:561-9.

31. Zhu S, Meng QH. Association of angiotensin II type 1 receptor gene polymorphism with carotid atherosclerosis. Clin Chem Lab Med 2006;44:282-4.

32. Curnow KM, Pascoe L, White PC. Genetic analysis of the human type-1 angiotensin II receptor. Mol Endocrinol 1992;6:1113-8.

33. Martin MM, Buckenberger JA, Jiang J, Malana GE, Nuovo GJ, Chotani M, Feldman DS, Schmittgen TD, Elton TS. The human angiotensin II type 1 receptor $+1166 \mathrm{~A} / \mathrm{C}$ polymorphism attenuates microrna155 binding. J Biol Chem 2007;282:24262-9.

34. Grote K, Drexler H, Schieffer B. Renin-angiotensin system and atherosclerosis. Nephrol Dial Transplant 2004;19:770-3.

35. Spiering W, Kroon AA, Fuss-Lejeune MM, Daemen MJ, de Leeuw PW. Angiotensin II sensitivity is associated with the angiotensin II type 1 receptor $A(1166) C$ polymorphism in essential hypertensives on a high sodium diet. Hypertension 2000;36:411-6.

36. He J, Ogden LG, Vupputuri S, Bazzano LA, Loria C, Whelton PK. Dietary sodium intake and subsequent risk of cardiovascular disease in overweight adults. JANA 1999;282:2027-34.

37. Weinberger MH, Fineberg NS, Fineberg SE, Weinberger M. Salt sensitivity, pulse pressure, and death in normal and hypertensive humans. Hypertension 2001;37(2 Part 2):429-32.

38. Li Y, Thijs L, Kuznetsova T, Zagato L, Struijker-Boudier H, Bianchi G, Staessen JA. Cardiovascular risk in relation to alpha-adducin Gly460Trp polymorphism and systolic pressure: a prospective population study. Hypertension 2005;46:527-32. 
39. van Rijn MJ, Bos MJ, Yazdanpanah M, Isaacs A, Arias-Vásquez A, Koudstaal PJ, Hofman A, Witteman $\mathrm{JC}$, van Duijn CM, Breteler MM. Alpha-adducin polymorphism, atherosclerosis, and cardiovascular and cerebrovascular risk. Stroke 2006;37:2930-4.

40. Sarzani R, Cusi D, Salvi F, Barlassina C, Macciardi F, Pietrucci F, Cola G, Catalini R, Dal Fiume C, DessìFulgheri $P$, Rappelli A. The 460Trp allele of alpha-adducin increases carotid intima-media thickness in young adult males. J Hypertens 2006;24:697-703.

41. Balkestein EJ, Wang JG, Struijker-Boudier HA, Barlassina C, Bianchi G, Birkenhäger WH, Brand E, Den Hond E, Fagard R, Herrmann SM, Van Bortel LM, Staessen JA. Carotid and femoral intima-media thickness in relation to three candidate genes in a Caucasian population. J Hypertens 2002;20: 1551-61.

42. Psaty BM, Smith NL, Heckbert SR, Vos HL, Lemaitre RN, Reiner AP, Siscovick DS, Bis J, Lumley T, Longstreth WT Jr, Rosendaal FR. Diuretic therapy, the alpha-adducin gene variant, and the risk of myocardial infarction or stroke in persons with treated hypertension. JAMA 2002;287:1680-9.

43. Tobin MD, Braund PS, Burton PR, Thompson JR, Steeds R, Channer K, Cheng S, Lindpaintner K, Samani NJ. Genotypes and haplotypes predisposing to myocardial infarction: a multilocus case-control study. Eur Heart J 2004;25:459-67.

44. Poredos P. Intima-media thickness: indicator of cardiovascular risk and measure of the extent of atherosclerosis. Vasc Med 2004;9:46-54.

45. Bots ML, Grobbee DE. Intima media thickness as a surrogate marker for generalised atherosclerosis. Cardiovasc Drugs Ther 2002;16:341-51.

46. Beeks E, van der Klauw MM, Kroon AA, Spiering W, Fuss-Lejeune MJ, de Leeuw PW. Alpha-adducin Gly460Trp polymorphism and renal hemodynamics in essential hypertension. Hypertension 2004;44:419-23.

47. Leeson $C P$, Hingorani $A D$, Mullen MJ, Jeerooburkhan N, Kattenhorn M, Cole TJ, Muller DP, Lucas A, Humphries SE, Deanfield JE. Glu298Asp endothelial nitric oxide synthase gene polymorphism interacts with environmental and dietary factors to influence endothelial function. Circ Res 2002;90:1153-8.

48. Paradossi U, Ciofini E, Clerico A, Botto N, Biagini A, Colombo MG. Endothelial function and carotid intima-media thickness in young healthy subjects among endothelial nitric oxide synthase Glu298-$>$ Asp and T-786-->C polymorphisms. Stroke 2004;35:1305-9.

49. Wolff B, Braun C, Schlüter C, Grabe HJ, Popowski K, Völzke H, Lüdemann J, John U, Cascorbi I. Endothelial nitric oxide synthase Glu(298)-->Asp polymorphism, carotid atherosclerosis and intimamedia thickness in a general population sample. Clin Sci (Lond) 2005;109:475-81.

50. Foerch C, Buehler A, von Kegler S, Sitzer M. Intima-media thickness side differences are limited to the common carotid artery. Hypertension 2003;42:e17; author reply e18.

51. Ioannidis JP, Trikalinos TA, Ntzani EE, Contopoulos-loannidis DG. Genetic associations in large versus small studies: an empirical assessment. Lancet 2003;361:567-71.

52. Ginsburg GS, Shah SH, McCarthy JJ. Taking cardiovascular genetic association studies to the next level. J Am Coll Cardiol 2007;50:930-2.

53. Kastelein JJ, Akdim F, Stroes ES, Zwinderman AH, Bots ML, Stalenhoef AF, Visseren FL, Sijbrands EJ, Trip MD, Stein EA, Gaudet D, Duivenvoorden R, Veltri EP, Marais AD, de Groot E; ENHANCE Investigators. Simvastatin with or without ezetimibe in familial hypercholesterolemia. N Engl J Med 2008;358:1431-43. 


\section{Chapter 6}

THE ASSOCIATION BETWEEN ARTERIAL STIFFNESS AND THE ANGIOTENSIN

II TYPE I RECEPTOR (AII66C) POLYMORPHISM IS INFLUENCED BY THE USE OF CARDIOVASCULAR MEDICATION

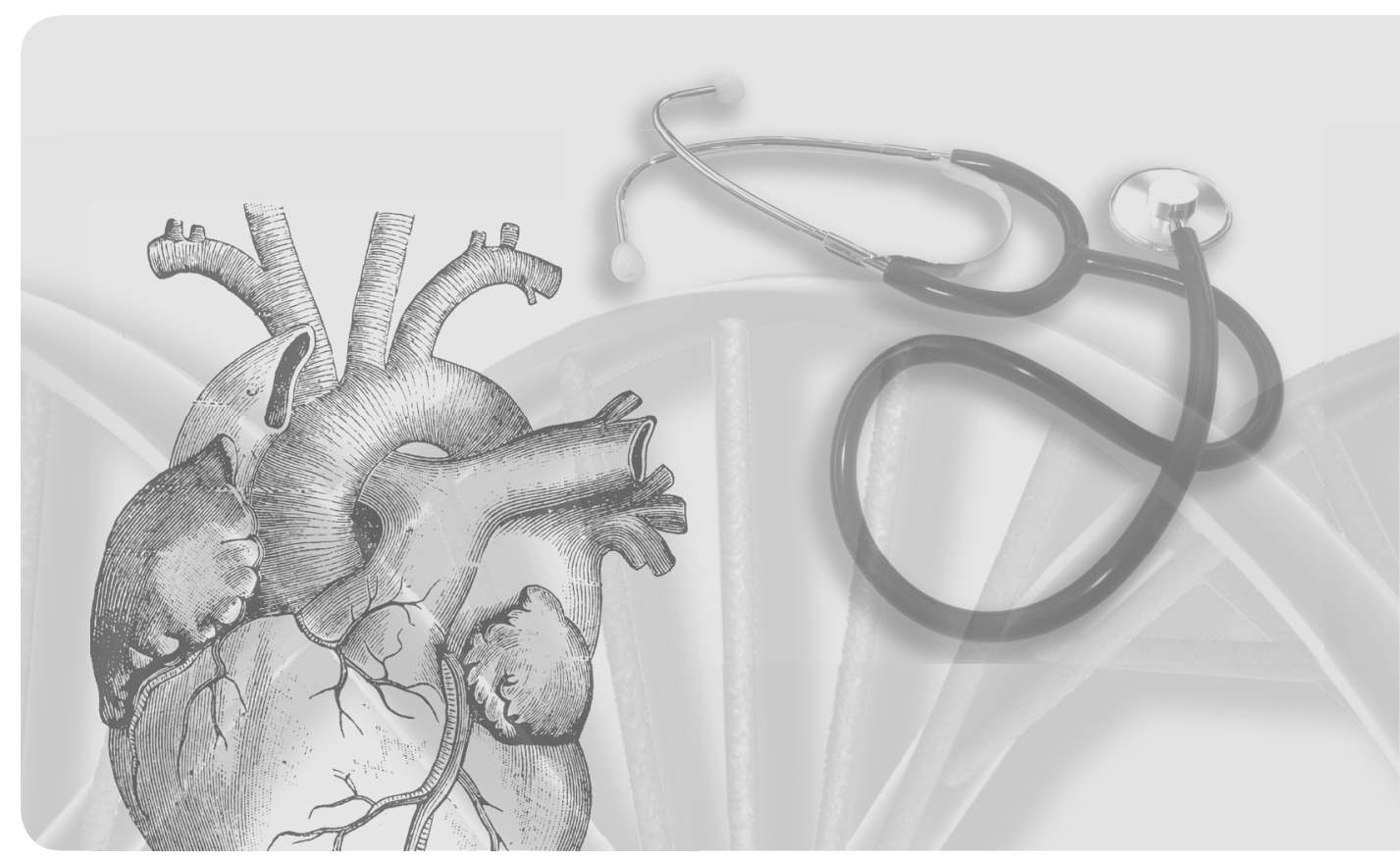

AW Plat, HEJH Stoffers, PW de Leeuw, CP van Schayck, FL Soomers, ADM Kester, K Aretz, AA Kroon Journal of Hypertension 2009;27:69-75 


\section{Abstract}

\section{Objective}

To examine in a population with a high prevalence of hypertension, the association between six cardiovascular polymorphisms, arterial stiffness and medication use.

\section{Methods}

In this cross-sectional study (HIPPOCRATES project), arterial stiffness was assessed by measuring pulse wave velocity (PWV) in 575 patients in one primary care practice. Patients were genotyped for the angiotensin II type 1 receptor (A1166C), angiotensinogen (M235T), angiotensin-converting enzyme (4656 $\mathrm{rpt}$ ), endothelial nitric oxide synthase (E298D), G-protein $\beta 3$ (C825T), and $\alpha$-adducin (G460W) polymorphisms. Linear regression analyses were performed to assess the association between polymorphisms and PWV.

\section{Results}

Thirty percent of the patients ( 273 men, 302 women) had a carotid-femoral pulse wave velocity above $12 \mathrm{~m} / \mathrm{s}$ and more than $60 \%$ of the patients had a carotid-femoral/carotid-radial PWV (CF/CR ratio) above 1. The CF/CR ratio was significantly associated with age, gender, dyslipidemia, cardiovascular medication use and pulse pressure. After correction for these covariates, multivariate linear regression analyses showed that the $C$ allele of AGTR1 was associated with a lower CF/CR ratio. This association was significantly influenced by cardiovascular medication use $(P=0.011)$, and showed a dose-allele effect, the $C F / C R$ ratio decreasing with the number of $C$ alleles $(P=0.04)$.

\section{Conclusion}

In a primary care population, this study showed an independent protective dose-allele effect for the presence of $\mathrm{C}$ alleles of the AGTR1 polymorphism on PWV. This association, which was influenced by the use of cardiovascular medication, needs further investigations to identify the underlying mechanisms. 


\section{Introduction}

The renin-angiotensin system (RAS) plays an important role in blood pressure (BP) regulation, cardiovascular cellular growth and remodelling. Many association studies have addressed the possible relationship between variant genes of the RAS with hypertension, left ventricular hypertrophy and myocardial infarction in different populations. ${ }^{1-4}$ In the HIPPOCRATES project (Hypertension: Interaction and Prevalence of POlymorphisms related to Cardiovascular Risk and the Association to Treatment Efficacy Study), three well studied polymorphisms of the RAS were determined, that is angiotensinogen [AGT (M235T)], angiotensin converting enzyme [ACE (4656 rpt $_{\text {f }}$ ], and the angiotensin II type 1 receptor [AGTR1 (A1166C)] polymorphism. Furthermore, three other polymorphisms closely aligned to the RAS were also determined, that is endothelial nitric oxide synthase [NOS3 (E298D)], G-protein $\beta 3$ subunit [GNB3 (C825T)], and $\alpha$-adducin [ADD1 (G460W)]. When HIPPOCRATES was designed, evidence in the literature for the role of these six polymorphisms in the development of cardiovascular disease (CVD) was very promising. HIPPOCRATES utilizes the population of a large general practice which is located in a region in the south-east of the Netherlands with a high burden of CVD compared with the average of the Netherlands ${ }^{5}$ and, therefore, these polymorphisms seemed very relevant for this study population. Finally, in Maastricht, the role of the RAS in the development of CVD is being studied for several years. Consequently, a complete infrastructure was available to determine these polymorphisms accurately and quickly. The overall objective of the HIPPOCRATES project is to analyse the contribution of the aforementioned polymorphisms with cardiovascular risk. We started off with a crosssectional data analysis and adopted arterial stiffness as a major surrogate marker for cardiovascular morbidity.

Increased arterial stiffness is an accepted strong independent predictor of cardiovascular risk and is associated with excess cardiovascular morbidity and mortality. ${ }^{6-8}$ Both genetic and environmental factors are responsible for structural changes in the arterial wall and progressive arterial stiffening. An index of central arterial stiffness is carotid-femoral pulse wave velocity (CF-PWV). The measurement of CF-PWV has been considered as the 'gold standard' of arterial stiffness in a recent expert consensus document. ${ }^{9}$ It is generally accepted as the simplest non-invasive, robust and reproducible method to determine aortic stiffness, and has been used in many epidemiological studies, demonstrating the predictive value of aortic stiffness for cardiovascular events ${ }^{10}$ and all-cause mortality. ${ }^{6,9}$ CF-PWV is mainly enhanced by increasing systolic and pulse pressure (PP) and, therefore, the association between CF-PWV and polymorphisms of the RAS is important to investigate. However, studies on CF-PWV and RAS polymorphisms are rather scarce. The few studies performed

thus far, showed that genetic variants of the RAS can influence the CF-PWV. ${ }^{11-14}$ Therefore, we hypothesized that in the presence of carriership of one or more rare 
alleles of the aforementioned polymorphisms, the CF-PWV values will be higher. In the present study, we investigated the association between aforementioned six polymorphisms and CF-PWV. Furthermore, we know from literature that pharmacological treatment is associated with a reduction in CF-PWV. ${ }^{6}$ Therefore, we hypothesized that in the presence of carriership of one or more rare alleles of our six polymorphisms, the CF-PWV will be lower in patients treated with cardiovascular medication. Therefore, we also investigated the influence of cardiovascular medication use on the association between our polymorphisms and CF-PWV.

\section{Methods}

\section{Study population}

All participants of the HIPPOCRATES project were recruited from one general practice in Kerkrade, The Netherlands between May 2003 and July 2005. This academic general practice takes part in the Registration Network Family Practices (RNH), which is a continuous and computerized database. All relevant health problems, including a full medical history of all cardiovascular events have been registered since $1990 .{ }^{15,16}$ Medical problems are coded according to the International Classification of Primary Care (ICPC) using the criteria of the International Classification of Health Problems in Primary Care for diagnoses. ${ }^{17,18}$ The general practice in Kerkrade has a list of approximately 4400 patients, among whom are more than 2300 patients of 40 years and older. The practice is located in a region with a high burden of CVD and, therefore, it has well implemented cardiovascular consulting hours. For many years the practice nurses conducted special cardiovascular consulting hours, to which patients are invited at least once every three months. For the HIPPOCRATES project, all known patients aged at least 40 years with CVD or hypertension, irrespective of their medication use, were invited. From the group with neither known CVD nor established hypertension, but with other cardiovascular risk factors, that is, smoking, alcohol, diabetes mellitus, hypercholesterolemia, overweight including obesity, a random 1:3 sample was taken. Of all 'healthy' patients (neither CVD, nor hypertension nor other cardiovascular risk factors), also a random 1:3 sample was taken. The initial classification was validated by a thorough assessment of the patients' records combined with additional measurements of risk factors for all patients. The total HIPPOCRATES population consisted of 803 patients (382 males, 421 females). During their first visit, participants were asked permission to measure the pulse wave velocity over the carotid-femoral (CF-PWV) and the carotid-radial (CR-PWV) route. Included patients did not differ in characteristics from those who did not consent (185 patients). PWV data of 22 patients were not included owing to premature withdrawal from the study ( 5 patients) or to poor quality of the measurements (17 patients), though again, these patients did not differ with respect to their characteristics. 
Additionally, 21 patients were excluded owing to the diagnosis of peripheral arterial occlusive disease. For the present study, 575 patients were included: 273 men and 302 women. The study was approved by the Medical Ethics Committee of the Maastricht University Medical Center. All patients gave written informed consent to participate in the study.

\section{Clinical data collection}

All clinical measurements in the HIPPOCRATES project were performed in the practice by one of the authors (AWP; first measurement) and a nurse practitioner (second, third and fourth measurement with in between periods of three months). The nurse practitioner measured weight and blood pressure. All persons were questioned on their smoking behaviour. Weight and height were measured. Body-mass index (BMI) was calculated as body weight divided by squared height. BMI values at least 27 were considered to be too high. The size of the waist was measured. BP and heart rate were measured three times per visit, after ten minutes rest in sitting position, using a sphygmomanometer. Fasting blood samples were drawn to determine serum creatinine, total cholesterol, low-density lipoprotein-cholesterol (LDL-c), high-density lipoprotein-cholesterol (HDL-c), serum triglycerides and glucose levels and were analyzed in one regional laboratory. Microalbuminuria was determined semiquantitatively in a first morning urine sample.

\section{Treatment status}

The computerized medication lists were analyzed for antihypertensive, hypolipidemic, antiplatelet and antidiabetic medication. Furthermore, all persons were questioned about their medication use at the start of the study. Cardiovascular medication was based on the anatomical therapeutic classification (ATC) and defined as having at least one prescription of antihypertensive (ATC level 2: C02, C03, C04, C07, C08, C09), hypolipidemic (ATC level 2: C10), or antiplatelet (ATC level 5: B01AC) medication in the selected study period. This definition was chosen since these drugs are most frequently prescribed for the prevention of CVD in primary care. Antidiabetics were defined as having at least one prescription of A10 (ATC level 2) in the study period.

\section{Definitions}

Hypertension was defined as a systolic blood pressure (SBP) at least $140 \mathrm{mmHg}$ diastolic blood pressure (DBP) at least $90 \mathrm{mmHg}$ or both according to the Guidelines for Hypertension specified by the European Society of Hypertension. ${ }^{19}$ PP was calculated as the difference between SBP and DBP. The presence of dyslipidemia was defined as total cholesterol to HDL-C ratio exceeding 4.0. Diabetes mellitus was considered to be present in case of fasting plasma glucose levels above $6.9 \mathrm{mmol} / \mathrm{l}$. Creatinine values higher than $115 \mu \mathrm{mol} / \mathrm{l}$ (men) or $107 \mu \mathrm{mol} / \mathrm{l}$ (women) were 
considered to be a risk factor for CVD. Creatinine clearance was calculated by the Cockcroft-Gault formula. ${ }^{20}$ Microalbuminuria was defined as albumin excretion above $20 \mathrm{mg} / \mathrm{l}$.

\section{Arterial stiffness}

The PWV measurements were performed at the circulation laboratory of the Department of Internal Medicine of the Maastricht University Medical Center. PWV was recorded by Complior (Artech, Pantin, France), a PWV measurement system for arterial stiffness evaluation. This system gives an automated measurement of PWV for two arterial segments simultaneously, with dedicated pulse wave sensors. ${ }^{9}$ This system determines the transit time the wave of dilatation (propagated in the arterial wall as a result of the pressure wave generated by contraction of the left ventricle) takes to arrive at a site over a known distance. ${ }^{9}$ After resting in a supine position for 15 minutes in a quiet, temperature-controlled room, participants were measured by a trained investigator (AWP), who obtained PWV measurements in two arterial segments simultaneously, that is carotid-radial and carotid-femoral. In order to enhance reproducibility, PWV was measured four times and mean values were calculated for both arterial segments. ${ }^{9}$

CF-PWV evaluates a mixed elastic and muscular segment of the arterial tree, whereas the CR-PWV evaluates a predominant muscular segment. The effect of aging has been shown to be more pronounced in the proximal, more elastic, and less muscular arteries. $^{21}$ Expressing PWV as a ratio of the CF/CR PWV improves the relationship with age, as has been demonstrated by Cameron et al. ${ }^{22}$ It is for this reason that we expressed our data as such, using the ratio of CF-PWV to CR-PWV. A CF-PWV $>12 \mathrm{~m} / \mathrm{s}$ and a CF/CR ratio above 1 were considered as threshold values. ${ }^{7}$ Consequently, values above these thresholds were considered to be increased. All patients were measured at the same period of the day, that is the afternoon.

\section{Genetic analyses}

The various polymorphisms were determined at the Cardiovascular Genotyping (CAGT) laboratory of the Department of Internal Medicine of the Maastricht University Medical Center. DNA was extracted from whole blood with the use of the QIAmp Blood Kit (Qiagen Inc., Venlo, the Netherlands). Genotyping of the angiotensin II type 1 receptor [AGTR1 (A1166C)], angiotensinogen [AGT (M235T)], angiotensin converting enzyme [ACE $\left(4656_{\mathrm{rpt}}\right)$ ], endothelial nitric oxide synthase [NOS3 (E298D)], G-protein $\beta 3$ subunit [GNB3 (C825T)], and $\alpha$-adducin [ADD1 (G460W)] polymorphisms was performed with a multiplex single base extension (SBE) assay (Multiplex SNaPshot, Applied Biosystems, Foster City, California, USA) similar to previously published protocols. ${ }^{23}$ Briefly, in the first stage, a multiplex PCR is carried out to amplify the gene fragments that contain the polymorphisms. In the second stage, the polymorphic positions are interrogated by a SBE reaction using fluorescently labeled 
ddNTPs. The oligos used for the single base extension have specific lengths, varying from 22-50 nt. After the SBE assay, the fragments are size-resolved on an ABI3100 Genetic Analyser (Applied Biosystems): the size of the peaks identifies the locus (e.g. ADD1) and the color of the peak(s) identifies the genotype (e.g. Gly/Trp). Raw data were analysed with Genescan Analysis software ( $v 3.7$ ), then genotypes were scored independently by two researchers and entered in the database. In 27 patients, a second analysis was necessary to obtain all the genotypes. The ACE (I/D) polymorphism was determined by detecting $A_{C E_{4656+C T}}$ observed on the SNaPshot as ACE $\left(4656_{\text {rpt }}\right)$. The use of this SNaPshot method does not allow the direct determination of the insertion/deletion polymorphism. The $\mathrm{ACE}_{4656+\mathrm{CT}}$ polymorphism in the $3^{\prime}$-untranslated region of the ACE gene consists of a repetition of two or three CT dinucleotides and is in complete linkage disequilibrium with ACE (I/D). ${ }^{24,25}$ The multiplex assay was validated on a set of 100 DNA samples that had previously been genotyped with an alternative technique; this technique concerned a multilocus genotyping assay for candidate markers of CVD risk (Roche Molecular systems Inc., Alameda, California, USA) and has been described in detail previously. ${ }^{26}$ Only four samples gave a discordant result for the NOS3 polymorphism. All other genotypes were concordant.

\section{Polymorphisms}

In short, the presumed function of the included polymorphisms is as follows. Patients homozygous for the C allele of the AGTR1 polymorphism, have increased sensitivity to angiotensin II (AngII) and this may in combination with the DD genotype of the ACE (I/D) polymorphism, lead to an increased risk of cardiovascular complications. ${ }^{27,28}$ The T allele of the AGT polymorphism is associated with high plasma levels of AGT and increased responsiveness to Ang II. $^{4}$ In the presence of a two allele of the $A C E_{4656+C T}$ polymorphism, comparable to the $D$ allele of the I/D polymorphism, increased ACE levels have been found, which have been associated with an increased risk for cardiovascular complications. ${ }^{2}$ The NOS3 (E298D) polymorphism is associated with reduced NO production in endothelial cells of the arterial wall, inducing elevation of the arterial pressure. ${ }^{26,29}$ The T allele of the GNB3 (C825T) polymorphism is associated with increased intracellular signal transduction and this leads to stimulation of the $\mathrm{Na}^{+} / \mathrm{H}^{+}$exchanger. ${ }^{30}$ The ADD1 (G460W) polymorphism is of interest because the rare allele is also associated with increased $\mathrm{Na}^{+}$transport, though here the $\mathrm{Na}^{+} / \mathrm{K}^{+}$ exchanger is stimulated. ${ }^{31}$ Both polymorphisms are associated with chronic volume expansion and, consequently, with related cardiovascular complications. ${ }^{31,32}$

\section{Statistical analyses}

Statistical analyses were performed by using SPSS statistical software, version 14.0 (SPSS, Inc., Chicago, Illinois, USA). A $P$-value of 0.05 or less was considered statistically significant. Genotype and allele frequencies were calculated to test the Hardy- 
Weinberg equilibrium. Furthermore, allele frequencies were analyzed using chi-square tests.

\section{Multivariate linear regression analyses}

Because of the skewed distribution of CF/CR ratio, log transformation was applied to achieve normality for further analyses. Univariate and multivariate linear regression analyses were performed to evaluate the relationship between polymorphisms and $\mathrm{CF} / \mathrm{CR}$ ratio. For that purpose, dummy variables were created using the homozygous wild-type genotype as reference category. Age and gender, both demographic variables, were incorporated in both the univariate as well as in the multivariate linear regression analyses. As indicated, we selected control individuals from different groups. Therefore, in the regression analyses we had to adjust for this selection and dummy variables had to be created using the normotensive group without cardiovascular risk factors as the reference category. Adjustment for potential confounders was performed by incorporating age, gender, dyslipidemia, cardiovascular medication and PP into these models (enter procedure). The simultaneous contribution of the six polymorphisms to the prediction of increased $\mathrm{CF} / \mathrm{CR}$ ratio was determined, using the overall $F$-test. If two or more polymorphisms reached statistical significance, interactions (effect modification) between two polymorphisms with respect to CF/CR ratio were assessed. Again linear regression analysis was used, in which the alleles at risk, the interaction term between the alleles and the other covariates were incorporated. If an interaction became statistically significant, the model was explored further.

If one or more polymorphisms reached statistical significance, interaction between cardiovascular medication use and the relevant polymorphism with respect to CF/CR ratio was assessed. Again, linear regression analysis (method: enter) was used, in which the alleles at risk, the interaction between cardiovascular medication use and the alleles and the other covariates were incorporated. If an interaction became statistically significant, the model was explored further.

\section{Results}

\section{Characteristics of the participants}

Characteristics of the study population are summarized in Table 6.1. Most patients were overweighted hypertensives with dyslipidemia. There were sligtly more women than men and their mean age was 60 years. Overall, $30 \%$ of the patients had a CF-PWV above $12 \mathrm{~m} / \mathrm{s}$ and more than $60 \%$ of the patients had a CF/CR ratio above 1 . 


\section{Allele frequencies}

Genotype and allele frequencies of all polymorphisms were in Hardy-Weinberg equilibrium. For all six polymorphisms, no statistically significant differences in allele frequencies were found.

Table 6.1 Characteristics of the study population $(n=575)$.

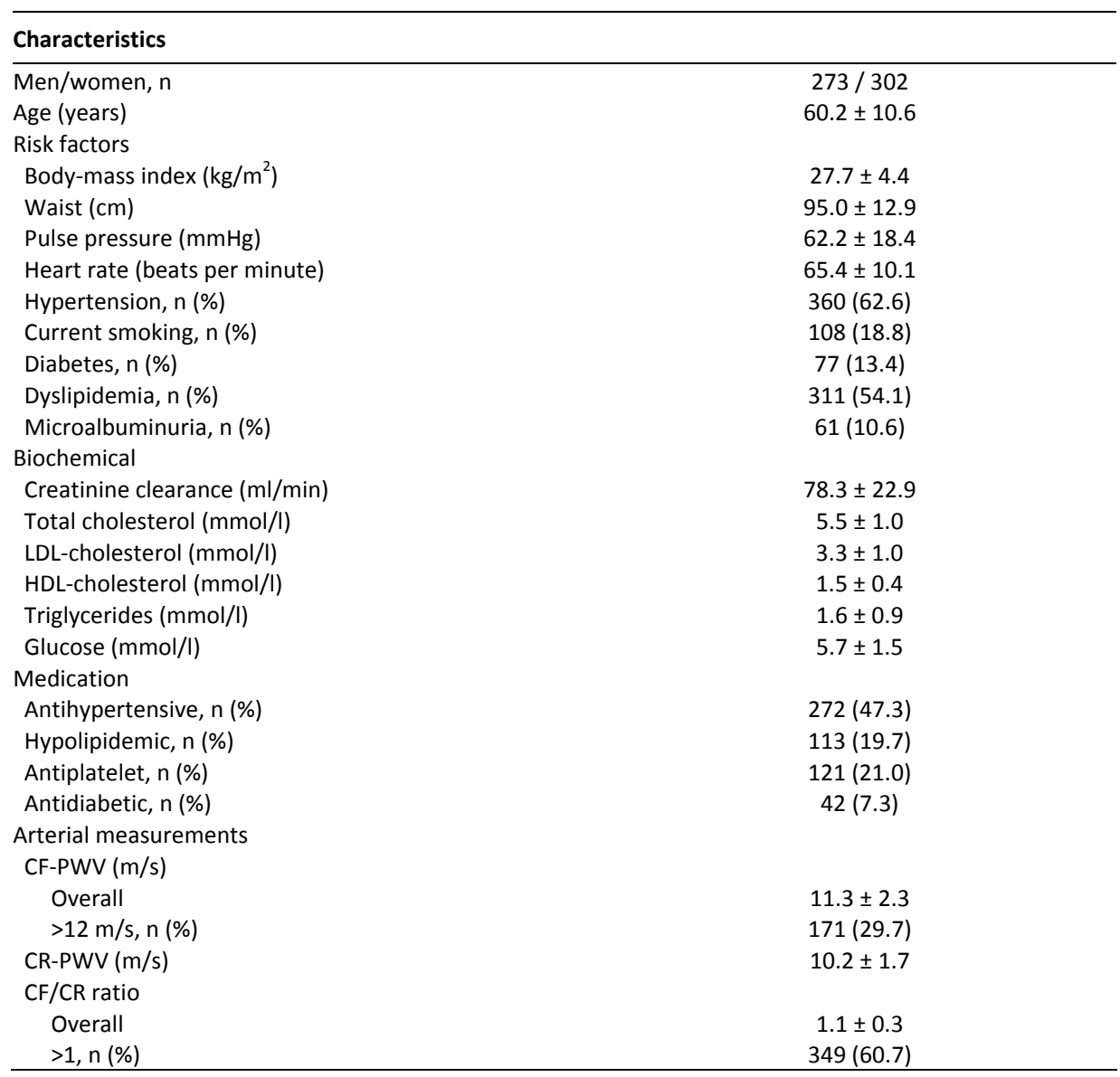

Values are given as mean \pm SD or as number of patients (with corresponding percentages between brackets); creatinine clearance by the Cockcroft-Gault formula; HDL, high-density lipoprotein; LDL, low-density lipoprotein; CF-PWV, carotidfemoral pulse wave velocity; CR-PWV, carotid-radial pulse wave velocity; CF/CR ratio, carotid-femoral to carotid-radial pulse wave velocity ratio.

\section{Arterial stiffness, cardiovascular polymorphisms and treatment status}

Stepwise regression analyses identified age, gender, dyslipidemia, cardiovascular medication use and PP as significant co-variables for the relationship between the six polymorphisms and the CF/CR ratio. In the univariate linear regression analyses (Table 
6.2), an association was found between carriership (dominant model) of the $C$ allele of AGTR1 and the $C F / C R$ ratio $(P=0.014)$. However, in the multivariate linear regression analyses (Table 6.2), the simultaneous contribution of the six polymorphisms to the change in the $C F / C R$ ratio (overall $F$-test) reached no statistically significance $(P=0.107)$. We assessed an independent statistically significant association between AGTR1 and the $C F / C R$ ratio $(P=0.011)$. It appeared that the $C F / C R$ ratio decreased by $4 \%$, if patients were carrier of the $C$ allele of AGTR1. For all other polymorphisms, carriership of the rare allele was not statistically significant associated with the CF/CR ratio. Analyses based on the assessments of the CF-PWV showed virtually the same results (data not shown).

Table 6.2 Linear regression model for six polymorphisms (dominant model) and carotid-femoral to carotid-radial ratio for all patients.

\begin{tabular}{|c|c|c|c|c|c|}
\hline \multirow[t]{2}{*}{ Polymorphism } & \multirow[t]{2}{*}{ Genotype* } & \multicolumn{2}{|c|}{ Univariate analysis $(95 \% \mathrm{Cl})^{\ddagger}$} & \multicolumn{2}{|c|}{ Multivariate analysis $(95 \% \mathrm{Cl})^{\ddagger \dagger}$} \\
\hline & & Overall & $P$ & Overall & $P$ \\
\hline AGTR1 (A1166C) & $C^{*}$ & $0.96(0.93-0.99)$ & 0.014 & $0.96(0.93-0.99)$ & 0.011 \\
\hline AGT (M235T) & $\mathrm{T}^{*}$ & $0.99(0.96-1.03)$ & 0.697 & $1.00(0.97-1.03)$ & 0.883 \\
\hline ACE $\left(4656_{\text {rpt }}\right)$ & $\mathrm{G}^{*}$ & $1.00(0.96-1.04)$ & 0.981 & $1.00(0.96-1.04)$ & 0.939 \\
\hline NOS3 (E298D) & $\mathrm{T}^{*}$ & $0.97(0.93-1.02)$ & 0.221 & $0.97(0.92-1.01)$ & 0.154 \\
\hline GNB3 (C825T) & $T^{*}$ & $1.00(0.97-1.04)$ & 0.792 & $1.00(0.97-1.04)$ & 0.825 \\
\hline ADD1 (G460W) & $\mathrm{T}^{*}$ & $0.99(0.96-1.03)$ & 0.725 & $1.00(0.96-1.03)$ & 0.744 \\
\hline
\end{tabular}

* The wild-type genotypes were used as reference category; PWV, pulse wave velocity; ${ }^{\ddagger}$ Data presented as unstandardized $\beta$ coefficient $(95 \% \mathrm{Cl})$ : the $\beta$ represents the change in carotid-femoral to carotid-radial ratio for each unit change in continuous risk factors and for a change (absent or present) in dichotomous risk factors; $\mathrm{Cl}$ denotes $95 \%$ confidence interval; ${ }^{+}$Multivariate adjustment was performed for age, gender, dyslipidemia, cardiovascular medication use and PP.

When comparing the CF/CR ratios for the whole study population, as well as for patients that were on cardiovascular medication, a statistically significant trend $(P=0.04)$ was found for the ratio to decrease with the number of $C$ alleles (codominant model, Figure 6.1). Furthermore, we performed an explorative analysis (dominant model) to evaluate the influence of cardiovascular medication use on the association between the AGTR1 (A1166C) polymorphism and the CF/CR ratio. The interaction between cardiovascular medication use and the AGTR1 (A1166C) polymorphism was statistically significant $(P=0.04)$. Because the interaction term was statistically significant, we performed a stratified analysis to explore the direction of the effect. The results of these analyses are presented in Figure 6.2. This figure shows that in patients treated with cardiovascular medication the $C$ allele of AGTR1 polymorphism is also significantly associated with a lower $C F / C R$ ratio $(P=0.011$, overall $F$-test $(P=0.078)$.), whereas no statistically significant association was observed in untreated patients. Post-hoc analyses of the different medication groups separately showed for all groups a protective association of the $C$ allele of AGTR1 with the CF/CR ratio. However, only for the $\beta$-blockers statistical significance was reached $(P=0.006)$, overall F-test $(P=0.03)$. 


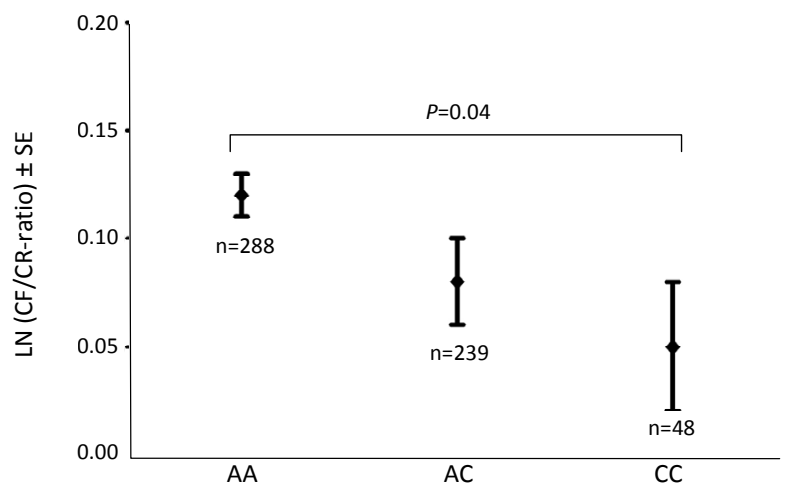

Genotype of the AGTR1 (A1166C) polymorphism

Figure 6.1 Carotid-femoral to carotid-radial pulse wave velocity ratio (log-transformed values) in the whole study population, according to the AGTR1 (A1166C) polymorphism. The observed differences in $C F / C R$ ratio are statistically significant $(P=0.04)$. For each allele combination the number of patients is depicted. Values are unadjusted means \pm standard error.

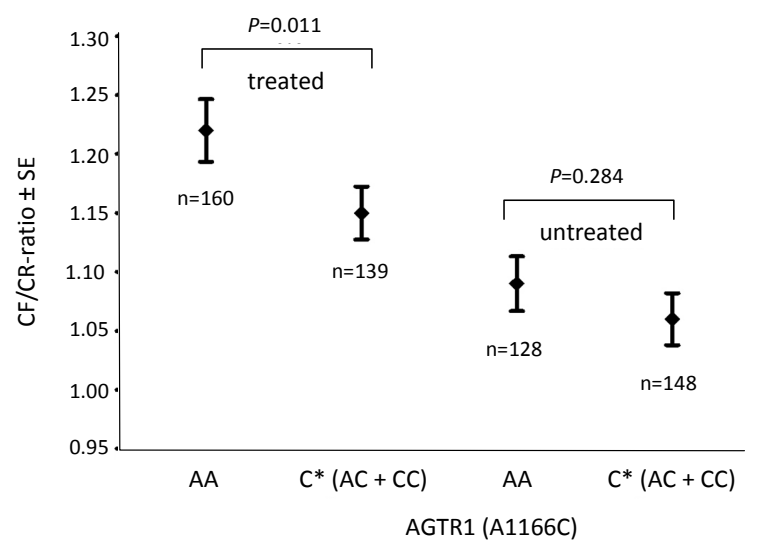

Figure 6.2 Carotid-femoral to carotid-radial pulse wave velocity ratio for carriership of the AGTR1 (A1166C) polymorphism. The observed difference in CF/CR ratio between patients treated with cardiovascular medication with $A A$ genotype and treated carriers of the $C$ allele is statistically significant $(P=0.011)$. For each combination the number of patients is indicated. Values are unadjusted means \pm standard error. 


\section{Discussion}

In the present study, we found a statistically significant protective association of the Callele of AGTR1 (A1166C) with PWV $(P=0.011)$ for patients in a primary care population. This effect was independent of age, gender, dyslipidemia, cardiovascular medication use and PP. Explorative analyses showed furthermore that patients treated with cardiovascular medication had a significantly lower CF/CR ratio in the presence of $\mathrm{C}$ alleles, of which the latter seemed to show a dose-allele effect.

\section{Arterial stiffness, angiotensin II type I receptor polymorphism and treatment status}

Angiotensin II plays a key role through the angiotensin II type I receptor in blood pressure regulation, cardiovascular cellular growth and remodelling. So, the AGTR1 polymorphism of the AGTR1 gene is, at least theoretically, a good candidate for an association with stiffening of the large arteries by inducing vascular remodelling. Indeed, our finding of an independent association of the AGTR1 (A1166C) polymorphism with CF-PWV is in accordance with the results of three previous studies. ${ }^{11,12,14}$ We found, like the study performed by Gardier et al., but in contrast to Benetos et al., that AA homzygous patients had a higher CF-PWV. ${ }^{14}$ Participants of our study were mainly overweight hypertensive patients from a primary care practice, whereas the patients in the study of Gardier et al. were retrieved from a hospital cardiology department with mainly severe or resistant hypertension. Benetos et al. included in his study never-treated hypertensives, retrieved from a hospital hypertension department. In our population, mainly antihypertensives were used. So, it can be argued that antihypertensive medication decreased arterial stiffness by a pressure-dependent effect, in particular in those patients with an increased CF-PWV in the untreated situation. ${ }^{33}$ Our analyses seem to confirm this. Moreover, post-hoc analyses of the different medication groups separately pointed in the same direction for all regression coefficients, that is, a protective association of the C allele of AGTR1 with the $C F / C R$ ratio. However, only for the $\beta$-blockers was statistical significance reached. One might argue that our results were confounded by disease severity: patients with most prominent risk factors were treated more intensively. First, our results were independent of dyslipidemia and PP. Second, the treatment intensity did not seem to play a role, as the number of drug classes was not significantly different among treated patients with the AA genotype versus those with the $C$ allele carriership.

The assessed association of the AGTR1 (A1166C) polymorphism needs further explanation. In a recent report, left ventricular cardiac stiffness was increased in homozygous $A$ allele carriers compared to $C^{*}(A C+C C)$ carriers in hypertensive patients, suggesting that chronic exposure to angiotensin II might induce, in 
hypertensive patients with A allele, an imbalance between collagen synthesis and degradation. ${ }^{34}$ An alternative explanation for the lower CF/CR ratio in the $\mathrm{C}$ allele carriers might be that the $\mathrm{C}$ allele is associated with an increased angiotensin IIinduced nitric oxide (NO) release, mediated in endothelial cells by AGTR1 receptors and, thus, counterbalancing the direct vasoconstrictive effect of Ang II on the smooth muscle. ${ }^{35,36}$ However, such hypotheses require further confirmation in other studies. Some limitations of the present study should be acknowledged. First, the AGTR1 (A1166C) polymorphism is probably not a functional one, because the AGTR1 polymorphisms is located in a noncoding region of the chromosome $3 q 22^{37}$ and, therefore, the amino-acid sequence of the receptor is not altered. It is possible that the AGTR1 polymorphism is in linkage disequilibrium with an unidentified functional variant of the AGTR1 gene, or, alternatively, the polymorphism could be in linkage disequilibrium with a nearby gene, which is responsible for the association with the $\mathrm{CF} / \mathrm{CR}$ ratio. Nevertheless, others and we have shown that this polymorphism, that is, the $\mathrm{C}$ allele, is associated with an increased sensitivity to angiotensin $\mathrm{II}^{28}$ Another limitation of this study is that we compared a recessive model of inheritance of the A allele in AA versus $C^{*}(A C+C C)$ carriers. This choice was made on the basis of results of other studies, though we realize this choice is arbitrary. Another approach would have been to analyse our data with a codominant model, therefore, we have shown the analysis presented in Figure 6.1. Finally, we realize that our design is crosssectional. This implicates two major problems. First of all, the CF-PWV is influenced by cardiovascular medication, and secondly, channeling plays an important role, that is, the most severe cardiovascular patients are treated more intensively. In a crosssectional design, the contribution of these two factors can not be distinguished and, therefore, our findings should be viewed as hypothesis generating and require further confirmation in prospective epidemiological studies. Nevertheless, our study has also a unique aspect. As compared to previous studies, we used a relatively unselected population from primary care. Results from studies among unselected populations may lead to better cardiovascular risk stratification.

In conclusion, this study shows that in this population a statistically significant relationship exists between the AGTR1 polymorphism, arterial stiffness and cardiovascular medication. Even though the underlying mechanisms have yet to be elucidated, these data suggest that the AGTR1 gene, or a yet unidentified gene locus in linkage disequilibrium with AGTR1 (A1166C) polymorphism, may be a genetic determinant of arterial stiffness. 


\section{References}

1. Kitsios G, Zintzaras E. Genetic variation associated with ischemic heart failure: a HuGE review and meta-analysis. Am J Epidemiol 2007;166:619-33.

2. Sayed-Tabatabaei FA, Oostra BA, Isaacs A, van Duijn CM, Witteman JC. ACE polymorphisms. Circ Res 2006;98:1123-33.

3. Dickson $M E$, Sigmund $C D$. Genetic basis of hypertension: revisiting angiotensinogen. Hypertension 2006;48:14-20.

4. Visvikis-Siest S, Marteau JB. Genetic variants predisposing to cardiovascular disease. Curr Opin Lipidol 2006;17:139-51.

5. Plat AW, te Wierik MJ, Kroon AA, Schouten HJ, van den Akker M, van Schayck CP, de Leeuw PW, Hajema KJ, Stoffers HE. Regional differences in cardiovascular risk factor profile cannot fully explain differences in cardiovascular morbidity in the Netherlands: a comparison of two urban areas. Neth J Med 2005;63:309-15.

6. Khoshdel AR, Carney SL, Nair BR, Gillies A. Better management of cardiovascular diseases by pulse wave velocity: combining clinical practice with clinical research using evidence-based medicine. Clin Med Res 2007;5:45-52.

7. Khoshdel AR, Thakkinstian A, Carney SL, Attia J. Estimation of an age-specific reference interval for pulse wave velocity: a meta-analysis. J Hypertens 2006;24:1231-7.

8. Laurent S, Boutouyrie P, Asmar R, Gautier I, Laloux B, Guize L, Ducimetiere P, Benetos A. Aortic stiffness is an independent predictor of all-cause and cardiovascular mortality in hypertensive patients. Hypertension 2001;37:1236-41.

9. Laurent S, Cockcroft J, Van Bortel L, Boutouyrie P, Giannattasio C, Hayoz D, Pannier B, Vlachopoulos C, Wilkinson I, Struijker-Boudier H; European Network for Non-invasive Investigation of Large Arteries. Expert consensus document on arterial stiffness: methodological issues and clinical applications. Eur Heart J 2006;27:2588-605.

10. Blacher J, Asmar R, Djane S, London GM, Safar ME. Aortic pulse wave velocity as a marker of cardiovascular risk in hypertensive patients. Hypertension 1999;33:1111-7.

11. Benetos A, Topouchian J, Ricard S, Gautier S, Bonnardeaux A, Asmar R, Poirier O, Soubrier F, Safar M, Cambien $\mathrm{F}$. Influence of angiotensin II type 1 receptor polymorphism on aortic stiffness in nevertreated hypertensive patients. Hypertension 1995;26:44-7.

12. Benetos A, Gautier S, Ricard S, Topouchian J, Asmar R, Poirier O, Larosa E, Guize L, Safar M, Soubrier $\mathrm{F}$, Cambien F. Influence of angiotensin-converting enzyme and angiotensin II type 1 receptor gene polymorphisms on aortic stiffness in normotensive and hypertensive patients. Circulation 1996;94:698-703.

13. Lajemi M, Labat C, Gautier S, Lacolley P, Safar M, Asmar R, Cambien F, Benetos A. Angiotensin II type 1 receptor-153A/G and $1166 \mathrm{~A} / \mathrm{C}$ gene polymorphisms and increase in aortic stiffness with age in hypertensive subjects. J Hypertens 2001;19:407-13.

14. Gardier S, Vincent M, Lantelme P, Rial MO, Bricca G, Milon H. A1166C polymorphism of angiotensin II type 1 receptor, blood pressure and arterial stiffness in hypertension. J Hypertens 2004;22:2135-42.

15. Landwehr JSTM, Akker Mvd, Metsemakers JFM, Buntinx F. Comorbidity of chronic cardiovascular disorders. A cross-sectional analysis in a large general practice population in the Netherlands. Archiv Public Health 2000;58:213-31.

16. Metsemakers JF, Knottnerus JA, van Schendel GJ, Kocken RJ, Limonard CB. Unlocking patients' records in general practice for research, medical education and quality assurance: the Registration Network Family Practices. Int J Biomed Comput 1996;42:43-50.

17. Lamberts $\mathrm{H}$, Wood $\mathrm{M}$, editors. ICPC: International Classification of Primary Care. Oxford: Oxford University Press; 1987.

18. Classification of Health Problems in Primary Care, 3rd edition. Oxford, Oxford University Press, 1983.Classification Committee of Wonca. Oxford: Oxford University Press; 1983.

19. Cifkova R, Erdine S, Fagard R, Farsang C, Heagerty AM, Kiowski W, Kjeldsen S, Lüscher T, Mallion JM, Mancia G, Poulter N, Rahn KH, Rodicio JL, Ruilope LM, van Zwieten P, Waeber B, Williams B, Zanchetti A; ESH/ESC Hypertension Guidelines Committee. Practice guidelines for primary care physicians: 2003 ESH/ESC hypertension guidelines. J Hypertens 2003;21:1779-86. 
20. Cockcroft DW, Gault MH. Prediction of creatinine clearance from serum creatinine. Nephron 1976; 16:31-41.

21. van der Heijden-Spek JJ, Staessen JA, Fagard RH, Hoeks AP, Boudier HA, van Bortel LM. Effect of age on brachial artery wall properties differs from the aorta and is gender dependent: a population study. Hypertension 2000;35:637-42.

22. Cameron JD, Bulpitt CJ, Pinto ES, Rajkumar C. The aging of elastic and muscular arteries: a comparison of diabetic and nondiabetic subjects. Diabetes Care 2003;26:2133-8.

23. Knaapen AM, Ketelslegers HB, Gottschalk RW, Janssen RG, Paulussen AD, Smeets HJ, Godschalk RW, Van Schooten FJ, Kleinjans JC, Van Delft JH. Simultaneous genotyping of nine polymorphisms in xenobiotic-metabolizing enzymes by multiplex PCR amplification and single base extension. Clin Chem 2004;50:1664-8.

24. Villard E, Tiret L, Visvikis S, Rakotovao R, Cambien F, Soubrier F. Identification of new polymorphisms of the angiotensin I-converting enzyme (ACE) gene, and study of their relationship to plasma ACE levels by two-QTL segregation-linkage analysis. Am J Hum Genet 1996;58:1268-78.

25. Keavney B, McKenzie CA, Connell JM, Julier C, Ratcliffe PJ, Sobel E, Lathrop M, Farrall M. Measured haplotype analysis of the angiotensin-I converting enzyme gene. Hum Mol Genet 1998;7:1745-51.

26. Veldman BA, Spiering W, Doevendans PA, Vervoort G, Kroon AA, de Leeuw PW, Smits P. The Glu298Asp polymorphism of the NOS 3 gene as a determinant of the baseline production of nitric oxide. J Hypertens 2002;20:2023-7.

27. Tiret L, Bonnardeaux A, Poirier O, Ricard S, Marques-Vidal P, Evans A, Arveiler D, Luc G, Kee F, Ducimetière $P$, et al. Synergistic effects of angiotensin-converting enzyme and angiotensin-II type 1 receptor gene polymorphisms on risk of myocardial infarction. Lancet 1994;344:910-3.

28. Spiering W, Kroon AA, Fuss-Lejeune MM, Daemen MJ, de Leeuw PW. Angiotensin II sensitivity is associated with the angiotensin II type 1 receptor $A(1166) C$ polymorphism in essential hypertensives on a high sodium diet. Hypertension 2000;36:411-6.

29. Casas JP, Cavalleri GL, Bautista LE, Smeeth L, Humphries SE, Hingorani AD. Endothelial nitric oxide synthase gene polymorphisms and cardiovascular disease: a HuGE review. Am J Epidemiol 2006;164: 921-35.

30. Zeltner R, Delles C, Schneider M, Siffert W, Schmieder RE. G-protein beta(3) subunit gene (GNB3) $825 \mathrm{~T}$ allele is associated with enhanced renal perfusion in early hypertension. Hypertension 2001; 37:882-6.

31. Manunta P, Bianchi G. Low-salt diet and diuretic effect on blood pressure and organ damage. J Am Soc Nephrol 2004;15 Suppl 1:S43-6.

32. Siffert W. G protein polymorphisms in hypertension, atherosclerosis, and diabetes. Annu Rev Med 2005;56:17-28.

33. Asmar RG, London GM, O'Rourke ME, Safar ME. Improvement in blood pressure, arterial stiffness and wave reflections with a very-low-dose perindopril/indapamide combination in hypertensive patient: a comparison with atenolol. Hypertension 2001;38:922-6.

34. Díez J, Laviades C, Orbe J, Zalba G, López B, González A, Mayor G, Páramo JA, Beloqui O. The A1166C polymorphism of the AT1 receptor gene is associated with collagen type I synthesis and myocardial stiffness in hypertensives. J Hypertens 2003;21:2085-92.

35. Pueyo ME, Arnal JF, Rami J, Michel JB. Angiotensin II stimulates the production of NO and peroxynitrite in endothelial cells. Am J Physiol 1998;274:C214-20.

36. Bayraktutan U. Effects of angiotensin II on nitric oxide generation in growing and resting rat aortic endothelial cells. J Hypertens 2003;21:2093-101.

37. Curnow KM, Pascoe L, White PC. Genetic analysis of the human type-1 angiotensin II receptor. Mol Endocrinol 1992;6:1113-8. 


\section{Chapter 7}

FAMILY HISTORY OF COMMON DISEASES AS GENETIC TOOL IN PRIMARY CARE: WHAT IS THE EVIDENCE? A SYSTEMATIC REVIEW

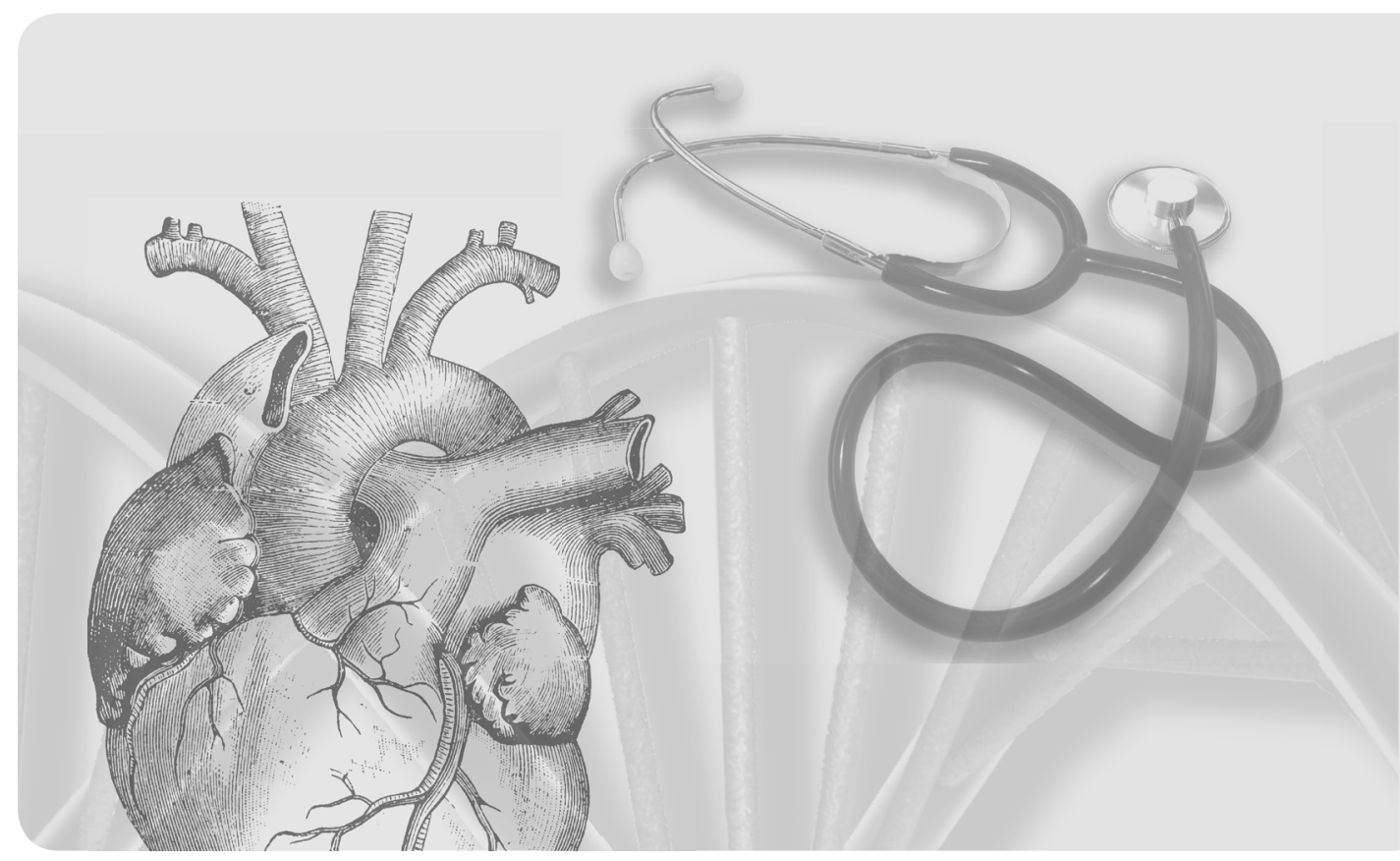

AW Plat, AA Kroon, CP van Schayck, PW de Leeuw, HEJH Stoffers 


\section{Abstract}

\section{Objective}

To summarize the evidence for the use of comprehensive family history taking for common, multifactorial diseases in primary health care.

\section{Design}

Systematic review of Medline (1966-2008), Embase (1986-2008) and Cochrane Library (until August 2008).

\section{Methods}

Search terms reflected 'primary care', 'family history' and 'genetics'. Included were original research papers on multifactorial disorders investigating family history taking in primary care. Given the heterogeneity of the studies, outcomes are presented in a qualitative way.

\section{Results}

Twenty-seven papers were identified: nine studies on primary care physicians' opinions, eight studies on current practice, seven studies on the development of family history tools, and three studies on the patient perspective. The general opinion that taking a family history is the task of the primary care physician was only partly confirmed by observational studies of consultations and analyses of medical records: wide variability, low regular update. Despite various efforts, the development of feasible, reproducible and valid family history tools is as yet unsatisfactory. Patient-doctor differences in perception of the meaning of a positive family history (for cancer, cardiovascular disease or diabetes) may cause miscommunication.

\section{Conclusion}

There is a need for research into feasible and high quality tools for detailed family history taking for multifactorial disorders in primary care. 


\section{Introduction}

Advances in genetic knowledge and the development of genetic tests offer a great promise for health care. The promise is that individualized 'genetic risk profiles' will enable tailored pharmacotherapy, tailored life style modification (like smoking cessation, diet measures) and tailored prevention of chronic, multifactorial diseases like cardiovascular disease (CVD), cancer, asthma, COPD, dementia, depression or addiction disorders. However, current knowledge of specific associations of polymorphisms and multifactorial diseases ('genetic tests') still has limited added predictive value. ${ }^{1}$

On the other hand, genetic information is hidden in the medical family history. Detailed knowledge of the medical family history could be most informative for detecting familial disease patterns, assessing the clinical significance of these patterns ('risk') and consequently use it in preventive and curative care. This hypothesis has led to new interest - as expressed in editorials and descriptive reviews - in the use of a comprehensive medical family history as a tool for primary and secondary prevention of chronic multifactorial diseases. ${ }^{2-9}$ Moreover, family history promises to serve as a critical element to identify candidates for genetic testing or targeted medical care. Given the community orientation of family physicians (primary care physicians, general practitioners), one can argue that they are in an ideal position to track subjects at risk and consequently to discuss possible preventive actions with them. In health care systems with a well developed primary care, family physicians like to see themselves as the 'case manager' of their patients and regard it their responsibility to keep an up to date comprehensive medical record of their patients. Furthermore, family history taking is supposed to be well established in primary care. ${ }^{4,7,11-12}$ Taking a detailed family history (for CVD and risk factors, cancer, dementia, COPD, asthma, mental disorders etc.) is regarded an inexpensive, non-invasive and reliable method for screening patients for their risk of developing one of these common multifactorial diseases. ${ }^{7}$ A few years ago, in a narrative review Rich et al. discussed various barriers that impede application of family history taking in primary care..$^{13}$ In this systematic review we aim to summarize the evidence supporting the use of comprehensive family history taking for common, multifactorial diseases in primary health care.

\section{Methods}

\section{Search strategy}

Systematic search of the literature was conducted for references on primary care and family history in MEDLINE (1966-2008), EMBASE (1986-2008) and the Cochrane Library (search until August 2008). For the purposes of this review, the terms 'primary care' and 'family practice' will be treated synonymously, as will 'general practitioner' 
and 'family physician'. Sets of terms relating to three specific elements were combined: (1) primary care, (2) family history, and (3) clinical genetics. When possible, the appropriate indexing term for each database was used.

\section{Inclusion and exclusion criteria}

Included were original research papers that investigated family history taking in primary care as a tool to identify individuals and families at increased risk for multifactorial disorders. Only papers in English were included. Titles and abstracts of papers identified by the electronic searches were screened by one reviewer (AWP) and obviously irrelevant papers were excluded. Full text copies of the remaining potentially relevant papers were screened and reviewed by two independent authors (AWP; HEJHS). When potentially relevant references were found in the bibliography of these papers, these were reviewed as well. Case reports, editorials, and papers concerning monogenetic disorders were excluded from this review. Therefore, studies on specific cancers were excluded from this review, whereas generic studies on cancer risk, or papers combining several cancers, were included.

\section{Identification and selection of studies}

Out of 109 titles, 64 were excluded on the basis of title and abstract, and of two papers no full text copies were available. After examination of the remaining 43 potentially relevant full text papers, eight papers were excluded from analysis (case report, editorials, reviews) and four potentially relevant titles were added for closer examination. After evaluation of the outcome, three papers were added for closer review and 15 papers on monogenetic disorders, psychological aspects, or a simple cardiovascular risk score were excluded. Finally, 27 original research papers were included in this review.

\section{Data extraction and analysis}

Data concerning study design, study population, methods, response rate and outcome were extracted according to the guidelines of the Cochrane Collaboration (Review Manager, version 4.2.8). On account of the heterogeneity of the papers reviewed, a qualitative analysis of the results was performed: the key findings from each paper were independently extracted by two authors (AWP; HEJHS), subsequently discussed and finally categorized and summarized in a table. 


\section{Results}

\section{Included papers}

The included papers could be arranged in four categories: studies on primary care physicians' opinions on the application of family history as genetic tool (nine papers, Table 7.1$)^{14-22}$, studies on the practice of family history taking (eight papers, Table $7.2)^{23-30}$, studies on developing tools for taking a family history (seven papers, Table $7.3)^{31-37}$ and, finally, qualitative studies on the patient perspective and risk communication (three studies, Table 7.4). ${ }^{38-40}$

\section{Physicians' opinions on taking a family history in the context of genetic medicine}

Nine original research papers, of which two had a qualitative design, had investigated opinions on the application of family history in daily practice (Table 7.1). ${ }^{14-22}$ Both qualitative studies, executed last decade in the UK and Australia, reveal that general practitioners (GPs) considered 'a focus on common diseases' an important issue for genetics in daily practice. Exploring the 'family tree' was believed to be an important task of the GP. GPs said that taking a family history was a routine activity for them. However, they admitted it was often limited in detail and often done reactive to a patient's request. Also, the family history was not updated regularly, and considered not adequate for genetic advice. GPs also expressed lack of skill in taking a detailed family history or genogram. ${ }^{16,20}$ The results from quantitative questionnaire studies confirm these qualitative results. ${ }^{15,17,18,21}$ A minority of (UK) GPs said they often enquire about family history during routine consultations. In their view the number of patients with a question on risk for a common disease associated with disease in a family member was low. ${ }^{15,17}$ On first registration of a patient in their practice (UK) GPs reported to enquire on disease in family members, especially CVD, less on cancer. Knowledge of family history was said to influence decisions on diagnostic test ordering or referral. ${ }^{15}$ Only a minority of GPs reported confidence in their own ability to take a detailed family history. ${ }^{17,18}$ Calculating cancer risk was neither regarded a GP's task nor considered the GP's competence. ${ }^{18,22}$ 


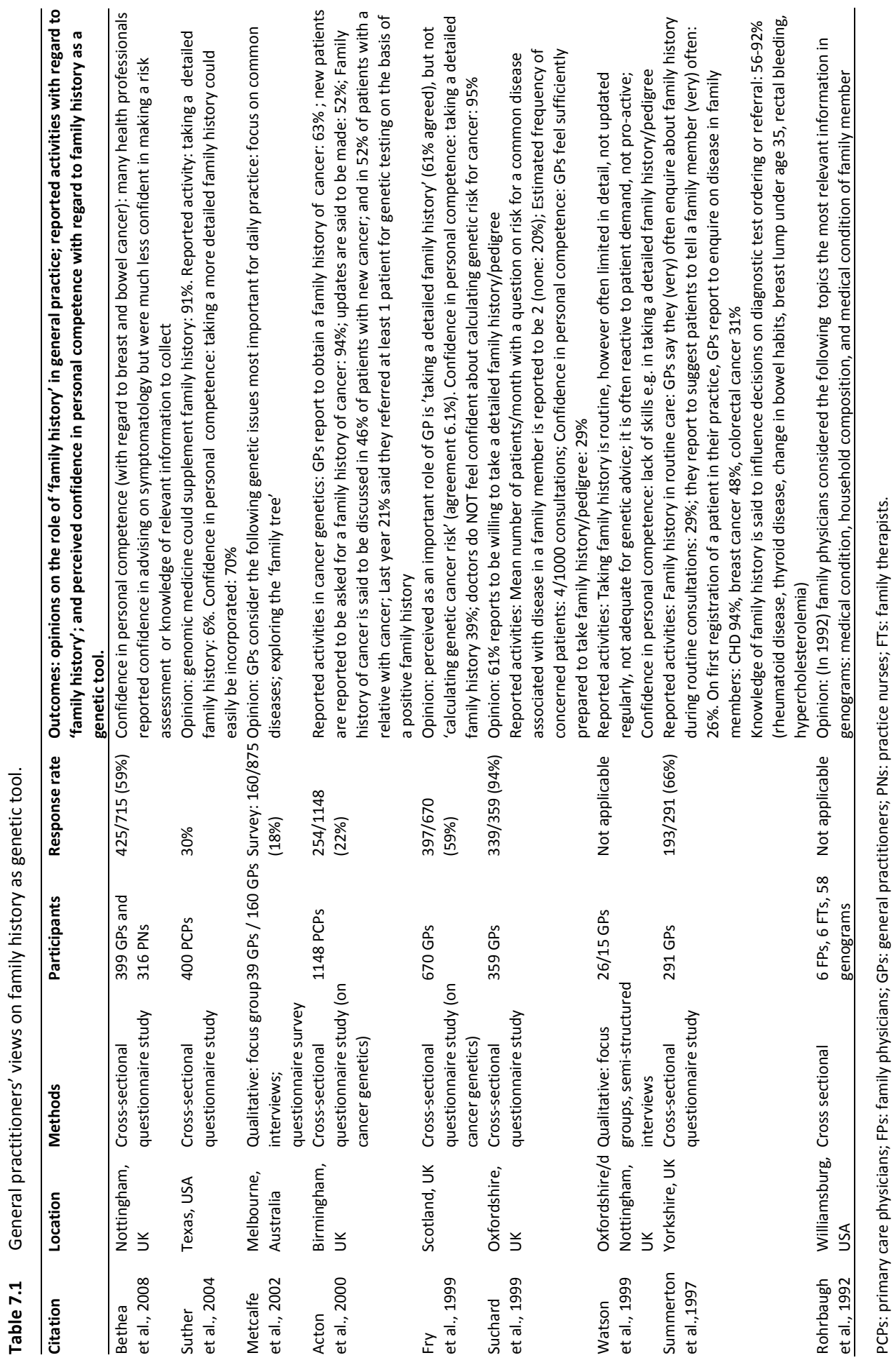




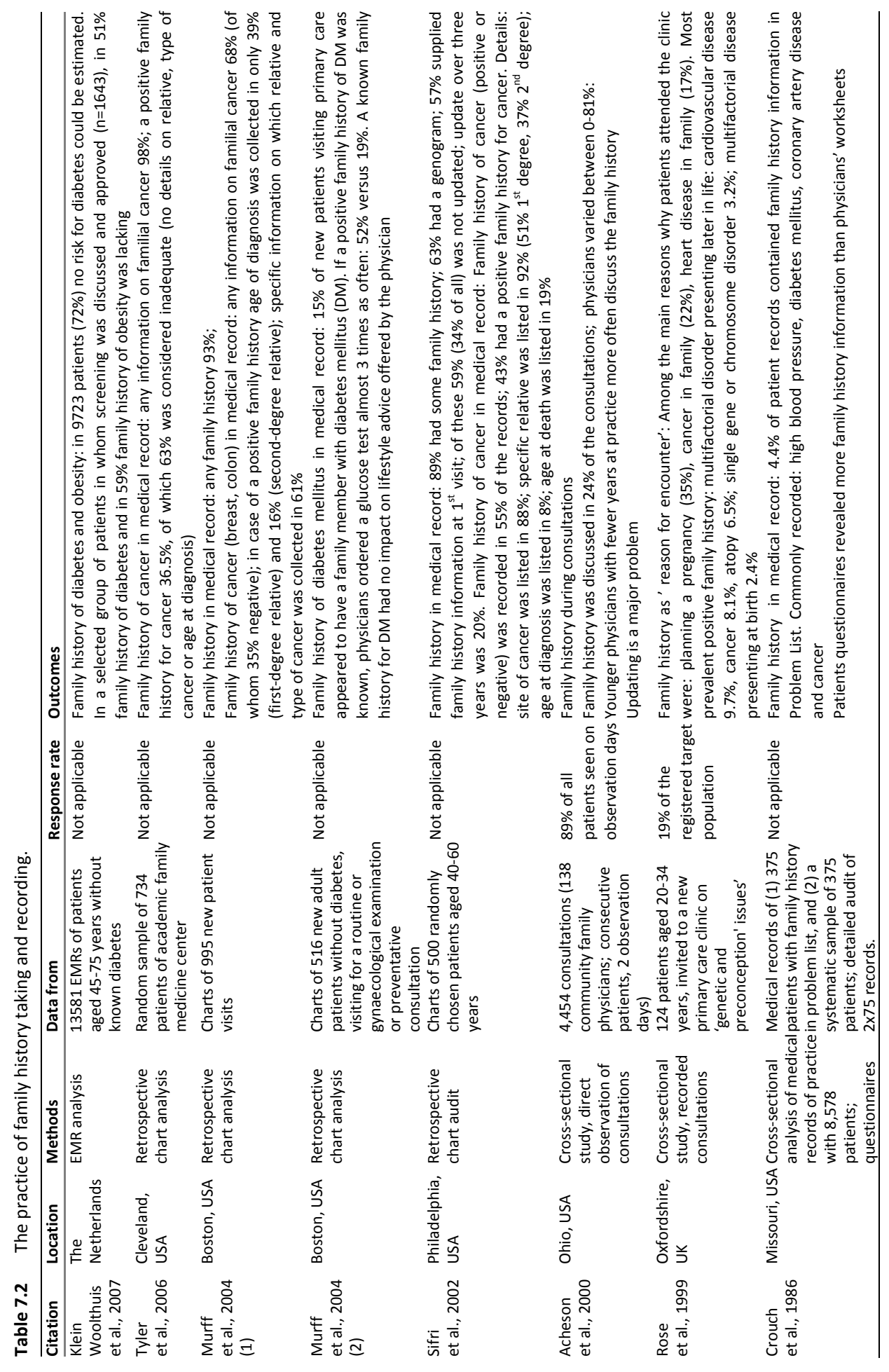




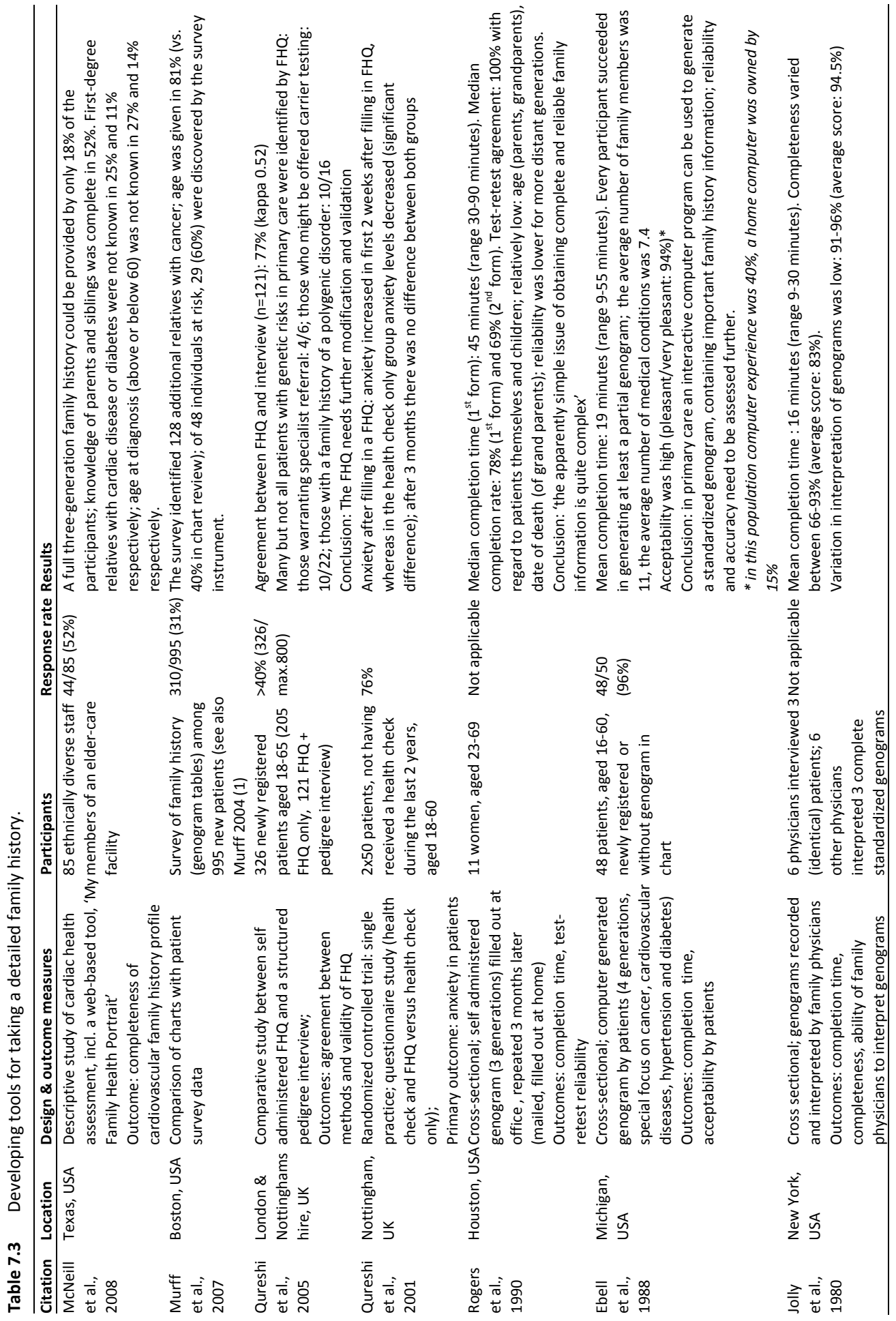




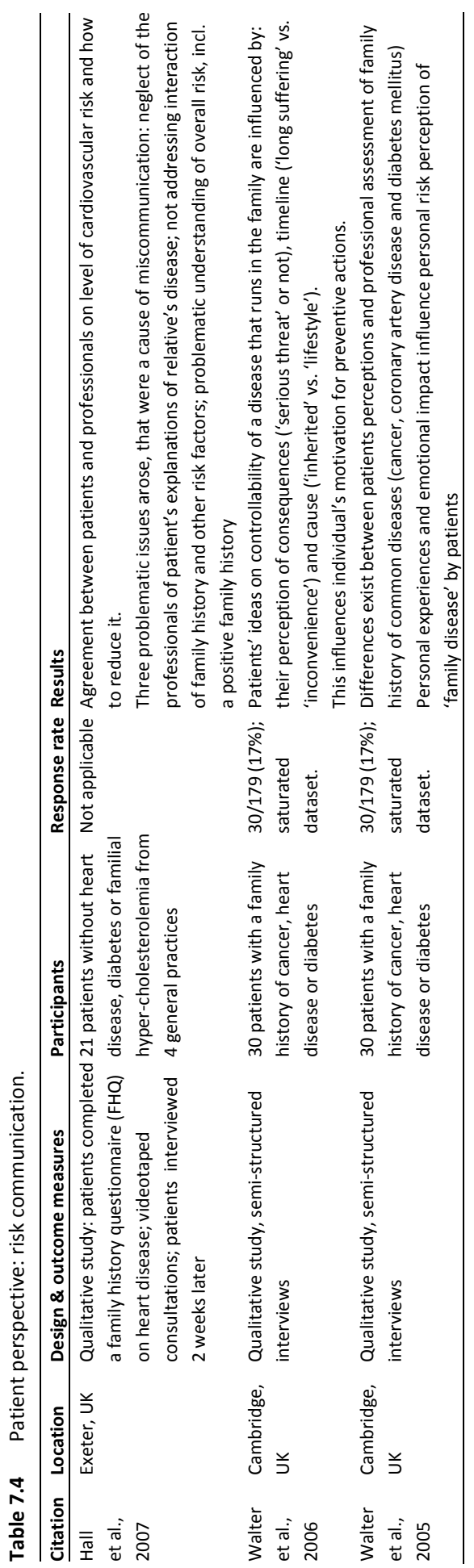




\section{The practice of family history taking and recording}

Eight empirical studies explored the practice of integrating family history in primary care (Table 7.2) ${ }^{23-30}$ Analyses of the presence of 'family history of common diseases' in the medical records showed a very low percentage (4.4\%) in a (US) study from 1986 and a much higher percentage in a (US) study from 2002 (89\%). ${ }^{23,26}$ In another (US) study, 'family history' appeared to be discussed in a quarter of all consultations, however there was a large variability among GPs (0-81\%). ${ }^{25}$ Updating was observed to be a problem. ${ }^{25,26}$ A recent Dutch study on diabetes screening showed that in $72 \%$ of patients the risk for diabetes could not be estimated from the electronic medical record (EMR) because data on family history were missing. ${ }^{30}$ Two studies from the US showed that data in the medical record often were insufficient to estimate cancer risk. ${ }^{28,29}$ One study confirmed the opinion that knowing the family history of a patient influences clinical decision making: if a positive family history of diabetes was known, physicians ordered a glucose test almost three times as often. However, this knowledge had no impact on lifestyle advice offered by the physician. ${ }^{27}$ One study revealed that patients considered more family information important than doctors. ${ }^{23}$

\section{Developing tools for taking family history}

Seven original research papers had explored the use of tools for taking family history in primary care. Various tools were studied: genograms recorded by doctors, selfadministered computer generated genograms (three or four generations), selfadministered paper genograms (three generations), a family history questionnaire, a structured pedigree interview and a web-based tool (Table 7.3). ${ }^{31-37}$ Three older (US) studies showed that it is possible to complete a genogram by a patient or a doctor (completeness on average $80 \%$ ), but it takes time (range 9-90 minutes). ${ }^{31-33} \mathrm{~A}$ recent small study in the US however, showed that a full three-generation family history could only be provided by a minority of the participants. ${ }^{37}$ In a small study, the testretest reliability of self-administered genograms appeared to be high for patients themselves and their children, but low for more distant generations and for details like age of onset (of parents and grandparents) and date of death (of grandparents). ${ }^{33}$ A recent (UK) study showed a moderate agreement between a self-administered family history questionnaire and a structured pedigree interview (Cohen's kappa 0.52). In this study the sensitivity of the family history questionnaire appeared to be suboptimal (Table 7.3). ${ }^{35}$ Another study from the US showed that by sending patients a questionnaire with genogram tables, much more detail in familial cancer risk could be established than was available from the medical record. ${ }^{36} \mathrm{~A}$ similar result was achieved in the Dutch study on diabetes risk mentioned here above, where additional risk assessment showed that in $51.2 \%$ of patients without an EMR-derived risk a positive family history of diabetes was present. ${ }^{30}$ 


\section{Patient perspective: risk communication}

Three recent qualitative studies from the UK revealed interesting facts on the patient perspective and communicating familial risk in cancer, diabetes and CVD (Table 7.4). ${ }^{38-40}$ Although there was agreement between doctors and patients on family risk, patient-doctor communication was hampered by differences in opinion on explanations for and implications of a higher family risk. Doctors often seemed not to know how to integrate patients' experiences and opinions into shared decision making on management (Table 7.4).

\section{Discussion}

This systematic review tried to summarize available evidence on comprehensive family history taking for common multifactorial diseases - like CVD, cancer or diabetes in primary care. Twenty-seven papers were analyzed. Four categories of studies were identified: studies on physicians' opinions on the application of family history as genetic tool, empirical studies on the daily practice of family history taking, studies on the development of tools for taking a family history, and finally, studies on the patient perspective and patient-doctor risk communication.

\section{Main findings}

Fifteen out of 27 studies were published more than five years ago. Many studies were small or suffered from a low response rate and the objectives and outcomes of the studies were heterogeneous. One third of the studies reviewed were on doctors' opinions. Studies on specific diseases were mostly on cancer, a few on diabetes and CVD. Still, a general picture can be derived from our analysis. Firstly, primary care physicians considered taking a detailed family history to be their role in genetic medicine and regarded it to be a routine activity. The first registration or visit of a patient was mentioned as suitable occasion to collect family history data. However, these opinions were only partly confirmed by empirical studies of consultations in which medical family issues were addressed ( $24 \%$ of observed consultations), as well as analyses of medical records (4-89\% contained 'some family history'). Chart analyses and observations of consultations also showed that family history data were not regularly updated (estimated at $20 \% / 3$ years).

Secondly, primary care physicians expressed doubts on their ability to gather detailed information to estimate genetic risk, e.g. for cancer. This opinion was confirmed by several empirical studies, that is, on cancer risk and diabetes, revealing insufficient data in the medical records to make reliable estimations.

Thirdly, taking a detailed family history or genogram appeared to be time-consuming (9-90 minutes). Reproducibility and validity of self-administered genograms or a family history questionnaire have been scarcely studied and the results are as yet 
unsatisfactory: test-retest appeared to be low for more distant generations as well as for dates of disease onset and death; agreement between self-administered questionnaire and structured interview was only moderate. Results for completeness were variable between studies and between doctors, but completeness decreased with genetic distance. One study, using a web-based family history tool, showed less than $20 \%$ complete three-generation family histories.

Finally, quantitative and qualitative studies showed discrepancies in perceptions of the meaning of a positive family history (for cancer, CVD or diabetes) between patients and physicians, with consequences for patient-doctor communication and (preventive) management.

\section{Interpretation}

A limitation of this review might be publication bias. It is well documented that studies with non-significant or negative results are substantially less likely to be submitted for publication. ${ }^{41,42}$ Additionally, generalizability to various primary care populations is a problem of the studies presented in this review. Although we only included studies from primary care, almost all papers we reviewed were from the US, the UK or Australia.

From our review it is evident that more research is needed to strengthen the feasibility, validity and added value of comprehensive family history taking for prevention and management of multifactorial disorders in general practice. Our review supports the view of Rich et al., who in their review demonstrated the barriers for application in primary care - lack of time, poor reimbursement, limited knowledge and skills - and the limited evidence for improved outcome. ${ }^{13}$

Furthermore, recent qualitative studies from the UK on family risk perception of patients and family risk communication between patients and doctors showed that integrating family history in diagnosis and management is problematic in many consultations. ${ }^{38-40}$ These results further specify the findings of an earlier systematic review of qualitative research on the understanding of familial risk by patients. ${ }^{43}$

\section{Added value of comprehensive medical family data}

The conviction that knowing a patient's detailed family history has added value should be proven in long-term prognostic studies. Primary care seems to be a likely setting for this kind of research. Inspiring developments come from the field of preventive medicine, that is, from a collaborative group associated with the Centers for Disease Control in the US. ${ }^{44,45}$ They developed a family history tool for CVD. It was demonstrated that a family history expanded beyond early-onset CVD in a first-degree relative (that is, the traditional question) was significantly associated with prevalent $\mathrm{CVD}^{46}$ Also, 'familial risk' added significantly to a risk model for identifying people with early-onset CVD. Finally, it was shown that patients with a strong familial risk 
possibly could derive great benefit from preventive life style interventions that reduce cardiovascular risk. ${ }^{47}$

Another example comes from the field of cancer research. In the GRAIDS trial, software was used that linked a pedigree-drawing tool to patient-specific management advice regarding breast/ovarian cancer and colorectal cancer, based on regional guidelines for these diseases. General practice teams (UK) that used this support system not only had higher referral rates to regional genetics clinics for familial breast and colorectal cancer, but their referrals also were more appropriate as compared to teams that only had received a short training on familial cancer risk. ${ }^{48}$ Similar software is developed in Australian primary care for heart disease and diabetes. $^{9}$

\section{Collection, interpretation and application of medical family data}

Only comprehensive and reliable medical family data can be the basis for the weighing of familial disease information within the context of each individual patient ('risk assessment'). As this review shows, high quality medical family information is not easily available from medical records. Furthermore, medical family data provided by patients also often are insufficient, whether provided on paper or collected with a web-based tool. On the other hand, patients can provide a simple family tree, that is, without morbidity data, quite easily. In many health care systems it is the responsibility of the family physician to keep an up to date comprehensive medical record of his patients, including a list of important diagnoses, such as chronic diseases. These diagnoses often are based on clear criteria or specialist examinations. Furthermore, they often are available in coded format.

Therefore, we propose the following idea. We suggest a development in which the family pedigree provided by the patient can be combined - through a secure web based interface - with the medical information kept in the electronic medical record management systems of the family physicians of his relatives. Developing informed consent procedures on both sides of the family line - 'I (do not) agree to share this medical information with my relatives if requested' and 'I (do not) agree that medical information of my relatives is made known to me if possibly clinically relevant' should be an integral part of such a technology. The aim would be to be able to generate genograms with up-to-date, complete and best quality medical diagnoses. Current information technology is able to facilitate this point-of-care delivery of detailed and high-quality medical family information. Consequently, the family physician - after having received adequate education in genetics and family risk communication - could take up his role of professional advisor on familial risk for common chronic disorders. Our group is planning literature reviews, pilot studies and qualitative research among GPs and patients to pursue the feasibility of this approach. 
In conclusion, although our review revealed that taking and recording detailed family history data in primary care as yet is insufficient for rational medical decision making, there also is a growing conceptual, methodological and technological basis for further research and development. 


\section{References}

1. Janssens AC, Aulchenko YS, Elefante S, Borsboom GJ, Steyerberg EW, van Duijn CM. Predictive testing for complex diseases using multiple genes: fact or fiction? Genet Med 2006;8:395-400.

2. Knottnerus JA. Community genetics and community medicine. Fam Pract 2003;20:601-6.

3. Acheson LS, Wiesner GL. Current and future applications of genetics in primary care medicine. Prim Care 2004;31:449-60.

4. Qureshi N, Modell B, Modell M. Timeline: Raising the profile of genetics in primary care. Nat Rev Genet 2004;5:783-90.

5. Beery TA, Shooner KA. Family history: the first genetic screen. Nurse Pract 2004;29:14-25.

6. Engstrom JL, Sefton MG, Matheson JK, Healy KM. Genetic competencies essential for health care professionals in primary care. J Midwifery Womens Health 2005;50:177-83.

7. Wolpert CM, Speer MC. Harnessing the power of the pedigree. J Midwifery Womens Health 2005;50:189-96.

8. Weir E. Using a family history tool to prevent chronic diseases. Cmaj 2005;172:631.

9. Reid G, Emery J. Chronic disease prevention in general practice--Applying the family history. Aust Fam Physician 2006;35:879-82, 884-5.

10. Harris R, Harris H. Genetics in primary care. Report on workshop of EC Concerted Action on Genetics Services in Europe (CAGSE) in association with the Royal College of GP Spring Meeting, Blackpool, UK, 28 April 1995. J Med Genet 1996;33:346-8.

11. Kinmonth AL, Reinhard J, Bobrow M, Pauker S. The new genetics. Implications for clinical services in Britain and the United States. Bmj 1998;316:767-70.

12. Rose P, Emery J. Assessment and management of genetic risk. In: Jones R, Britten N, Culpepper L, editors. Oxford Textbook of Primary Medical Care. Oxford: Oxford University Press; 2004.

13. Rich EC, Burke W, Heaton CJ, Haga S, Pinsky L, Short MP, Acheson L. Reconsidering the family history in primary care. J Gen Intern Med 2004;19:273-80.

14. Rohrbaugh $M$, Rogers JC, McGoldrick M. How do experts read family genograms? Fam Syst Med 1992;10:79-89.

15. Summerton N, Garrood PV. The family history in family practice: a questionnaire study. Fam Pract 1997;14:285-8.

16. Watson EK, Shickle D, Qureshi N, Emery J, Austoker J. The 'new genetics' and primary care: GPs' views on their role and their educational needs. Fam Pract 1999;16:420-5.

17. Suchard MA, Yudkin P, Sinsheimer JS, Fowler GH. General practitioners' views on genetic screening for common diseases. Br J Gen Pract 1999;49:45-6.

18. Fry A, Campbell H, Gudmunsdottir H, Rush R, Porteous M, Gorman D, Cull A. GPs' views on their role in cancer genetics services and current practice. Fam Pract 1999;16:468-74.

19. Acton RT, Burst NM, Casebeer L, Ferguson SM, Greene P, Laird BL, Leviton L. Knowledge, attitudes, and behaviors of Alabama's primary care physicians regarding cancer genetics. Acad Med 2000;75:850-2.

20. Metcalfe S, Hurworth R, Newstead J, Robins R. Needs assessment study of genetics education for general practitioners in Australia. Genet Med 2002;4:71-7.

21. Suther SG, Goodson P. Texas physicians' perceptions of genomic medicine as an innovation. Clin Genet 2004;65:368-77.

22. Bethea J, Qureshi N, Drury N, Guilbert P. The impact of genetic outreach education and support to primary care on practitioner's confidence and competence in dealing with familial cancers. Community Genet 2008;11:289-94.

23. Crouch MA, Thiedke CC. Documentation of family health history in the outpatient medical record. J Fam Pract 1986;22:169-74.

24. Rose $\mathrm{P}$, Humm E, Hey K, Jones L, Huson SM. Family history taking and genetic counselling in primary care. Fam Pract 1999;16:78-83.

25. Acheson LS, Wiesner GL, Zyzanski SJ, Goodwin MA, Stange KC. Family history-taking in community family practice: implications for genetic screening. Genet Med 2000;2:180-5.

26. Sifri RD, Wender R, Paynter N. Cancer risk assessment from family history: gaps in primary care practice. J Fam Pract 2002;51:856. 
27. Murff HJ, Rothman RL, Byrne DW, Syngal S. The impact of family history of diabetes on glucose testing and counseling behavior in primary care. Diabetes Care 2004;27:2247-8.

28. Murff HJ, Byrne D, Syngal S. Cancer risk assessment: quality and impact of the family history interview. Am J Prev Med 2004;27:239-45.

29. Tyler CV, Jr., Snyder CW. Cancer risk assessment: examining the family physician's role. J Am Board Fam Med 2006;19:468-77.

30. Klein Woolthuis EP, de Grauw WJ, van Gerwen WH, van den Hoogen HJ, van de Lisdonk EH, Metsemakers JF, van Weel C. Identifying people at risk for undiagnosed type 2 diabetes using the GP's electronic medical record. Fam Pract 2007;24:230-6.

31. Jolly W, Froom J, Rosen MG. The genogram. J Fam Pract 1980;10:251-5.

32. Ebell $\mathrm{MH}$, Heaton CJ. Development and evaluation of a computer genogram. J Fam Pract 1988;27:536-8.

33. Rogers J, Holloway R. Completion rate and reliability of the self-administered genogram (SAGE). Fam Pract 1990;7:149-51.

34. Qureshi N, Standen PJ, Hapgood R, Hayes J. A randomized controlled trial to assess the psychological impact of a family history screening questionnaire in general practice. Fam Pract 2001;18:78-83.

35. Qureshi N, Bethea J, Modell B, Brennan P, Papageorgiou A, Raeburn S, Hapgood R, Modell M. Collecting genetic information in primary care: evaluating a new family history tool. Fam Pract 2005;22:663-9.

36. Murff HJ, Greevy RA, Syngal S. The comprehensiveness of family cancer history assessments in primary care. Community Genet 2007;10:174-80.

37. McNeill JA, Cook J, Mahon M, Rauschhuber M, Jones ME, Estrada R. Family history: value-added information in assessing cardiac health. Aaohn J 2008;56:297-305.

38. Walter FM, Emery J. 'Coming down the line'-- patients' understanding of their family history of common chronic disease. Ann Fam Med 2005;3:405-14.

39. Walter FM, Emery J. Perceptions of family history across common diseases: a qualitative study in primary care. Fam Pract 2006;23:472-80.

40. Hall R, Saukko PM, Evans PH, Qureshi N, Humphries SE. Assessing family history of heart disease in primary care consultations: a qualitative study. Fam Pract 2007;24:435-42.

41. Easterbrook PJ, Berlin JA, Gopalan R, Matthews DR. Publication bias in clinical research. Lancet 1991;337:867-72.

42. Dickersin K, Min YI. Publication bias: the problem that won't go away. Ann N Y Acad Sci 1993;703:13546; discussion 146-8.

43. Walter FM, Emery J, Braithwaite D, Marteau TM. Lay understanding of familial risk of common chronic diseases: a systematic review and synthesis of qualitative research. Ann Fam Med 2004;2:583-94.

44. Scheuner MT, Wang SJ, Raffel LJ, Larabell SK, Rotter JI. Family history: a comprehensive genetic risk assessment method for the chronic conditions of adulthood. Am J Med Genet 1997;71:315-24.

45. Yoon PW, Scheuner MT, Khoury MJ. Research priorities for evaluating family history in the prevention of common chronic diseases. Am J Prev Med 2003;24:128-35.

46. Scheuner MT, Whitworth WC, McGruder H, Yoon PW, Khoury MJ. Expanding the definition of a positive family history for early-onset coronary heart disease. Genet Med 2006;8:491-501.

47. Scheuner MT, Whitworth WC, McGruder H, Yoon PW, Khoury MJ. Familial risk assessment for earlyonset coronary heart disease. Genet Med 2006;8:525-31.

48. Emery J, Morris H, Goodchild R, Fanshawe T, Prevost AT, Bobrow M, Kinmonth AL. The GRAIDS Trial: a cluster randomised controlled trial of computer decision support for the management of familial cancer risk in primary care. Br J Cancer 2007;97:486-93. 


\section{Chapter 8}

\section{GENERAL DISCUSSION}

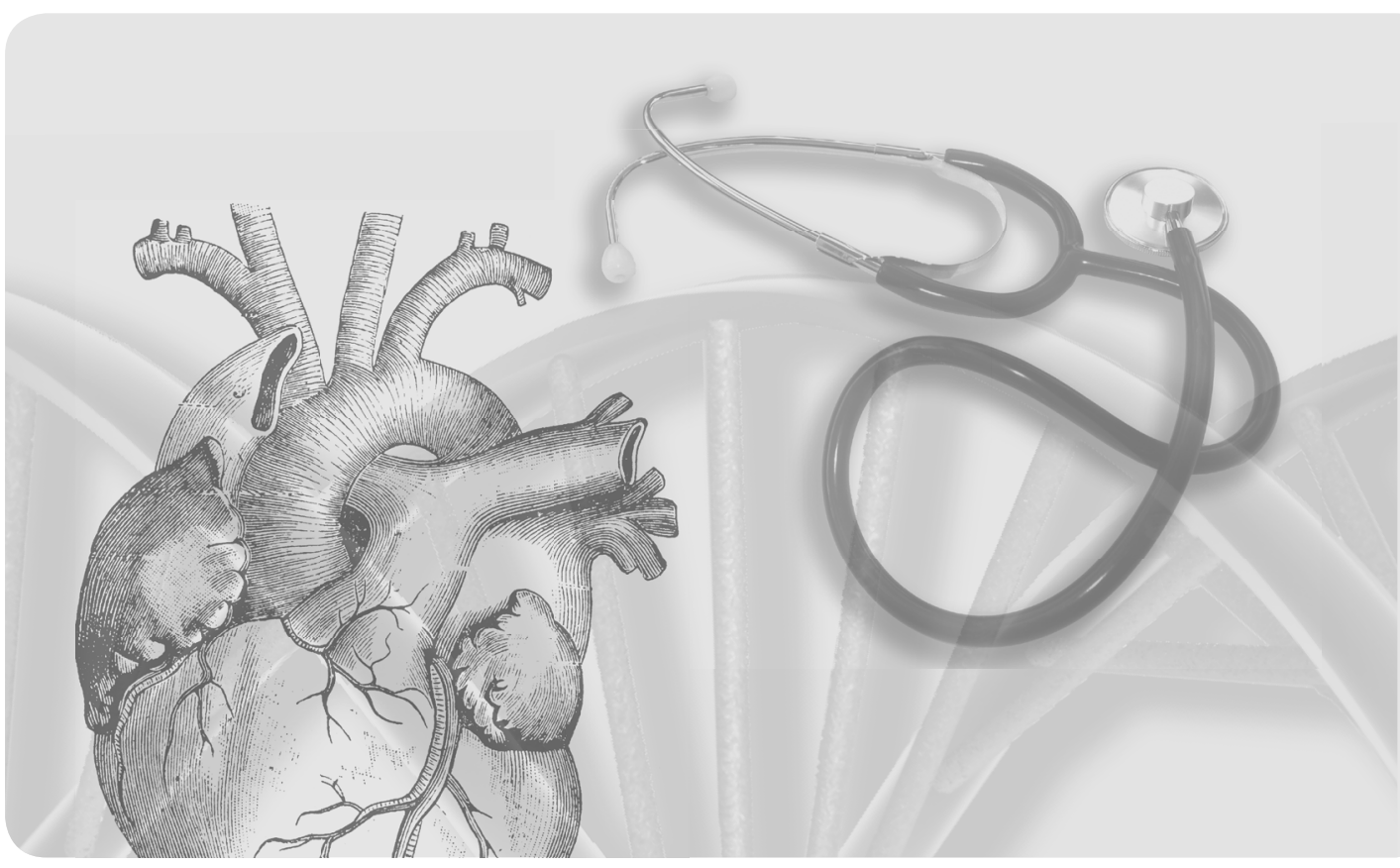




\section{Introduction}

The general aim of the work described in this thesis was to determine in a nonselected patient population the relationship between polymorphisms and biological (risk factors) and clinical (intermediate endpoints) cardiovascular outcome parameters. Based on the literature available at the start of the project, we restricted ourselves to the analysis of six polymorphisms. Three of the polymorphisms - angiotensinogen [AGT (M235T)], angiotensin-converting enzyme [ACE $\left(4656_{\text {rpt }}\right)$ ] and the angiotensin II type 1 receptor [AGTR1 (A1166C)] - were analyzed since these genes are involved in the generation and action of angiotensin II. $^{1}$ In addition, we assessed the role of two polymorphisms that might be related to an enhanced reabsorption of sodium: the G-protein $\beta 3$ subunit [GNB3 (C825T)] and $\alpha$-adducin [ADD1 (G460W)] polymorphisms. ${ }^{2,3}$. Finally, we looked at the endothelial nitric oxide (NO) synthase [NOS3 (E298D)] polymorphism due to its possible association with altered NO availability. ${ }^{4}$ We reasoned that these six polymorphisms could be relevant individually or in combination as additional risk factors for cardiovascular disease (CVD). We hypothesized that the presence of one or more rare alleles of these polymorphisms would improve cardiovascular risk stratification, not only for an individual but probably also for all (first-degree) family members with a comparable allele pattern, and that this approach might yield genetically tailored treatments. This resulted in the Hypertension: Interaction and Prevalence of POlymorphisms related to Cardiovascular Risk and the Association to Treatment Efficacy Study (HIPPOCRATES), of which baseline results have been described in this thesis. The different studies that formed part of work focused on (1) the burden of CVD in the south of the Netherlands, (2) the association between CVD and the six polymorphisms, (3) the association between intermediate endpoints and the six polymorphisms and (4) a systematic review of the role of family history. This last focus of our work addressed the practice and outcomes of family history-taking, since family history is closely related to the genetic background. This chapter presents and discusses the main findings of these studies, and addresses the possible implications for clinical practice and perspectives for future research.

\section{Main findings}

\section{Cardiovascular disease in the south of the Netherlands}

The HIPPOCRATES project involved the population of a general practice centre (Medisch Centrum West Kerkrade) located in the southeast of Limburg, which constitutes an urbanized area around the cities of Heerlen and Kerkrade. From a population genetics point of view, this region is interesting for two reasons: (1) a relatively high cardiovascular mortality had been described in unpublished Dutch 
reports and (2) migration (both into and out of the region) is relatively low. In Chapter 2 of this thesis we compare the burden of CVD in the Heerlen/Kerkrade region relative to those in a nearby region (Maastricht) and the average Dutch population. That study showed that the burden of CVD is higher in the Heerlen/Kerkrade region than in the Maastricht region, and this was not fully explained by a higher prevalence of risk factors. We conclude in that chapter that a better characterization of the interactions between environmental and genetic factors could be the key to understanding the pathogenesis of CVD. Consequently, we studied both genetics and classic risk factors at the individual level in the HIPPOCRATES project.

\section{Cardiovascular disease and polymorphisms of the renin-angiotensin system}

Chapter 3 describes the results of our baseline cross-sectional data analyses. We included a total of 803 study subjects (48\% males, $52 \%$ females) who were mainly overweight hypertensives with dyslipidemia. There were no significant differences in allele frequencies of the six polymorphisms between patients with CVD and the control group. Although some alleles showed a protective effect after Bonferroni correction for multiple testing, these findings were of little clinical significance to the group as a whole. Receiver operating characteristic (ROC) analyses showed that adding the six polymorphisms to a multivariate model including all the main traditional risk factors improved the predictive value of traditional cardiovascular risk factors by only $1 \%$. It should be emphasized that ROC analyses were not the objective of this study, and hence the ROC results should be interpreted as indicative (and hence not quantitatively accurate) of the contribution of genetic information. However, our data suggested that the studied polymorphisms are unlikely to make a major contribution to cardiovascular risk prediction in this primary-care population, although our findings could still be relevant to an individual patient.

The data presented in Chapter 3 raise the question of whether variability in cardiovascular endpoints influenced our results. We, therefore, performed a study in which ischemic heart disease (IHD) was the only outcome measure. The selection criterion for IHD was narrowed down to a first event of IHD. The variability in the association with the first event of IHD was further reduced by specifying the results according to gender and age. The main finding of that study, described in Chapter 4, was that the rare $\mathrm{T}$ allele of the AGT (M235T) polymorphism is protective for males with a first event of IHD, even after applying Bonferroni correction for multiple testing. A possible explanation for this unexpected observation is a low-renin state, which can be enhanced by the GNB3 (C825T) polymorphism and being older. ${ }^{2,5,6}$ A protective association for the T allele of AGT could be related to lower angiotensin levels under these conditions. Xu et al. recently performed a meta-analysis of the AGT 
(M235T) polymorphism, studying 43 association studies on coronary artery disease that included 13,478 cases and 17,024 controls. $^{7}$ Their meta-analysis showed that the overall effect of this polymorphism is weak, showing minor effects that could be either protective or harmful. ${ }^{7}$

As described in Chapter 4, most findings of gender-specific associations of cardiovascular phenotypes with candidate genes are rather unexpected. Such findings are often categorized as type I errors that are attributed to sample stratification with multiple comparisons and in some cases to the small number of individuals in a subgroup. ${ }^{8}$ However, adjustment for gender during the analyses and interpretation of data can actually hide a significant portion of genome-driven physiology unique to males and females. ${ }^{9-12}$ This is illustrated in Chapter 4 by sliding-mean analyses showing that the risks of a first IHD event are completely different for men and women at different ages. Together these findings underscore the need for genderspecific evaluations.

\section{Intermediate endpoints and polymorphisms of the renin-angiotensin system}

In the subsequent two studies, described in Chapters 5 and 6, we were interested in the association of the six polymorphisms with so-called intermediate vascular endpoints: carotid intima media thickness (CIMT) and arterial stiffness as assessed by pulse wave velocity (PWV) measurements. These new non-invasive technologies might help in applying preventive measures correctly at a relatively early stage, ${ }^{13}$ a strategy that might be particularly helpful in a primary care setting.

The study described in Chapter 5 investigated the association between CIMT as an intermediate endpoint for preclinical atherosclerosis and our six polymorphisms. The results show that CIMT was significantly associated with age, gender, waist circumference, dyslipidemia and use of cardiovascular medication. Multiple linear regression analyses with correction for these covariates showed that the $C$ allele of AGTR1 was associated with a thicker CIMT in females only, and that the T allele of ADD1 coincided with a smaller CIMT.

The described association between carriership of the C allele of AGTR1 and thicker CIMT has been reported by other authors. ${ }^{14,15}$ The AGTR1 (A1166C) polymorphism is located in the $3^{\prime}$-untranslated region ( $3^{\prime}$-UTR) of the gene, which is where mRNA stability is regulated. The $C$ allele of AGTR1 has previously been reported to be nonfunctional and is presumed to be in linkage disequilibrium with a variant that alters receptor sensitivity, resulting in an increased response to angiotensin 1 I. $^{16,17}$ The 3'-UTR site has recently been shown to be involved in microRNA gene silencing. ${ }^{18,19}$ MicroRNAs are single-stranded RNA molecules - typically 21-23 nucleotides in length - 
that regulate gene expression. They are processed from primary transcripts and their main function is to down-regulate gene expression (gene silencing). C allele carriers have impaired microRNA binding and a consequent impairment of translation attenuation, resulting in increased receptor density. Such AGTR1 receptor alterations could exert several possible effects that would influence CIMT (see Chapter 5), eventually together initiating the inflammation process in vascular cells. ${ }^{20}$ It is therefore not unreasonable to assume that this explains the observed thicker CIMT in C allele carriers of the AGTR1 polymorphism. There is no evidence in the literature that these mechanisms differ with gender.

Several studies have found an association between the ADD1 (G460W) polymorphism, salt sensitivity or high sodium intake, and an increased risk of cardiovascular events and mortality. ${ }^{21}$ In these studies, the CIMT and cardiovascular morbidity and mortality were increased in T allele carriers. However, in our study we observed that this T allele coincided with a reduced CIMT. Tobin et al. also found such a protective association for ADD1 and suggested that this was attributable to the premature death of $\mathrm{T}$ allele carriers or to a protective effect of this allele through a cellular mechanism that differs from its effect leading to hypertension. ${ }^{22}$ However, as described in Chapter 5, we suggest that this is related to the treatment status of the study subjects. More specifically, as indicated by other authors, a longer duration of pharmacological treatment reduces the increase in CIMT. ${ }^{23,24}$ Our cross-sectional study indicates that this could indeed be an alternative explanation for the observed protective effect of the T allele of ADD1. Carriers of the rare T allele of the ADD1 (G460W) polymorphism are probably medicated at an earlier age and consequently for longer, leading to a reduced $\mathrm{CIMT} .{ }^{25}$ We checked for the effect of treatment duration in our database, and found no statistically significant difference in treatment duration between carriers with the normal genotype (GG) and carriers of the rare T allele of the ADD1 (G460W) polymorphism. However, there are two major problems with our study design being cross-sectional: (1) CIMT is influenced by cardiovascular medication and (2) channelling plays an important role; that is, the most severe cardiovascular patients receive more intensive treatment. A cross-sectional study cannot distinguish the contribution of these two factors. However, these types of associations are observed in patients treated in daily clinical practice. Therefore, future prospective studies are needed to establish the role of treatment.

The finding of the protective association of the T allele of ADD1 raised the question of whether the same sort of association could be assessed using another intermediate vascular endpoint, that is, increased arterial stiffness as measured by carotid-femoral PWV measurements. In the study presented in Chapter 6, we found a significant protective association for the AGTR1 (A1166C) polymorphism with arterial stiffness. This association was significantly influenced by the use of cardiovascular medication and showed a dose-allele effect, with the carotid-femoral/carotid-radial ratio 
(CF/CR ratio) decreasing with the number of $\mathrm{C}$ alleles. However, the results found in that study were not consistent with the results presented in Chapter 5 . More specifically, Chapter 5 describes how the AGTR1 (A1166C) polymorphism is associated with a thicker CIMT, whereas Chapter 6 states that the same polymorphism is associated with a lower PWV. Various hypotheses to explain these results are presented in Chapter 6, and testing them again requires prospective epidemiological studies. Although the findings presented in Chapters 5 and 6 are important for future research in the field of functional genomics, they are currently of little clinical significance.

\section{Strengths and limitations}

Most of the studies presented in this thesis compared a recessive model of inheritance of the homozygous wild-type with heterozygous and homozygous rare allele carriers. This choice was made based on the results of other studies, though we realize this choice is somewhat arbitrary. Furthermore, we only studied the effect of one polymorphism per gene, which does not exclude the role of other polymorphic alleles that are not in linkage disequilibrium.

Our work also had some strong aspects, such as the inclusion of a primary care population in which the entire range of low-to-high-risk patients was available. Additionally, our population was selected using strict inclusion criteria from a rather small geographical area and hence had similar social living conditions. Although our work had an exploratory character, each study generally had a clear a-priori hypothesis, which reduced multiple hypothesis testing.

\section{Family history of common diseases in primary care}

Family history is closely related to the genetic background. We can hypothesize that the presence of certain genetic variants is more important in subjects with a positive family history for CVD. This can only be studied in the presence of high-quality family history-taking. In Chapter 7 we present the results from a systematic literature search of studies that have dealt with family history-taking in primary care as a genetic tool to identify individuals and families at increased risk of multifactorial disorders. We found that it is useful to know a patient's detailed family history, but this has not been shown in long-term prognostic studies. Although our review revealed that taking and recording detailed family-history data in primary care are currently insufficient for rational medical decision-making, there is also a growing conceptual, methodological and technological basis for further research and development. 


\section{What the present work adds}

It could be concluded retrospectively that we were slightly naive at the start of HIPPOCRATES, in that we expected that genetics would clarify major causes of all kinds of multifactorial diseases, including CVD. The results from the association studies presented in this thesis show that the contribution of the six polymorphisms to the 'prediction' of cardiovascular risk is of minor clinical significance for this primary care population as a whole. Estimations of the cardiovascular risk based on the traditional risk factors in this population are already excellent. On the other hand, this thesis presents several results that might be important for individual patients. Firstly, the rather unexpected protective associations of the AGT (M235T) polymorphism (Chapters 3 and 4) and the ADD1 (G460W) polymorphism (Chapter 5) need to be evaluated in future research. Secondly, the gender-specific association of the AGT (M235T) polymorphism (Chapter 4) needs to be further investigated. Thirdly, our investigation of the influence of medication use yielded possible new insights into and hypotheses for the associations between the ADD1 (G460W) polymorphism and CIMT (Chapter 5) and between the AGTR1 (A1166C) polymorphism and PWV (Chapter 6). Again these findings need to be evaluated in long-term follow-up studies. Together these findings are important for future research in the field of functional genomics. However, the results of this thesis also question whether it is useful to proceed with this type of population-based genetic research (that is, association studies of genetic polymorphisms with intermediate or hard endpoints in primary care), or whether other options would be better.

\section{Perspectives for future research}

\section{Assessment of more polymorphisms}

Jeunemaitre recently reviewed the evidence from the most recent studies on the genetics of the human renin-angiotensin system (RAS). ${ }^{1}$ His main conclusion was that although there is still major interest in elucidating the role of these polymorphisms, it is currently too early to propose recommendations and/or specific drug treatments for patients with particular RAS genotypes. ${ }^{1}$ The results of our work described in this thesis are consistent with this conclusion. It should be noted that a novel and promising approach for unravelling the genetic basis of complex genetic diseases has recently been introduced. ${ }^{26}$ These so-called genome-wide association studies analyze several hundreds of thousands of polymorphisms simultaneously, posing substantial biostatistical and computational challenges. The expectation is that applying this new methodology to large and comprehensively phenotyped patient cohorts will readily reveal the most clinically relevant disease-modifying and drug-responsive genes. ${ }^{27}$ This will hopefully reveal the exact value of RAS polymorphisms for individual 
patients. HIPPOCRATES is currently too small to perform such an investigation. On the other hand, what would be the impact on the daily clinical practice of the general practitioner (GP) of being able to interpret the results of several hundreds of thousands of polymorphisms per patient? For this specific population, we consider that it would be better to apply the time and effort involved in such genetic assessments to risk management based on the traditional cardiovascular risk factors.

\section{Add CIMT or PWV?}

Primary prevention of CVD is based only on the most important traditional risk factors. The literature indicates that exposure to every risk factor substantially influences atherosclerosis. ${ }^{13}$ For example, it was recently shown that adding the results of an ankle-brachial index measurement to the Framingham risk score improved risk prediction. ${ }^{28}$ Assessment over time by non-invasive CIMT or PWV might reveal the progression of preclinical atherosclerosis in patients who are not yet diagnosed with manifest CVD. Combining these measurements with traditional cardiovascular risk-factor management appears to be relevant to clinical prevention, since this might improve cardiovascular risk stratification. However, as indicated by Ter Avest et al., before the clinical application of CIMT and PWV is considered in individual CVD risk prediction, the additive value of these measurements in predicting the CVD risk in an individual above and beyond measurements of traditional clinical and biochemical parameters has to be demonstrated in long-term follow-up studies. ${ }^{13}$ Furthermore, appropriate cut-off values have to be derived across populations exhibiting various risk levels, including those at high risk. This could be a challenging objective for a HIPPOCRATES follow-up study.

\section{Assessment of comprehensive family history}

Since current knowledge of specific associations of polymorphisms and multifactorial diseases has limited added predictive value, ${ }^{29}$ another approach could be to use the family medical history. Detailed knowledge of the family medical history could detect familial disease patterns, assess the clinical significance of these patterns (that is, the 'risk') and consequently use this knowledge in preventive and curative care. This hypothesis has led to new interest-as expressed in editorials and descriptive reviews - in the use of a comprehensive family medical history as a tool for the primary and secondary prevention of chronic multifactorial diseases. ${ }^{30-37}$ Moreover, the family history would allow candidates for genetic testing or targeted medical care to be identified. The community orientation of family physicians (primary care physicians and GPs) puts them in an ideal position to track subjects at risk and consequently to discuss possible preventive actions with them. However, only comprehensive and reliable family medical data should be used for weighting the importance of familial disease information within the context of each patient ('risk assessment'). Our review showed that high-quality family medical information is not 
readily obtainable from medical records. Furthermore, the family medical data provided by patients are also often insufficient, whether provided on paper or collected with a web-based tool. On the other hand, patients can provide a simple family tree (that is, without morbidity data) quite easily. Therefore, in Chapter 7 we propose the development of an information and communication technology tool that combines pedigree information provided by patients - through a secure web-based interface - with medical information kept in the electronic-medical-record management systems of family physicians of the patients' relatives. The aim will be to provide genograms with up-to-date, complete, detailed and correct medical diagnoses (and results of genetic tests). Our group is currently planning pilot studies and qualitative research involving GPs and patients to assess the feasibility of this approach. As part of the HIPPOCRATES project we could perform additional exploratory association analyses in subjects with a positive family history of CVD in first-degree family members, either men or women, versus those without this condition. These options illustrate that a large field of research remains to be explored. This could eventually lead to new insights into the pathophysiology of CVD, changes in the approach to CVD diagnosis and to more appropriate therapeutic strategies for managing CVD patients in primary care. 


\section{References}

1. Jeunemaitre X. Genetics of the human renin angiotensin system. J Mol Med 2008;86:637-41.

2. Zeltner R, Delles C, Schneider M, Siffert W, Schmieder RE. G-protein beta(3) subunit gene (GNB3) $825 \mathrm{~T}$ allele is associated with enhanced renal perfusion in early hypertension. Hypertension 2001; 37:882-6.

3. Manunta P, Bianchi G. Low-salt diet and diuretic effect on blood pressure and organ damage. J Am Soc Nephrol 2004;15 Suppl 1:S43-6.

4. Casas JP, Cavalleri GL, Bautista LE, Smeeth L, Humphries SE, Hingorani AD. Endothelial nitric oxide synthase gene polymorphisms and cardiovascular disease: a HuGE review. Am J Epidemiol 2006;164:921-35.

5. Schunkert H, Hense HW, Doring A, Riegger GA, Siffert W. Association between a polymorphism in the $G$ protein beta3 subunit gene and lower renin and elevated diastolic blood pressure levels. Hypertension 1998;32:510-3.

6. Siffert W. G protein polymorphisms in hypertension, atherosclerosis, and diabetes. Annu Rev Med 2005;56:17-28.

7. $\mathrm{Xu} \mathrm{MQ}, \mathrm{Ye} \mathrm{Z}, \mathrm{Hu} F B, \mathrm{He}$ L. Quantitative assessment of the effect of angiotensinogen gene polymorphisms on the risk of coronary heart disease. Circulation 2007;116:1356-66.

8. Hingorani A. Resolving inconsistency in the results of genetic association studies of cardiovascular disease. Clin Sci (Lond) 2004;107:251-3.

9. Jain M, Liao R, Podesser BK, Ngoy S, Apstein CS, Eberli FR. Influence of gender on the response to hemodynamic overload after myocardial infarction. Am J Physiol Heart Circ Physiol 2002;283: H2544-50.

10. Ueno T, Tremblay J, Kunes J, Zicha J, Dobesová Z, Pausova Z, Deng AY, Sun Y, Jacob HJ, Hamet P. Gender-specific genetic determinants of blood pressure and organ weight: pharmacogenetic approach. Physiol Res 2003;52:689-700.

11. Weiss LA, Pan L, Abney M, Ober C. The sex-specific genetic architecture of quantitative traits in humans. Nat Genet 2006;38:218-22.

12. Seda O, Tremblay J, Gaudet D, Brunelle PL, Gurau A, Merlo E, Pilote L, Orlov SN, Boulva F, Petrovich $M$, Kotchen TA, Cowley AW Jr, Hamet P. Systematic, genome-wide, sex-specific linkage of cardiovascular traits in French Canadians. Hypertension 2008;51:1156-62.

13. Ter Avest E, Stalenhoef AF, de Graaf J. What is the role of non-invasive measurements of atherosclerosis in individual cardiovascular risk prediction? Clin Sci (Lond) 2007;112:507-16.

14. Pontremoli R, Ravera M, Viazzi F, Nicolella C, Berruti V, Leoncini G, Giacopelli F, Bezante GP, Sacchi G, Ravazzolo R, Deferrari G. Genetic polymorphism of the renin-angiotensin system and organ damage in essential hypertension. Kidney Int 2000;57:561-9.

15. Zhu S, Meng QH. Association of angiotensin II type 1 receptor gene polymorphism with carotid atherosclerosis. Clin Chem Lab Med 2006;44:282-4.

16. van Geel PP, Pinto YM, Voors AA, Buikema H, Oosterga M, Crijns HJ, van Gilst WH. Angiotensin II type 1 receptor $\mathrm{A} 1166 \mathrm{C}$ gene polymorphism is associated with an increased response to angiotensin II in human arteries. Hypertension 2000;35:717-21.

17. Spiering W, Kroon AA, Fuss-Lejeune MM, Daemen MJ, de Leeuw PW. Angiotensin II sensitivity is associated with the angiotensin II type 1 receptor $A(1166) C$ polymorphism in essential hypertensives on a high sodium diet. Hypertension 2000;36:411-6.

18. Martin MM, Buckenberger JA, Jiang J, Malana GE, Nuovo GJ, Chotani M, Feldman DS, Schmittgen TD, Elton TS. The human angiotensin II type 1 receptor $+1166 \mathrm{~A} / \mathrm{C}$ polymorphism attenuates microrna155 binding. J Biol Chem 2007;282:24262-9.

19. Sethupathy P, Borel C, Gagnebin M, Grant GR, Deutsch S, Elton TS, Hatzigeorgiou AG, Antonarakis SE. Human microRNA-155 on chromosome 21 differentially interacts with its polymorphic target in the AGTR1 3' untranslated region: a mechanism for functional single-nucleotide polymorphisms related to phenotypes. Am J Hum Genet 2007;81:405-13.

20. Grote K, Drexler H, Schieffer B. Renin-angiotensin system and atherosclerosis. Nephrol Dial Transplant 2004;19:770-3. 
21. Bianchi G, Ferrari P, Staessen JA. Adducin polymorphism: detection and impact on hypertension and related disorders. Hypertension 2005;45:331-40.

22. Tobin MD, Braund PS, Burton PR, Thompson JR, Steeds R, Channer K, Cheng S, Lindpaintner K, Samani NJ. Genotypes and haplotypes predisposing to myocardial infarction: a multilocus case-control study. Eur Heart J 2004;25:459-67.

23. Bots ML, Grobbee DE. Intima media thickness as a surrogate marker for generalised atherosclerosis. Cardiovasc Drugs Ther 2002;16:341-51.

24. Poredos P. Intima-media thickness: indicator of cardiovascular risk and measure of the extent of atherosclerosis. Vasc Med 2004;9:46-54.

25. Beeks E, van der Klauw MM, Kroon AA, Spiering W, Fuss-Lejeune MJ, de Leeuw PW. Alpha-adducin Gly460Trp polymorphism and renal hemodynamics in essential hypertension. Hypertension 2004;44: 419-23.

26. Kronenberg F. Genome-wide association studies in aging-related processes such as diabetes mellitus, atherosclerosis and cancer. Exp Gerontol 2008;43:39-43.

27. Grant SF, Hakonarson H. Recent development in pharmacogenomics: from candidate genes to genome-wide association studies. Expert Rev Mol Diagn 2007;7:371-93.

28. Ankle Brachial Index Collaboration, Fowkes FG, Murray GD, Butcher I, Heald CL, Lee RJ, Chambless LE, Folsom AR, Hirsch AT, Dramaix M, deBacker G, Wautrecht JC, Kornitzer M, Newman AB, Cushman M, Sutton-Tyrrell K, Fowkes FG, Lee AJ, Price JF, d'Agostino RB, Murabito JM, Norman PE, Jamrozik K, Curb JD, Masaki KH, Rodríguez BL, Dekker JM, Bouter LM, Heine RJ, Nijpels G, Stehouwer CD, Ferrucci L, McDermott MM, Stoffers HE, Hooi JD, Knottnerus JA, Ogren M, Hedblad B, Witteman JC, Breteler MM, Hunink MG, Hofman A, Criqui MH, Langer RD, Fronek A, Hiatt WR, Hamman R, Resnick HE, Guralnik J, McDermott MM. Ankle brachial index combined with Framingham Risk Score to predict cardiovascular events and mortality: a meta-analysis. JAMA 2008;300:197-208.

29. Janssens AC, Aulchenko YS, Elefante S, Borsboom GJ, Steyerberg EW, van Duijn CM. Predictive testing for complex diseases using multiple genes: fact or fiction? Genet Med 2006;8:395-400.

30. Knottnerus JA. Community genetics and community medicine. Fam Pract 2003;20:601-6.

31. Acheson LS, Wiesner GL. Current and future applications of genetics in primary care medicine. Prim Care 2004;31:449-60, vii.

32. Qureshi N, Modell B, Modell M. Timeline: Raising the profile of genetics in primary care. Nat Rev Genet 2004;5:783-90.

33. Beery TA, Shooner KA. Family history: the first genetic screen. Nurse Pract 2004;29:14-25.

34. Engstrom JL, Sefton MG, Matheson JK, Healy KM. Genetic competencies essential for health care professionals in primary care. J Midwifery Womens Health 2005;50:177-83.

35. Wolpert CM, Speer MC. Harnessing the power of the pedigree. J Midwifery Womens Health 2005; 50:189-96.

36. Weir E. Using a family history tool to prevent chronic diseases. Cmaj 2005;172:631.

37. Reid G, Emery J. Chronic disease prevention in general practice--Applying the family history. Aust Fam Physician 2006;35:879-82, 884-5. 


\section{SUMMARY}

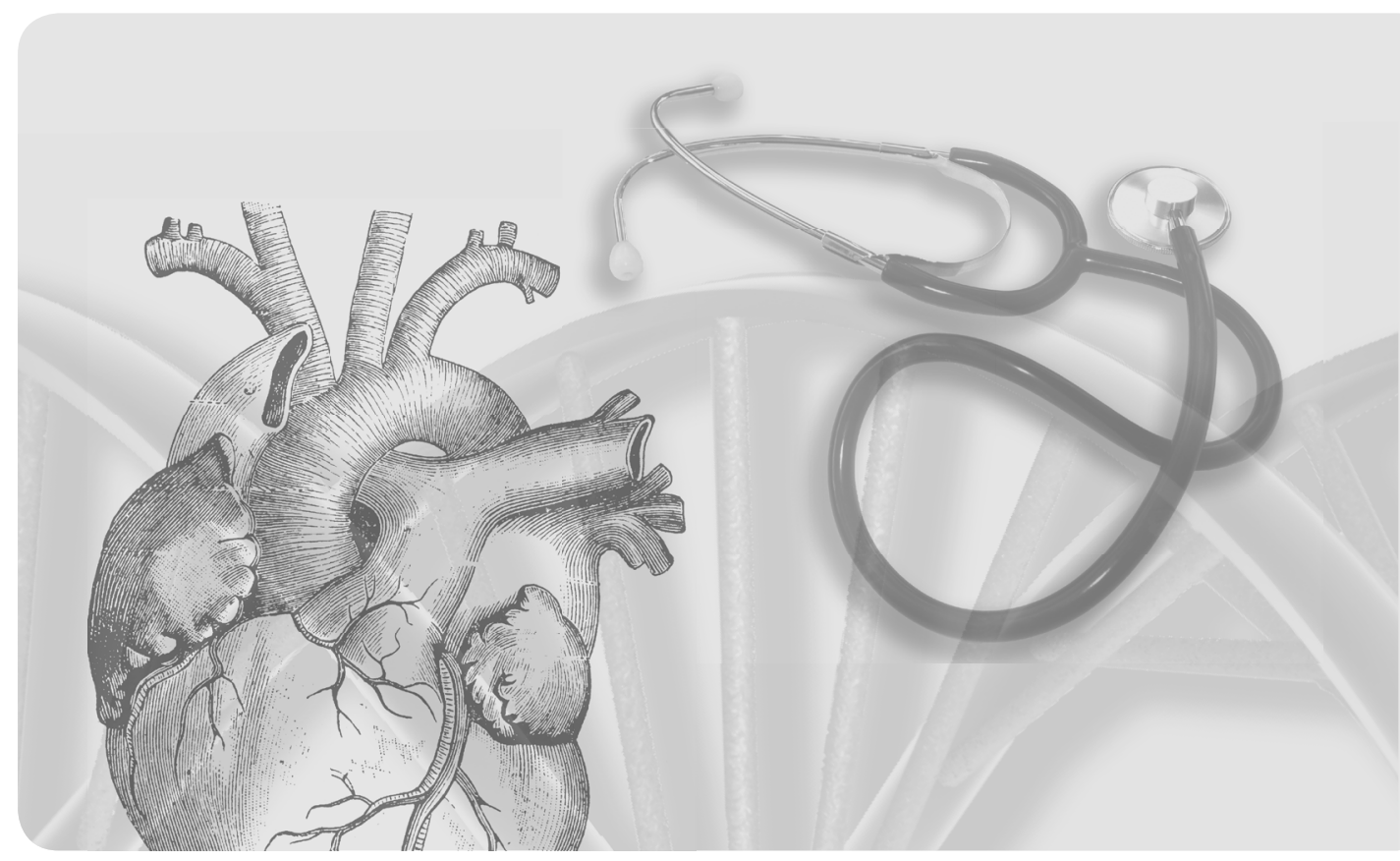




\section{Summary}

Atherosclerotic cardiovascular disease (CVD), involving the heart, brain and peripheral arteries of the legs, is a major health problem around the world. The aetiology of CVD is multifactorial. Both genetic and environmental factors play an important role. The most common forms of CVD are believed to be multifactorial and the result of interaction of several genes, each with a relatively small effect, working alone or in combination with other modifiers, genes and/or environmental factors. Research, predominantly epidemiologic studies, is continuing at high speed to elucidate which (combination of) genes or genetic factors play an active role in the aetiology of CVD.

In this thesis we determined biological (risk factors) and clinical (intermediate endpoints) cardiovascular outcome parameters in a non-selected patient population and set out to establish the association of certain polymorphisms and these parameters. Based on the literature available at the start of the project, we restricted ourselves to the analysis of six polymorphisms. Three of these polymorphisms - angiotensinogen [AGT (M235T)], angiotensin-converting enzyme [ACE $\left(4656_{\text {rpt }}\right)$ ] and the angiotensin II type 1 receptor [AGTR1 (A1166C)] - were analyzed since these genes are involved in the generation and action of angiotensin II. In addition, we assessed the role of two polymorphisms that might be related to an enhanced reabsorption of sodium: the G-protein $\beta 3$ subunit [GNB3 (C825T)] and $\alpha$-adducin [ADD1 (G460W)] polymorphisms. Finally, we looked at the endothelial nitric oxide (NO) synthase [NOS3 (E298D)] polymorphism due to its possible association with altered NO availability. We reasoned that these six polymorphisms could be relevant individually or in combination as additional risk factors for CVD, given their role in the regulation of blood pressure, water and salt balance and endothelial function. We hypothesized that the presence of one or more rare alleles of these polymorphisms would improve cardiovascular risk stratification, not only for an individual but probably also for all (first-degree) family members with a comparable allele pattern, and that this approach might yield genetically tailored treatments. This resulted in the Hypertension: Interaction and Prevalence of POlymorphisms related to Cardiovascular Risk and the Association to Treatment Efficacy Study (HIPPOCRATES), of which baseline results have been described in this thesis. The different studies that were performed as part of this project focused on (1) the burden of CVD in the south of the Netherlands, (2) the association between CVD and six polymorphisms, (3) the crosssectional association between intermediate endpoints and six polymorphisms and (4) a systematic review of the role of family history as a tool in genetic studies in primary care.

\section{Cardiovascular disease in the south of the Netherlands}

After a general introduction in Chapter 1, Chapter 2 focuses on the comparison of the burden of CVD in the Heerlen/Kerkrade region relative to those in a nearby region 
(Maastricht) and the average Dutch population. That study showed that the burden of CVD is higher in the Heerlen/Kerkrade region than in the Maastricht region, and this was not fully explained by a higher prevalence of classical risk factors. At that time, we concluded that a better characterization of the interactions between environmental and genetic factors could be the key to understanding the pathogenesis of CVD. Consequently, we continued studying both genetics and classical risk factors at the individual level in the HIPPOCRATES project.

\section{Cardiovascular disease and six polymorphisms}

Chapter 3 describes the results of our baseline cross-sectional data analyses. We included a total of 803 study subjects ( $48 \%$ males, $52 \%$ females) who were mainly overweight hypertensives with dyslipidemia. There were no significant differences in allele frequencies of the six polymorphisms between patients with CVD and event-free controls. Although some alleles showed a protective effect after Bonferroni correction for multiple testing, these findings were of little clinical significance to the group as a whole. Our data suggested that the studied polymorphisms are unlikely to make a major contribution to cardiovascular risk prediction in this primary care population, although our findings could still be relevant to an individual patient.

In Chapter 4, we investigated whether the mix of cardiovascular endpoints influenced the results described in Chapter 3. We therefore performed a study in which ischemic heart disease (IHD) was the only outcome measure. The selection criterion for IHD was narrowed down to a first event of IHD. The variability in the association with the first event of IHD was further reduced by specifying the results according to gender and age. The main finding of that study was that the rare T allele of the AGT (M235T) polymorphism is protective for males with regard to a first event of IHD. A possible explanation for this unexpected observation is a low-renin state, which can be enhanced by the presence of the mutant allele of the GNB3 (C825T) polymorphism and older age. Consequently, the protective association for the T allele of AGT could be related to lower angiotensin II levels under these conditions.

\section{Intermediate endpoints and six polymorphisms}

The study described in Chapter 5 investigated the association between carotid intima media thickness (CIMT) as an intermediate endpoint for preclinical atherosclerosis and the six polymorphisms. The results show that CIMT was significantly associated with age, gender, waist circumference, dyslipidemia and use of cardiovascular medication. Multiple linear regression analyses with correction for these covariates showed that the $C$ allele of AGTR1 was associated with a thicker CIMT in females only, and that the $T$ allele of ADD1 coincided with a smaller CIMT. The described association between carriership of the $C$ allele of AGTR1 and thicker CIMT could be explained by the fact that $C$ allele carriers have probably impaired microRNA binding. The main function of microRNA is to down-regulate gene expression (gene silencing). Such AGTR1 receptor 
alterations could exert several possible effects that, in combination with the other risk factors, can influence CIMT eventually resulting in the observed thicker thickness. However, evidence for gender differences with respect to these mechanisms was not present in the literature. While in most studies male gender is associated with a thicker CIMT and females have often the thinnest CIMT, we found in the study described in Chapter 5 the opposite. A possible explanation might be that males are treated more than females with cardiovascular risk-reducing therapies.

The finding that the T allele of ADD1 coincided with a smaller CIMT was more difficult to explain. We suggested in Chapter 5 that this may be related to the duration of pharmacological treatment of the study subjects, that is, carriers of the rare T allele of the ADD1 (G460W) polymorphism are probably medicated at an earlier age and consequently treated for a longer period, leading to a reduced CIMT. However, in the present database we were unable to adequately investigate this hypothesis due to two major problems: (1) CIMT is influenced by cardiovascular medication and (2) channelling plays an important role; that is, the most severe cardiovascular patients receive more intensive treatment. Our cross-sectional study cannot distinguish the contribution of these two factors. However, these types of associations are observed in patients treated in daily clinical practice. Therefore, future prospective studies are needed to establish the role of treatment.

The arterial system gradually stiffens because of the shared effects of ageing, high blood pressure, genetic factors, and other risk factors. Arterial stiffness, and especially a stiffened aorta, has been associated with an excess of cardiovascular morbidity and mortality. In the study presented in Chapter 6 we found a significant protective association for the AGTR1 (A1166C) polymorphism with arterial stiffness as assessed by pulse wave velocity (PWV) measurements. This association was significantly influenced by the use of cardiovascular medication and showed a dose-allele effect, with the carotid-femoral/carotid-radial ratio (CF/CR ratio) decreasing with the number of $C$ alleles. Various hypotheses to explain these results are presented in this chapter, but testing them, again, would require prospective epidemiological studies. Although the findings presented in the Chapters 5 and 6 are important for future research in the field of functional genomics, they should be appreciated as hypothesis generating, and are currently of little clinical significance.

\section{Family history of common diseases in primary care}

Family history is closely related to the genetic background. Given their community orientation, general practitioners (family physicians, primary care physicians) seem to be in the ideal position to integrate medical family data in their primary and secondary preventive activities. In Chapter 7 we presented the results of a systematic literature search of studies that have dealt with family history-taking in primary care as a genetic tool to identify individuals and families at increased risk of multifactorial 
disorders. We found that it is useful to know a patient's detailed family history, but this has, unfortunately, not (yet) been shown in long-term prognostic studies. Although our review revealed that taking and recording detailed family history data in primary care are currently insufficient for rational medical decision-making, there is also a growing conceptual, methodological and technological basis for further research and development.

\section{Discussion and conclusion}

In Chapter 8 the main findings of the studies in this thesis are discussed in light of the current literature. In addition, the clinical relevance of the findings and recommendations for future research are given. We concluded that the contribution of the six polymorphisms to the 'prediction' of cardiovascular risk is of minor clinical significance for this primary care population as a whole. On the other hand, this thesis presents several results that might be important for individual patients. Firstly, the rather unexpected protective associations of the AGT (M235T) polymorphism (Chapters 3 and 4) and the ADD1 (G460W) polymorphism (Chapter 5). Secondly, the gender-specific association of the AGT (M235T) polymorphism (Chapter 4). Thirdly, our investigation of the influence of medication use yielded possible new insights into and hypotheses for the associations between the ADD1 (G460W) polymorphism and CIMT (Chapter 5) and between the AGTR1 (A1166C) polymorphism and PWV (Chapter 6). Together these findings are important for future research in the field of functional genomics. Finally we provide suggestions for future research. We would like to emphasize that determination of more polymorphisms in the HIPPOCRATES population is not useful. Indeed, what would be the impact on the daily clinical practice of the general practitioner of being able to interpret the results of several hundreds of thousands of polymorphisms per patient? Secondly, the results of this thesis indicate that combining CIMT and PWV measurements with traditional riskfactor management might be relevant in clinical prevention, since this might improve cardiovascular risk stratification. However, before the clinical application of CIMT and PWV is considered in individual CVD risk prediction, the additive value of these measurements in predicting the CVD risk in an individual above and beyond measurements of traditional clinical and biochemical parameters has to be demonstrated in long-term follow-up studies. This could be a challenging objective for a HIPPOCRATES follow-up study. Finally we indicate that since current knowledge of specific associations of polymorphisms and multifactorial diseases has limited added predictive value another approach could be to use the family medical history. Currently, our group is planning pilot studies and qualitative research among GPs and patients to pursue the feasibility of this approach. 


\section{SAMENVATTING}

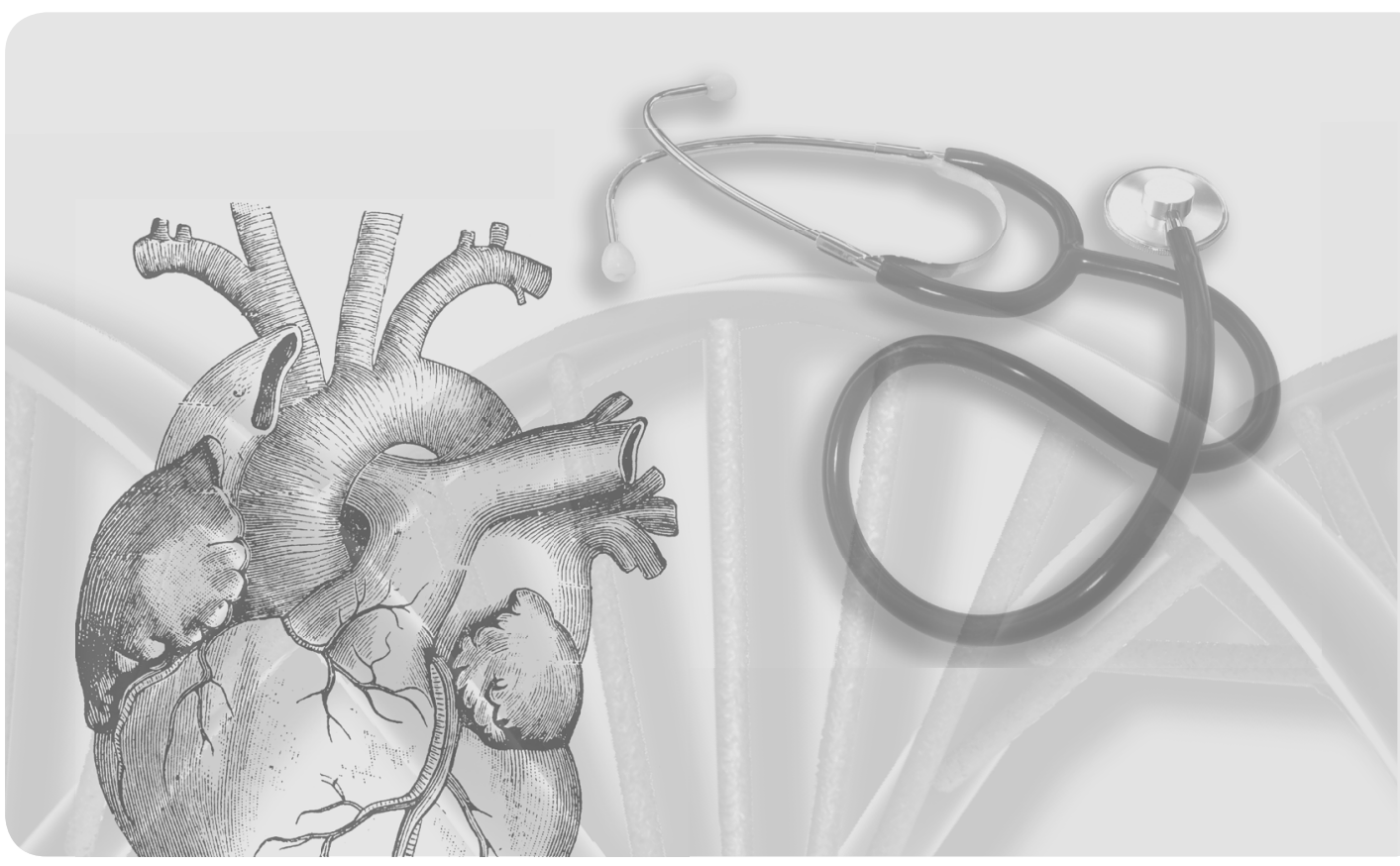




\section{Samenvatting}

Hart-en vaatziekten (HVZ) behoren tot de belangrijkste doodsoorzaken in de westerse wereld. Het ontstaan van HVZ is multifactorieel. Omgevingsfactoren en meer of minder bekende risicofactoren, waaronder ook genetische factoren, spelen hierbij een belangrijke rol. Bij de meeste vormen van HVZ geldt dat de genetische predispositie het resultaat is van interactie tussen verschillende genen, ieder met een relatief klein effect, die in sommige gevallen samenwerken met andere genen of (omgevings)factoren. Deze complexe interacties zijn bij lange na nog niet opgehelderd. Daarom vindt er continu onderzoek plaats, met name epidemiologisch onderzoek, om op te helderen welke combinaties van genen of genetische factoren een rol spelen in het ontstaan van HVZ.

Voor dit proefschrift hebben we biologische (risicofactoren) en klinische (intermediaire) cardiovasculaire eindpunten bepaald in een eerstelijns patiëntenpopulatie. In deze populatie zijn we vervolgens associaties tussen deze eindpunten en bepaalde polymorfismen gaan bestuderen. Op basis van de literatuur die bij het begin van dit promotieonderzoek beschikbaar was, hebben we ons beperkt tot de analyse van zes polymorfismen. Drie van deze polymorfismen - angiotensinogeen [AGT (M235T)], angiotensine I converterend enzym [ACE (4656rpt)] en de angiotensine II type 1 receptor [AGTR1 (A1166C)] - werden geanalyseerd omdat deze genen betrokken zijn bij de vorming en effecten van angiotensine II. Daarnaast bepaalden we de rol van twee polymorfismen die gerelateerd zijn aan verhoogde zoutgevoeligheid, namelijk de G-protein $\beta 3$ subunit [GNB3 (C825T)] en het $\alpha$-adducine [ADD1 (G460W)] polymorfisme. Als laatste werd het endotheliaal stikstofoxide synthase NOS3 (E298D)] polymorfisme bestudeerd, een polymorfisme dat betrokken is bij de gewijzigde beschikbaarheid van endotheelafhankelijk stikstofoxide (NO). Onze redenering was dat deze zes polymorfismen, individueel of in combinatie, relevant zouden kunnen zijn als additionele risicofactoren voor HVZ. Onze hypothese was dan ook dat de aanwezigheid van één of meer allelen van deze polymorfismen de cardiovasculaire risicoclassificatie zou verbeteren en mogelijk niet alleen voor een indviduele patiënt maar hoogstwaarschijnlijk ook voor alle (eerstegraads) familieleden met een vergelijkbaar patroon van allelen. Deze benadering zou er toe kunnen leiden dat patiënten op basis van hun genetisch profiel specifieke (preventieve) behandelingen zouden kunnen krijgen. Dit resulteerde in het "Hypertension: Interaction and Prevalence of POlymorphisms related to Cardiovascular Risk and the Association to Treatment Efficacy Study (HIPPOCRATES)" project waarvan de baseline resultaten in dit proefschrift beschreven staan. De verschillende studies die als onderdeel van dit project werden uitgevoerd, gaan over (1) de prevalentie van HVZ in het zuiden van Nederland, (2) de associatie tussen HVZ en de zes polymorfismen, (3) de crosssectionele associatie tussen intermediaire eindpunten en de zes polymorfismen en (4) 
de rol van familie-anamnese in de eerstelijns geneeskunde in kaart gebracht in een systematische review.

\section{Hart-en vaatziekten in het zuiden van Nederland}

$\mathrm{Na}$ een algemene introductie in Hoofdstuk 1, worden in Hoofdstuk 2 de prevalenties van HVZ beschreven en met elkaar vergeleken voor de regio's Heerlen/Kerkrade en Maastricht. Bovendien wordt de prevalentie van HVZ in de regio Heerlen/Kerkrade vergeleken met die van de Nederlandse bevolking. Deze studie liet zien dat er meer HVZ voorkomen in Heerlen/Kerkrade en dat deze hogere prevalentie van HVZ niet volledig kan worden verklaard door een hogere prevalentie van traditionele cardiovasculaire risicofactoren. Toentertijd concludeerden we dan ook dat een betere karakterisering van de interacties tussen gen- en omgevingsfactoren essentieel zou zijn om de pathogenese van HVZ verder te ontrafelen. Daarom gingen we in HIPPOCRATES verder met de bestudering van zowel de genetische als de klassieke cardiovasculaire risicofactoren op een individueel niveau.

\section{Hart-en vaatziekten en zes polymorfismen}

Hoofdstuk 3 beschrijft de basale resultaten van ons cross-sectionele onderzoek. We includeerden 803 personen (48\% mannen, 52\% vrouwen) die voor het merendeel gekarakteriseerd konden worden als hypertensieve patiënten met overgewicht en dislipidemie. Er werden tussen de patiënten met HVZ en de controlepersonen zonder HVZ geen statistisch significante verschillen in allelfrequenties van de zes polymorfismen gevonden. Hoewel sommige allelen een beschermend effect lieten zien, leken deze bevindingen op grond van ROC-analyses van slechts gering klinisch belang voor de populatie als geheel. De resultaten in dit hoofdstuk laten zien dat het onwaarschijnlijk is dat de bestudeerde polymorfismen een belangrijke bijdrage leveren aan de voorspelling van het cardiovasculaire risico in deze eerstelijns populatie als geheel. Dat sluit niet uit dat onze bevindingen nog steeds relevant kunnen zijn voor individuele patiënten.

We vroegen ons af of het feit dat we cardiovasculaire eindpunten gecombineerd hadden geanalyseerd, invloed zou kunnen hebben op de resultaten in Hoofdstuk 3. Daarom werd in Hoofdstuk 4 ischemische hartziekte (IHZ) als enigste uitkomstmaat gekozen. De selectie criteria werden beperkt tot een eerste optreden van IHZ. De diversiteit van de associatie tussen een eerste optreden van IHZ en de zes polymorfismen werd verder gereduceerd door de resultaten te stratificeren naar geslacht en leeftijd. De belangrijkste bevinding van dit onderzoek was dat het T allel van het AGT (M235T) polymorfisme beschermend is voor mannen met een eerste optreden van IHZ. Een mogelijke verklaring voor deze onverwachte waarneming zou te maken kunnen hebben met een laag, niet-geactiveerd renine, waarvan het effect kan worden versterkt door de aanwezigheid van het GNB3 (C825T) polymorfisme en hogere leeftijd. Beide gevallen worden namelijk gekenmerkt door een niet 
geactiveerd renine-angiotensine systeem. Onder deze omstandigheden kan een beschermend effect van het T allel van AGT gerelateerd zijn aan lagere angiotensine II spiegels, zoals die worden gevonden bij dragers van het $T$ allel van het AGT polymorfisme.

\section{Intermediaire eindpunten en zes polymorfismen}

In de studie beschreven in Hoofdstuk 5 onderzochten we de associatie tussen carotis intima media dikte (CIMD) als een intermediair eindpunt voor preklinische atherosclerose en de zes polymorfismen. We vonden dat er een statistisch significante associatie was tussen CIMD en leeftijd, geslacht, middelomtrek, dislipidemie en het gebruik van cardiovasculaire medicatie. Lineaire regressie-analyse met correctie voor deze covariabelen liet zien dat alleen bij vrouwen het C allel van het AGTR1 (A1166C) polymorfisme geassocieerd was met een dikkere CIMD en dat het T allel van het ADD1 (G460W) polymorfisme gerelateerd is aan een dunnere CIMD. De beschreven associatie tussen dragerschap van het $C$ allel van het AGTR1 polymorfisme en een dikkere CIMD kan worden verklaard door het feit dat dragers van het $C$ allel een verminderde binding hebben van het zogenaamde microRNA. Dit microRNA speelt een belangrijke rol in het down-reguleren van de gen-expressie. Als dit downreguleren niet of minder gebeurt, leidt dit tot een toegenomen receptor dichtheid. Dergelijke veranderingen in de relatie tussen angiotensine II en zijn receptor kunnen verschillende effecten induceren die, in combinatie met andere risicofactoren, de CIMD beïnvloeden. Dit zou uiteindelijk kunnen leiden tot de waargenomen dikkere CIMD. Echter er zijn nog geen studies beschikbaar die een verschil tussen mannen en vrouwen laten zien aangaande deze mechanismen. Eerdere algemene studies naar CIMD hebben laten zien dat juist mannen een dikkere CIMD hebben dan vrouwen. Een mogelijke verklaring voor de dikkere CIMD bij vrouwen in onze populatie zou kunnen zijn dat het cardiovasculair risico management bij mannen intensiever is dan bij vrouwen.

De bevinding dat bij dragers van het $T$ allel van het ADD1 (G460W) polymorfisme vaker een dunnere CIMD werd gevonden, is moeilijker te verklaren. We suggereerden dat deze bevinding weleens verklaard zou kunnen worden door de duur van medicamenteuze behandeling van de geïncludeerde patiënten. Met andere woorden, dragers van het T allel van het ADD1 (G460W) polymorfisme beginnen waarschijnlijk op jongere leeftijd met cardiovasculaire medicatie, worden daardoor langer medicamenteus behandeld en dit leidt uiteindelijk tot een dunnere CIMD. Helaas konden we in de huidige database deze hypothese niet meer afdoende onderzoeken, omdat de cross-sectionele opzet van onze onderzoek de volgende twee belangrijke problemen veroorzaakt: (1) CIMD wordt beïnvloed door het gebruik van cardiovasculaire medicatie en (2) 'channelling' speelt een belangrijke rol, dat wil zeggen dat patiënten met de meest ernstige uitingen van HVZ de meest krachtige 
behandelingen krijgen. Onze studie kan door zijn cross-sectionele karakter geen onderscheid maken tussen de bijdragen van deze twee factoren. Dit type associatie wordt echter wel waargenomen bij patiënten die behandeld zijn in de dagelijkse klinische praktijk. Het is daarom van belang dat toekomstige prospectieve studies de rol van behandeling verder in kaart gaan brengen.

De gevolgen van veroudering, hoge bloeddruk, genetisch factoren en andere risicofactoren op de circulatie, leiden tot een geleidelijke verstijving van de bloedvatwand, met name van de arteriën. Personen met een toegenomen arteriële stijfheid, in het bijzonder van de aorta, hebben een verhoogde kans op het krijgen van cardiovasculaire morbiditeit en mortaliteit. In de studie beschreven in Hoofdstuk 6 vonden we een statistisch significante, beschermende associatie tussen het AGTR1 (A1166C) polymorfisme en door middel van pulse wave velocity (PWV) bepalingen vastgestelde stijfheid van de aortawand. Deze associatie werd significant beïnvloed door het gebruik van cardiovasculaire medicatie en liet zien dat de carotisfemoralis/carotis-radialis ratio afnam met het aantal $\mathrm{C}$ allelen. In dit hoofdstuk geven we verschillende hypothesen om deze resultaten te verklaren, maar om die te toetsen is prospectief epidemiologisch onderzoek nodig. Alhoewel de bevindingen in Hoofdstuk 5 en 6 belangrijk zijn voor toekomstig 'functional genomics' onderzoek en dientengevolge ook moeten worden gezien als hypothese genererend, zijn deze bevindingen op dit moment van minder klinisch belang.

\section{Familie-anamnese van veel voorkomende ziekten in de eerstelijns geneeskunde}

Familie-anamnese is nauw verbonden met het genetisch profiel van patiënten. Omdat de huisarts dichtbij de patiënt staat en vaak de familie kent, lijken huisartsen in de ideale positie te verkeren om de familie-anamnese in hun primaire en secundaire preventieve activiteiten te integreren. In Hoofdstuk 7 staan de resultaten beschreven van een systematische review over studies die gingen over het afnemen van de familie-anamnese in de eerstelijns geneeskunde, als instrument om individuen en families te identificeren met een verhoogd risico op multifactoriële chronische aandoeningen, zoals HVZ en kanker. De resultaten lieten zien dat het belangrijk is om een gedetailleerde familie-anamnese te kennen, maar dat het voordeel hiervan op de lange termijn nog niet is aangetoond. Daarnaast bleek uit deze review dat de huidige mogelijkheden voor het afnemen en vastleggen van een uitgebreide familieanamnese in de eerstelijn beperkt en onvoldoende zijn om verstandige medische besluitvorming op te baseren. We geven aan welke conceptuele, methodologische en technische basis aanwezig is om het gebruik van een uitgebreide familie-anamnese verder te ontwikkelen. 


\section{Beschouwing en conclusie}

Tenslotte worden in Hoofdstuk 8 de belangrijkste resultaten van dit proefschrift besproken in het licht van de huidige literatuur. Daarnaast worden de klinische relevantie en de aanbevelingen voor toekomstig onderzoek gegeven. Wij concludeerden dat het onwaarschijnlijk is dat de bestudeerde polymorfismen een belangrijke bijdrage leveren aan de voorspelling van het cardiovasculair risico in deze eerstelijns populatie als geheel. Aan de andere kant laat dit proefschrift een aantal bevindingen zien die nog steeds relevant kunnen zijn voor individuele patiënten. Voorbeelden hiervan zijn allereerst de onverwachte bevinding van het beschermend effect van het AGT (M235T) polymorfisme (Hoofdstuk 3 en 4) en het ADD1 (G460W) polymorfisme (Hoofdstuk 5). Ten tweede de rol van geslacht bij het AGT (M235T) polymorfisme (Hoofdstuk 4). Ten derde leverden de studies naar de invloed van medicatiegebruik op de associaties tussen het ADD1 (G460W) polymorfisme en CIMT (Hoofdstuk 5) en tussen het AGTR1 (A1166C) polymorfisme en PWV (Hoofdstuk 6) nieuwe inzichten en hypotheses op. Deze bevindingen zijn belangrijk voor toekomstig onderzoek specifiek op het gebied van de functional genomics. Tot slot geven we nog een aantal extra aanbevelingen voor toekomstig onderzoek. Wij stellen dat bepaling van nog veel meer polymorfismen in de HIPPOCRATES populatie niet zinvol zal zijn. Immers, wat zal het effect zijn op de dagelijkse klinische praktijk van de huisarts als deze de resultaten moet interpreteren van een paar honderdduizend polymorfismen per patiënt? Ten tweede vonden wij aanwijzingen dat het combineren van CIMD of PWV met traditioneel risicofactor management weleens relevant zou kunnen zijn voor klinische preventie, omdat patiënten beter kunnen worden geclassificeerd. Voordat IMD en PWV echter kunnen worden toegepast in de voorspelling van het cardiovasculair risico, zal eerst moeten worden gekeken naar de toegevoegde waarde van deze metingen ten opzichte van bepaling en management van de traditionele cardiovasculaire en biochemische parameters in langdurige follow-up studies. Dit zou een uitdagend onderwerp zijn voor een vervolgonderzoek binnen het HIPPOCRATES project. Als laatste doen we de suggestie dat, gezien het feit dat polymorfismen slechts een beperkte voorspellende waarde blijken te hebben bij het schatten van het cardiovasculaire risico, zou kunnen worden overwogen om na te gaan of een (positieve) familie-anamnese voldoende bijdraagt aan de risicoclassificatie. Op dit moment worden pilot studies en kwalitatief onderzoek onder huisartsen en patiënten voorbereid om de haalbaarheid van deze benadering in kaart te brengen. 
142 


\section{LIST OF PUBLICATIONS}

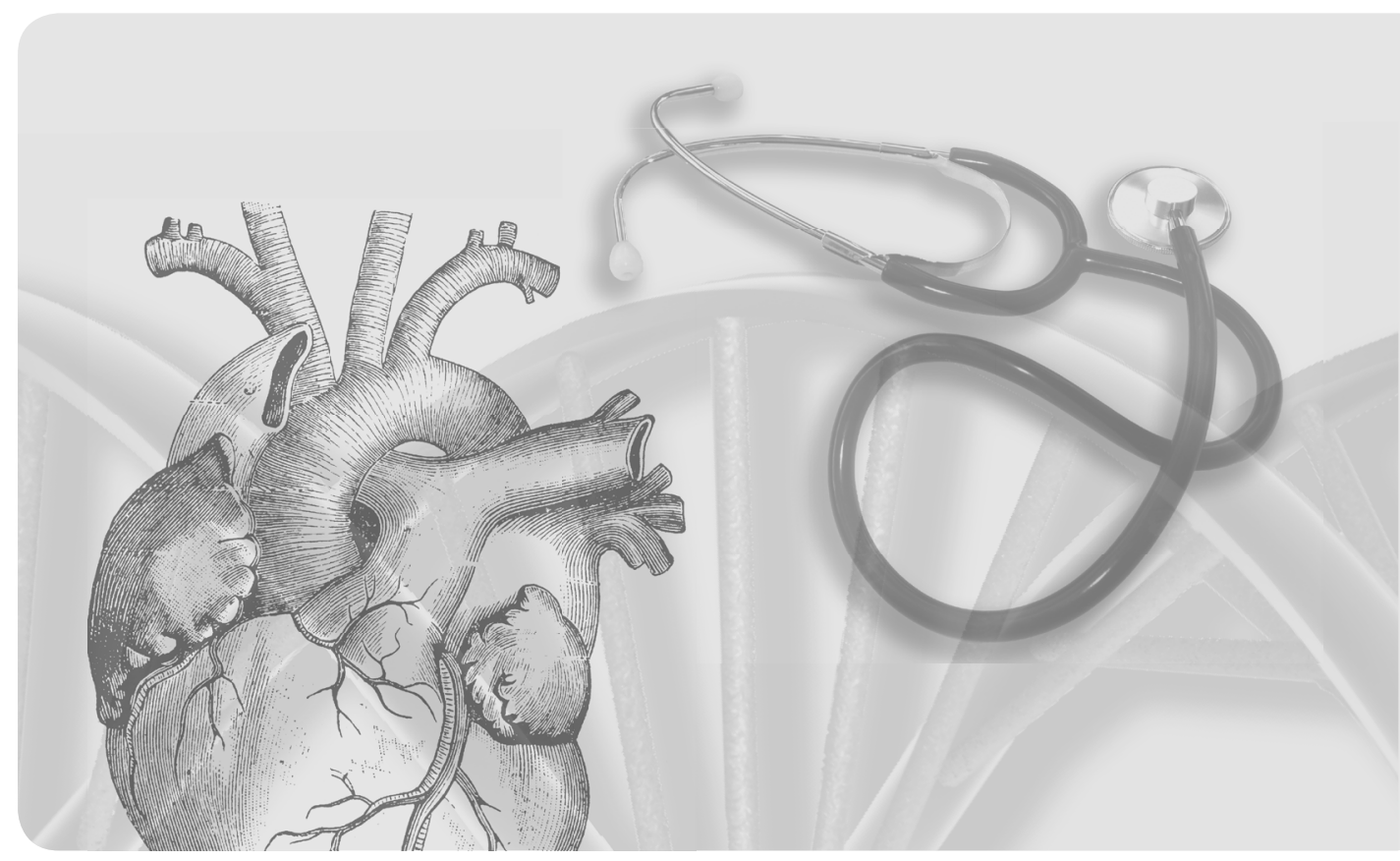




\section{List of publications}

Plat AW, de Vries-Bots AM, Piersma-Wichers M, de Jong-van den Berg LTW. Inbreng apotheek essentieel voor trombosedienst. Pharm. Weekblad 2001;136:756-60.

van Dijk KN, Plat AW, van Dijk AA, Piersma-Wichers $M$, de Vries-Bots AM, Slomp J, de Jong-van den Berg LTW, Brouwers JRBJ. Potential interaction between acenocoumarol and diclofenac, naproxen and ibuprofen and role of CYP2C9 genotype. Thromb Haemost 2004;91:95-101

van Onna M, Kroon AA, Houben AJ, Koster D, Zeegers MP, Plat AW, Stoffers HE, de Leeuw, PW. Genetic risk in atherosclerotic renal artery disease: the candidate gene approach in a renal angiography cohort. Hypertension 2004;44:448-53.

Plat AW, te Wierik MJM, Kroon AA, Schouten HJA, van den Akker M, van Schayck CP, de Leeuw PW, Hajema $\mathrm{KJ}$, Stoffers HE. Regional differences in cardiovascular risk factor profile cannot fully explain differences in cardiovascular morbidity in the Netherlands: a comparison of two urban areas. Neth J Med 2005;63:28-34.

Plat AW, Stoffers HEJH, de Leeuw PW, van Schayck CP, Soomers FL, Kester ADM, Aretz K, Kroon AA. The association between arterial stiffness and the angiotensin II type 1 receptor (A1166C) polymorphism is influenced by the use of cardiovascular medication. Journal of Hypertension 2009;27:69-75.

Plat AW, Stoffers HEJH, Klungel OH, van Schayck CP, de Leeuw PW, Soomers FL, Schiffers PM, Kester ADM, Kroon AA. The contribution to cardiovascular risk of six polymorphisms in a Dutch high risk primary care population: The HIPPOCRATES project. J Hum Hypertens 2009; in press.

Plat AW, Stoffers HEJH, de Leeuw PW, van Schayck CP, Soomers FL, Kester ADM, Aretz K, Kroon AA. Genderspecific effect of the $\alpha$-adducin (G460W) and AGTR1 (A1166C) polymorphism on carotid intima media thickness. Submitted.

Plat AW, Stoffers HEJH, de Leeuw PW, van Schayck CP, Soomers FL, Kester ADM, Aretz K, Kroon AA. The influence of six cardiovascular polymorphisms on a first event of ischemic heart disease is modified by gender and age. Submitted.

Plat AW, Kroon AA, de Leeuw PW, van Schayck CP, Stoffers HEJH. Family history of common diseases as genetic tool in primary care: what is the evidence? A systematic review. Submitted.

van der Bij S, Heintjes E, Plat AW, Sturkenboom MC, Penning-van Beest FJ, Herings RMC. The role of LDLlevels in initiating statin treatment (abstract). Value Health 2008;11:A381.

van der Linden MW, Plat AW, Erkens JA, Emneus M, Herings RMC. Large impact of antidiabetic drug treatment and hospitalizations on economic burden of diabetes mellitus in the Netherlands during 2000 to 2004. Value Health 2009; in press.

van den Haak P, Heintjes E, Plat AW, Webb K, Meerding WJ, Sturkenboom MC, Herings RMC. More than $50 \%$ of high risk patients are not prescribed statins. Submitted.

Heintjes E, Plat AW, Sturkenboom MC, Penning-van Beest FJA, Herings RMC. Comparison of goal attainment rates between users of simvastatin $40 \mathrm{mg}$ and other statins. Submitted.

Plat AW, Penning-van Beest FJA, Kessabi S, Groot MT, Herings RMC. More than $40 \%$ of type 2 diabetes patients change initial therapy with oral glucose lowering drugs. Submitted. 


\section{DANKWOORD}

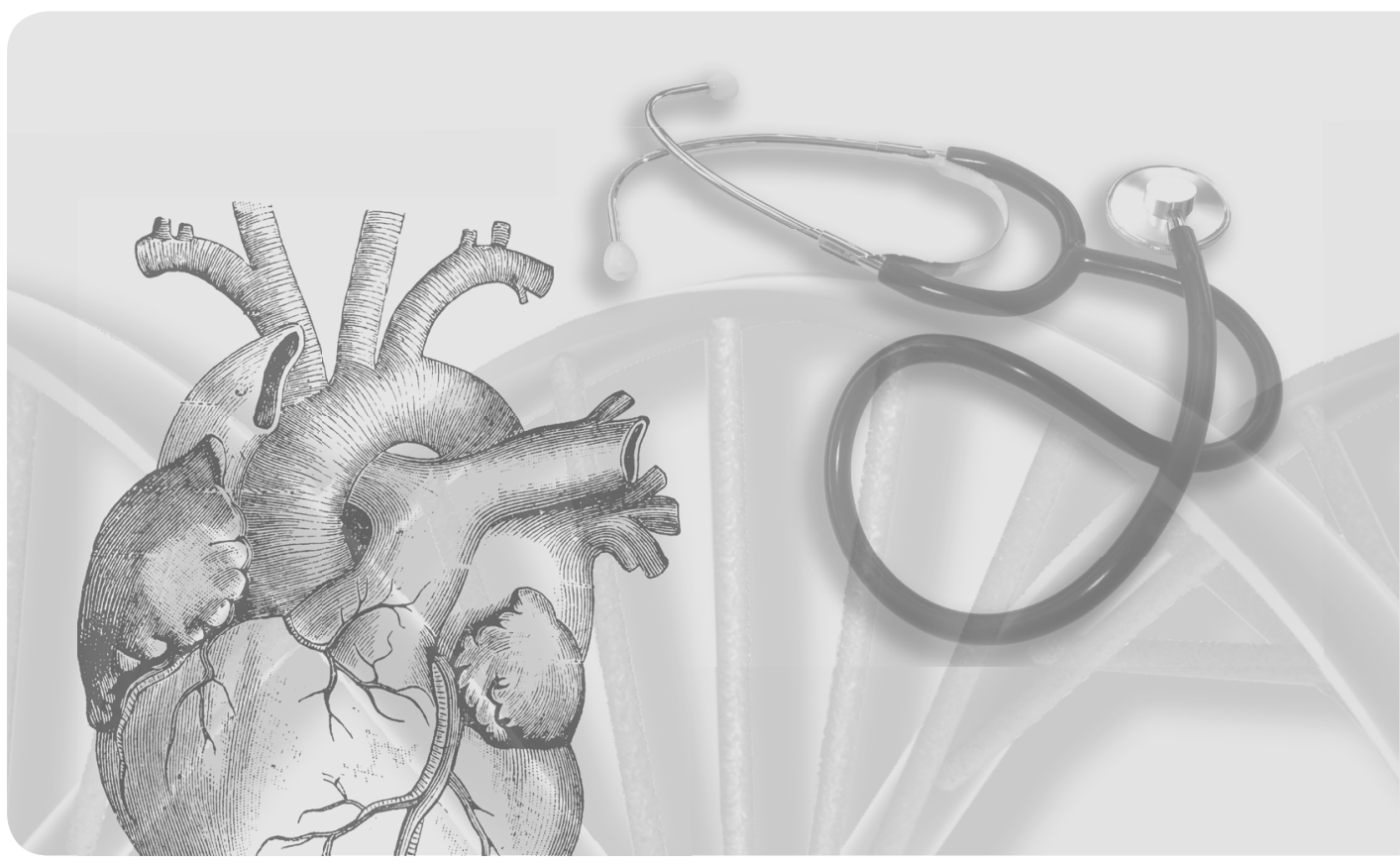




\section{Dankwoord}

De laatste pagina's van dit boekje zijn aangebroken, tijd om te memoreren. De kernwoorden die mijn promotietraject karakteriseren zijn motivatie, enthousiasme, leerzaam, plezier en avontuur. Er waren natuurlijk ook frustraties en teleurstellingen, maar die maken je scherp. Immers, geen hoogtepunten zonder dieptepunten. Promoveren op een multidisciplinair project schept verplichtingen, vele verplichtingen. De allergrootste verplichting (en uitdaging) is nu gekomen: iedereen hartelijk bedanken voor de diverse bijdragen aan de tot standkoming van dit proefschrift.

Ik voel het als mijn grootste verplichting om allereerst de vele patiënten (meer dan 800 !) te noemen die deelnamen aan HIPPOCRATES. Via hen leerde ik het Limburgs te verstaan en was er een soort 'gentlements-agreement' dat zij mochten praten in het Limburgs en dat ik in het Nederlands mocht antwoorden. Vele malen heb ik moeten uitleggen dat ik geen dokter was, maar onderzoeker. Maar toen na maanden en na de zoveelste uitleg een patiënt vertrok met de woorden: 'Hot diech jot! Bis de nieëkste kieër dokter Plat! Adië wah!', heb ik het maar opgegeven. Ik vond het een eer dat jullie deelnamen aan HIPPOCRATES en ik vond het bijzonder dat de overgrote meerderheid van jullie zo gemotiveerd en enthousiast waren én zijn gebleven. Dank jullie wel! Daarmee heb ik wat betreft het aantal personen het meest efficiënte deel van dit dankwoord gehad.

Ik wil nu een aantal mensen in het bijzonder noemen. Mijn (co)promotoren, Onno van Schayck, Peter de Leeuw, Jelle Stoffers en Bram Kroon wil ik bedanken voor hun begeleiding. Onno, al bij de eerste kennismaking in juni 2001 zat je mij intellectueel uit te dagen. Scherp, concreet en een harde werker dat is zoals ik jou heb leren kennen. Echter altijd met veel enthousiasme en plezier en je korte zakelijke manier van afhandelen zorgde ervoor dat we de snelheid erin hielden. Peter, vaak de man op de achtergrond maar ook voor HIPPOCRATES onmisbaar. Velen hebben het al aangegeven, maar de beheersing van je Engels is subliem, om maar te zwijgen over het feit dat je regelmatig een zinnetje weer zo weet te draaien dat het complete artikel weer scherper en beter publiceerbaar wordt. Ik heb er van genoten. Bovendien was je er op de echt cruciale momenten in het project. Dank je wel! Jelle, bedankt voor alles! Vanaf de eerste dag hebben we heel plezierig met elkaar samengewerkt en heb je mijn belangen altijd met vuur verdedigd. Je bent een ware mentor. Soms vierden emoties hoogtij, maar altijd kwamen we weer in een plezierige sfeer tot de kern van de zaak: een klasse en kwalitatief hoogwaardig promotieonderzoek afleveren. Je bent zeer nauwkeurig, gedreven, enthousiast en ik heb veel van je geleerd. Bram, jij was het rustpunt binnen HIPPOCRATES. Jouw devies was telkens: we gaan voor kwaliteit, dus signaleer en analyseer de knelpunten en dan lossen we die samen op! Daarnaast werk je graag samen met andere onderzoeksgroepen en niet 
zelden leidt zo'n samenwerking tot een nieuwe wending in iemands carrière (ook in mijn geval!), maar bovenal ben je de relaxte internist waar je af en toe eens lekker mee kunt lachen! Bedankt!

De leden van de beoordelingscommissie, Prof. dr. Martin Prins, Prof. dr. Martina Cornel, Prof. dr. Joep Geraerdts, Prof. dr. André Knottnerus en Prof. dr. Harry Struijker Boudier wil ik bedanken voor hun bereidheid mijn proefschrift te lezen en te beoordelen.

Vervolgens huisartsenpraktijk Medisch Centrum West in Kerkrade. Beste Frank en Marianne, dank dat ik te gast mocht zijn in jullie praktijk en voor de plezierige manier van samenwerken over de afgelopen jaren. Een bijzonder woord van dank ook voor Miriam Debets die één van de stille krachten was achter dit project. Honderden patiënten zijn door haar gebeld en ingepland en vervolgens gezien op de opéénvolgende consulten: een assistente waar je zuinig op moet zijn! Overigens wellicht een aanrader voor mijn opvolger: voorzien van een lekkere zak snoep weet ze van geen ophouden. Met Miriam samen werkte Peggy Paffen mee aan dit project en van haar heb ik vooral in het begin geleerd hoe gezellig, maar toch ook weer hoe correct je met patiënten dient om te gaan. Peggy, grote klasse! Daarnaast zijn er natuurlijk de andere assistentes Anita, Wendy, Eline, Ellen, Marian, Celine en Ria. Als ik spreekuur draaide voor mijn onderzoek waren zij continu in de back-up voor bloedprikken en dat liep als een trein. Dank voor jullie inzet en gezelligheid! Ook de andere huisartsen Hans, Dietert, Tessi en de diëtiste Marlies wil ik bedanken voor hun interesse, adviezen en support.

Dan waren daar de collega's, vriendjes en vriendinnetjes bij de vakgroep Huisartsgeneeskunde. Allereerst mocht ik de eerste twee jaren gebruik maken van de diensten van Margreet, 'mijn' gepromoveerde student-assistent. Margreet, jij gaf mij een vliegende start door mij in no-time wegwijs te maken in het academische wereldje van Maastricht. Heel veel dank voor al het werk dat je hebt verzet, maar bovenal voor je dosis humor en relativeringsvermogen. Vervolgens mijn kamergenoten, Piet en Magda. Vanaf werkdag één werd ik bij jullie op de kamer zeer gastvrij ontvangen. Piet, dank voor je gezelligheid en je verhalen over Noord-Holland, de dieselmotor (traditioneel, common-rail), je gezin (wat ben je toch trots) en het delen van je ervaringen als praktiserend huisarts in Limburg. Magda, ik mag toch wel zeggen dat wij menig minuutje samen hebben verkletst. Of het nu ging over onze promotieperikelen of over andere zaken die in de wereld spelen (politiek, zeilen, Limburgers), vaak bleken wij hetzelfde over dingen te denken en dat leidde tot een samenzweerderige sfeer. Dit resulteert vandaag in het feit dat je één van mijn paranimfen bent, heel erg bedankt dat je deze rol wilt vervullen. Dan de collega lotgenoten van Deb1 (lees: AIO's \& AIOTHO's): Judith, Paul, Janneke, Tanja, Sandra, Patrick, Roelf, Ischa, Bianca en Marja. Dank voor jullie interesse en gezelligheid door 
de jaren heen! Jos Boesten en Marian van de Akker van het RNH en Alfons en Annemie van het MEMIC wil ik bedanken voor hun hulp bij het opzetten van de HIPPO module en later bij het uitspoelen van diagnose- en medicatielijsten. Veel dank ben ik ook verschuldigd aan Arnold Kester die mij leidde langs alle valkuilen van de methodologie en statistiek. Het gaf telkens een goed gevoel om zo'n ervaren statisticus in de back-up te hebben! Karin Aretz leverde een zeer belangrijke bijdrage aan het opzetten en draaien van de analyses. Beste Karin, jij maakte het analyseren tot een feest, dank voor alle gezellige woensdagmiddagen. Ook dank aan Frits, Ine en Linda voor jullie ondersteuning op allerlei gebied!

En dan steken we nu de Debyelaan over en komen we bij de afdeling Interne Geneeskunde. Allereerst vinden we daar Boy Houben en Claudia de Haan. Boy, dank je voor het leren uitvoeren van de IMT en PWV metingen. Leren biomedici het nu sneller of niet? Claudia, samen hebben we menig probleem gefixed. Dank voor je inzet en support! Vervolgens de 'echo-proefkonijnen': Bianca, Ischa, Marja, Ingrid, Margreet, Paul, Janneke, Judith en Dennis. Dankzij jullie kon ik al vrij snel zelfstandig de metingen uitvoeren. Dank voor jullie tijd, moeite en geduld! Dan Claudia Beyrus, mijn leerling! Claudia, volgens mij kun je nu uitstekend IMTs meten en PWVs bepalen: niet alleen omdat je het van mij geleerd hebt, maar ook omdat jij deze bepalingen combineert met de lieflijkheid van een researchverpleegkundige; wat zullen de patiënten uit Kerkrade worden verwend. Hedi, Monique en Stella wezen regelmatig een verdwaalde patiënt de weg: dames bedankt! Jeroen Hameleers van biofysica was de man van de IMT machine. Jeroen, dank voor de uitleg, support en troubleshooting tijdens de meetperiode! De meiden van het vaatlab, Bianca, Laura, Sandra, Marian, Evelien en Gertie wil ik bedanken voor hun interesse, gezelligheid, humor en support! Ik vervolg met mijn collega promovendi: Leon, Willem, Marieke, Esther en Wilco. Bedankt voor jullie support door de jaren heen. Een speciaal woord van dank aan Leon en Wilco die samen met Frank en Bram de eigenlijke grondleggers zijn van HIPPOCRATES. Monique en Lilian, de girls van het secretariaat van Interne Geneeskunde, die mij regelmatig met raad en daad terzijde stonden: bedankt voor jullie inzet. Vervolgens de mensen van de genotypering: Jet, Michael en Daniëla onder de bezielende leiding van Paul Schiffers en natuurlijk Rob Janssen van het Genome Centre Maastricht. Heel veel werk is er ook door jullie verzet: dank voor jullie inspanningen, nauwkeurigheid en support.

Tiny Wouters, door iedereen geroemd, en zeker dus ook door mij. Beste Tiny, bedankt voor al je hulp en tijd bij het vormgeven van dit proefschrift. Wat een prachtig stukje werk!

Mijn collega's van het PHARMO Institute for Drug Outcomes Research in Utrecht wil ik ook hartelijk bedanken. Het is fantastisch om direct na je promotietijd te starten als 
onderzoeker in een dergelijk prachtige en interessante omgeving en binnen twee jaar door te groeien naar business development manager.

Op het einde van dit dankwoord wil ik mij richten tot de kleine kern van mensen om mij heen. Dit zijn de mensen die precies weten wat mij beweegt en bij wie ik altijd terecht kan. Beste Edwin, ik begin bij jou. Heel veel dank voor je inspanningen en interesse door de jaren heen. Sinds de HAVO kennen wij elkaar. Een vriendschap door dik en dun. Tijdens dit promotieonderzoek was je altijd beschikbaar bij noodsituaties, in het bijzonder als er onverhoopt iets 'vreemds' gebeurde met mijn computer. Je bent een super kerel! Ik vind het een grote eer dat je vandaag als paranimf aan mijn zijde staat. Mocht er onverhoopt iets fout gaan dan ben ik ervan overtuigd dat je al het gereedschap bij je hebt om het één en ander te fixen! Vervolgens kom ik bij Thom en natuurlijk de rest van zijn familie uit Leeuwarden. Dank voor jullie vriendschap en interesse door de jaren heen. Thom, vandaag ben je mijn persoonlijke huisfotograaf, super!

Lieve $\mathrm{Pa}$ en $\mathrm{Ma}$, dank voor alle kansen en mogelijkheden die jullie mij hebben gegeven. Pa zei altijd: 'kennis is macht en geeft je inzichten die zich niet laten uitbetalen in dollars'. Dit is jullie lijfspreuk geweest door de jaren heen en jullie hebben er alles aan gedaan om mij dit via allerlei facetten te laten ervaren. Ik had mij geen betere ouders kunnen wensen! Lieve Ma, helaas zal Pa vandaag niet meer mee maken. Echter, zoals wij door de jaren heen hebben gezegd: 'dan genieten we voor één persoon extra' en dat gaan we vandaag dan ook zeker doen! Natuurlijk ook veel dank voor al je 'troostpakketten' die mee gingen over de Napoleonsbaan.

Tenslotte is de allerlaatste alinea voor 'mijn vriendinnetje'. Lieve Leen, wij hebben het overtuigende bewijs geleverd dat Vlaanderen bij Nederland hoort of was het nu andersom? Zeker wil ik vermelden dat jij tijdens dit promotieonderzoek regelmatig de finishing touch voor de prachtige tabellen bij de manuscripten verzorgde en daarnaast de lay-out voor de verschillende powerpoint presentaties voor je rekening nam. Echter, het belangrijkste is dat wij er altijd voor elkaar zijn, door dik en dun. Dank voor je liefde, zorg en inspiratie en voor nog zoveel meer door de jaren heen. Dit is af! De toekomst ligt voor ons! 


\section{Curriculum vitae}

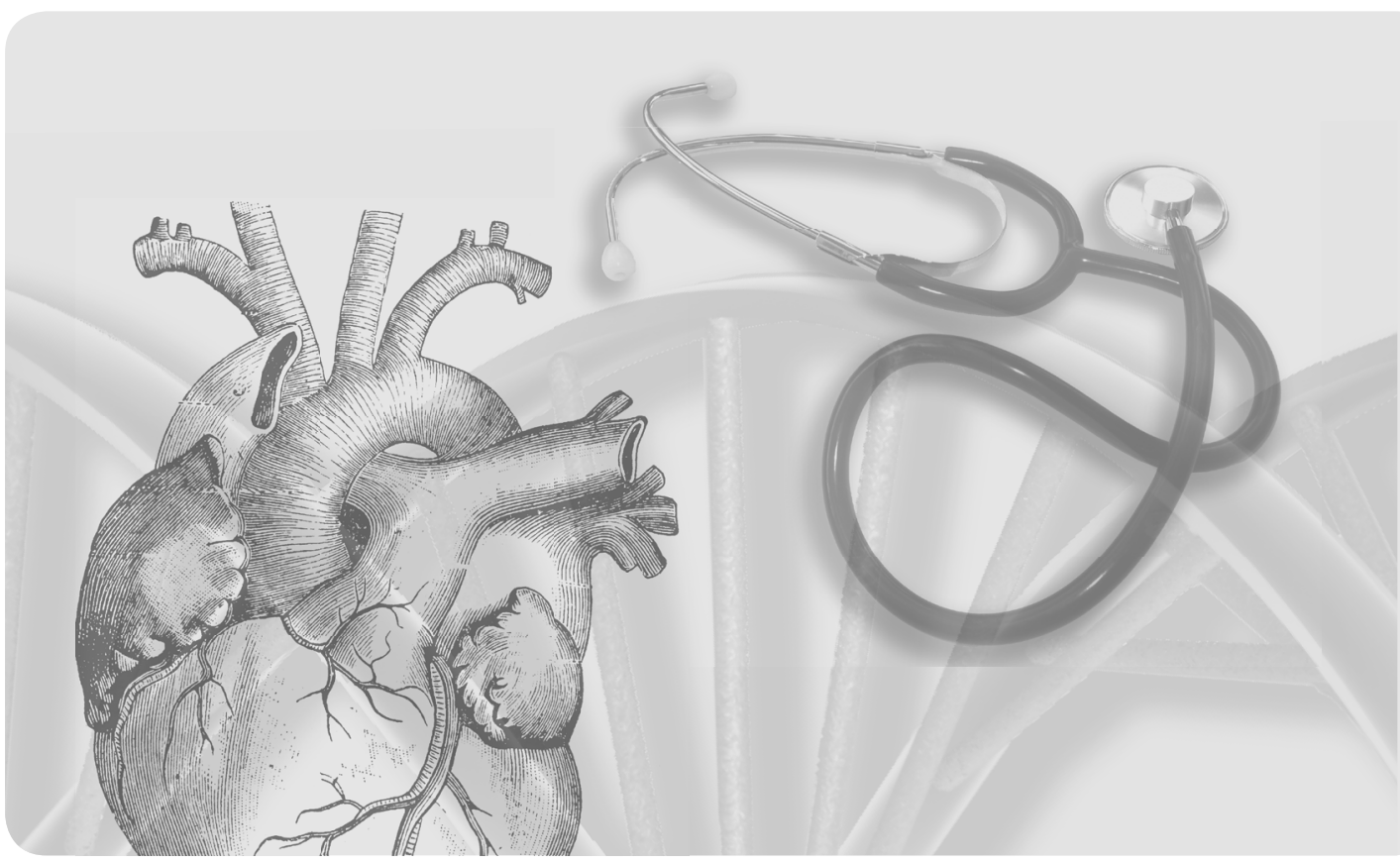


154 


\section{Curriculum vitae}

Arian Plat werd geboren op 1 maart 1975 te Steenwijk. In 1992 behaalde hij het HAVO diploma aan de Katholieke Scholengemeenschap (KSG) Gelderingen te Steenwijkerwold en in 1994 behaalde hij het VWO diploma aan de Regionale Scholengemeenschap (RSG) te Steenwijk. Aansluitend startte hij met de studie Farmacie aan de Rijksuniversiteit Groningen (RuG), waar hij in 2001 zijn doctoraalexamen in de farmaco-epidemiologie behaalde. Het onderwerp van zijn doctoraalscriptie was het bepalen van de mate van inbreng van de apotheek bij het voorkomen van interacties met cumarines in de regio Groningen. Deze studie werd uitgevoerd in nauwe samenwerking met de Stichting Trombosedienst Groningen (thans Labnoord; Margriet Piersma - Wichers, internist), apotheek 't Hooge Zand (Anne de Vries - Bots, apotheker) en de afdeling Sociale Farmacie, Farmacoepidemiologie en Farmacotherapie (prof. dr. Lolkje de Jong - van den Berg) waar onder enthousiaste begeleiding zijn interesse in wetenschappelijk onderzoek ontstond. Alle resultaten van deze studie zijn zowel nationaal als internationaal gepubliceerd.

Van november 2001 tot en met juni 2007 werkte hij als promovendus bij de afdeling Huisartsgeneeskunde, School for Public Health and Primary Care (CAPHRI), Maastricht Universitair Medisch Centrum en de afdeling Interne Geneeskunde, Cardiovascular Research Institute Maastricht (CARIM), Maastricht Universitair Medisch Centrum, onder leiding van dr. Jelle Stoffers, dr. Bram Kroon, prof. dr. Onno van Schayck en prof. dr. Peter de Leeuw. Het onderzoek dat tijdens deze periode werd uitgevoerd, heeft geleid tot dit proefschrift. Gedurende het promotietraject voltooide hij ook een opleidingsprogramma voor wetenschappelijk onderzoeker epidemioloog (Epidemioloog B) onder begeleiding van prof. dr. Martin Prins.

Sinds juli 2007 werkt hij bij het PHARMO Institute for Drug Outcomes Research in Utrecht. De eerste zes maanden werkte hij als onderzoeker (research associate) en daarna werd hij onderzoeksmanager (research manager). In deze functie verzorgt hij het management van onderzoeksprojecten op het gebied van hart-en vaatziekten en diabetes. Vanaf mei 2008 is hij tevens verantwoordelijk voor de acquisitie van deze onderzoeksprojecten binnen de afdeling business development and global accounts.

$\mathrm{Hij}$ is lid van de Koninklijke Nederlandse Maatschappij ter bevordering der Pharmacie (KNMP), de Vereniging voor Epidemiologie (VvE) en de European Association for the Study of Diabetes (EASD).

Hij woont samen met zijn vriendin Leen Liefsoens in hun spiksplinternieuwe appartement in Blokhoeve Buiten te Nieuwegein. 
$\left.\right|_{187}$ 
